A Comparison Between Dispersed Nuclear Power Plants and a Nuclear Energy Center at a Hypothetical Site on Kentucky Lake, Tennessee

\title{
Vol. II. Transmission of Power
}

D. B. Reister

L. W. Zelby

\section{OAK RIDGE NATIONAL LABORATORY}




\section{DISCLAIMER}

This report was prepared as an account of work sponsored by an agency of the United States Government. Neither the United States Government nor any agency Thereof, nor any of their employees, makes any warranty, express or implied, or assumes any legal liability or responsibility for the accuracy, completeness, or usefulness of any information, apparatus, product, or process disclosed, or represents that its use would not infringe privately owned rights. Reference herein to any specific commercial product, process, or service by trade name, trademark, manufacturer, or otherwise does not necessarily constitute or imply its endorsement, recommendation, or favoring by the United States Government or any agency thereof. The views and opinions of authors expressed herein do not necessarily state or reflect those of the United States Government or any agency thereof. 


\section{DISCLAIMER}

Portions of this document may be illegible in electronic image products. Images are produced from the best available original document. 


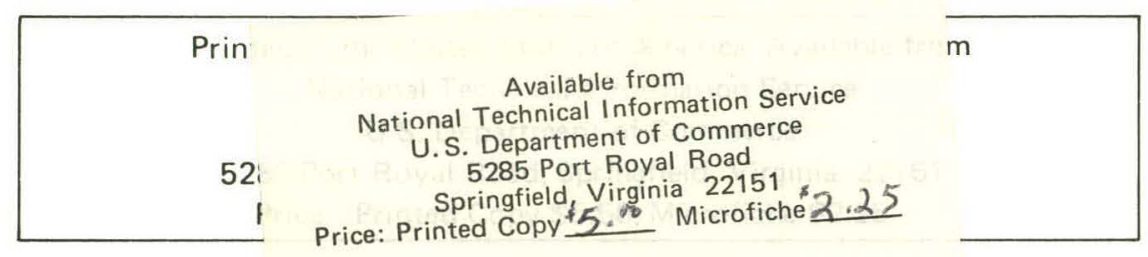

This report was prepared as an account of work sponsored by the United States Government. Neither the United States nor the Energy Research and Development Administration/United States Nuclear Regulatory Commission, nor any of their employees, nor any of their contractors, subcontractors, or their employees, makes any warranty, express or implied, or assumes any legal liability or responsibility for the accuracy, completeness or usefulness of any information, apparatus, product or process disclosed, or represents that its use would not infringe privately owned rights.

The complete report is composed of the following volumes:

Vo1. I. Summary (ORNL/TM-5310)

Vo1. II. Transmission of Power (ORNL/TM-5311)

Vo1. III. Environmenta1 Considerations (ORNL/TM-5312)

Vo1. IV. A Site Selection Methodology (ORNL/TM-5313) 
ORNL/TM-5311

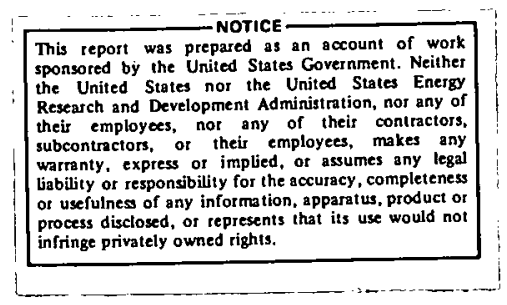

(Second Volume of ORNL/TM-5310) UC-80

Contract No. W-7405-eng-26

ENERGY DIVISION

A COMPARISON BETWEEN DISPERSED NUCLEAR POWER PLANTS AND A NUCLEAR ENERGY CENTER AT A HYPOTHETICAL SITE ON KENTUCKY LAKE, TENNESSEE

VOL. II., TRANSMISSION OF POWER

D. B. Reister*

L. W. Zelby*

* Institute for Energy Analysis

This study was performed for the Nuclear Regulatory Commission in connection with the develupment of their Nuclear Energy Center Site Survey report to Congress.

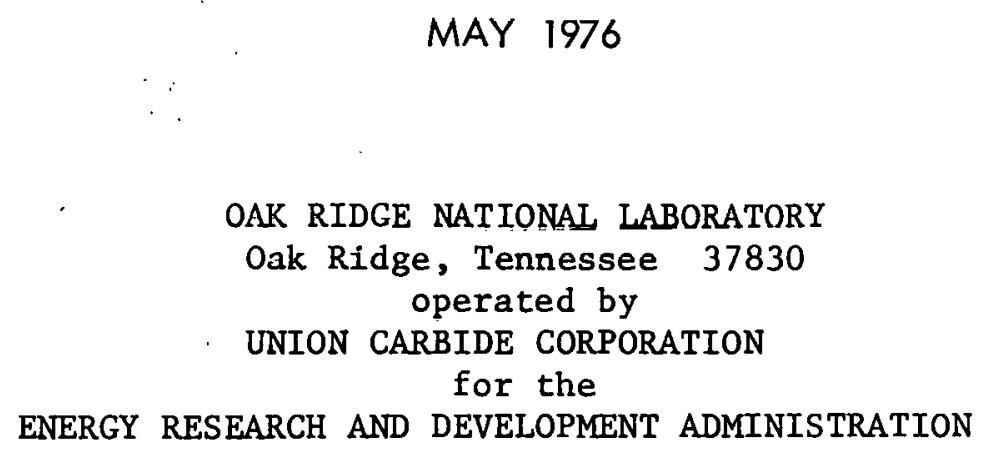


THIS PAGE

WAS INTENTIONALLY

LEFT BLANK 
FOREWORD . . . . . . . . . . . . . . . ... . . . . vi ABSTRACT . . . . . . . . . . . . . . . . . . . . . vii

1. INTRODUCTION . . . . . . . . . . . . . . . . 1

2. TRANSMISSION LINES AND SYSTEMS . . . . . . . . . . 6

2.1 Introduction . . . . . . . . . . . . . . 6

2.2 Power Consideration . . . . . . . . . . . . 7

2.3 Load Flow Studies ................ 10

2.4 Transmission Planning . . . . . . . . . . . 12

2.5 IEA Linear Programming System for Transmission

Expansion Planning . . . . . . . . . . . . 13

3. SURROGATE SITE ANALYSIS . . . . . . . . . . . . . 14

3.1 Introduction . . . . . . . . . . . . . . . . 14

3.2 Case A . . . . . . . . . . . . . . . 15

3.2.1 Load Centers and Demand . . . . . . . . . 15

3.2.2 Dispersed Sites . . . . . . . . . . . . 19

3.2.3 Differential Analysis . . . . . . . . . . 19

3.2.4 Sensitivity Analysis . . . . . . . . . . . 21

3.2.5 Transmission Corridors . . . . . . . . . 22

3.2.6 Analytical Tools ............. 23

3.2.7 Transmission System for One Energy Center at the Kentucky Lake Surrogate Site . . . . . . . 27

3.2.8 Transmission System and Development P1an for Ten Dispersed Energy Centers . . . . . . . . 28

3.2.9 Transmission System and Development Plan for Four Energy Centers . . . . . . . . . . 30

3.2.10 Comparison of the Transmission System in 2020 for One Energy Center, Four Energy Centers, and Ten Dispersed Energy Centers . . . . . . 35

3.3 Case B. . . . . . . . . . . . . . . . 36

3.3.1 Introduction ............. . . 36

3.3.2 Dispersed Cases . . . . . . . . . . . 42

3.3.3 Center Case . . . . . . . . . . . 50 
4. COSTS AND DISCUSSION OF RESULTS . . . . . . . . . 60

4.1 Introduction . . . . . . . . . . . . . 60

4.2 Transmission System Costs for One Energy Center, Four Energy Centers, and Ten Energy Centers . . . . 60

4.3 The National Electric Reliability Council Study . . . 62

4.4 The General Electric Study for the National Science Foundation . . . . . . . . . . . 64 REFERENCES .............................. 73

Appendix A. RETIREMENTS AND DEMAND PROJECTIONS . . . . . 76

Appendix B. DISPERSED SITES WITHIN 300 MILES OF THE KENTUCKY LAKE SURROGATE SITE . . . . . . . . 85

Append Lx C. DERIVATION OF DEMAND ............. 91 
FOREWORD

Section 207 of the Energy Reorganization Act of 1974 required the Nuclear Regulatory Commission to conduct a nuclear energy center site survey and report its findings to the Congress and the Council on Environmental Quality. The Survey included a general screening of the 48 contiguous States to identify large land areas that would be likely to contain sites potentially suitable for nuclear energy centers. It evaluated the technical and practical considerations involved in locating the production of electric power at a nuclear energy center and compared these considerations with those involved in producing an equivalent amount of power at dispersed sites.

One of the techniques utilized in the Survey was an analysis of several "surrogate" sites. These specimen sites were selected to permit study of certain concepts and analysis of alternatives as they applied to a real, rather than hypothetical, location. Selection of a particular area for a surrogate site did not mean that it was a preferred or even well-suited site, but only that it represented particular site problems which were deemed worthy of study.

One of the surrogate sites selected for study was at Kentucky Lake, Tennessee. The Nuclear Regulatory Commission contracted with the Oak Ridge National Laboratory to undertake analysis of this site and to prepare reports on the various tasks when completed. This is one of a series of reports in the fulfillment of this assignment.

The complete report is composed of the following volumes:
Vọl. I. Summary
Vol. II. Transmission of Power
Vol. III. Environmental Considerations
Vol. IV. A Site Selection Methodology 


\section{THIS PAGE}

WAS INTENTIONALLY

LEFT BLANK 


\begin{abstract}
A comparison is made among power transmission systems required to serve a single set of load center demands from four modes of siting the generating facilities: a single generation site with an ultimate generation capacity of $48,000 \mathrm{MW}$; four generation sites each with a generation capacity of $12,000 \mathrm{MW}$; 10 generation sites each with a generation capacity of 4,800 MW; and a system that resulted when the existing utility plan for future generation was logically expanded. The time period for the study is from the year 1985 to the year 2020, when the full 48,000 MW of new capacity from the single large nuclear energy center is on-line, The load centers served are Huntsville, Alabama; Evansville, Indiana; Paducah, Kentucky; and Chattanooga, Nashville, and Memphis, Tennessee. Generation sites are real locations but are hypothetical in terms of miles of transmission lines, the product of the amount of power transmitted and the distance transmitted (GW-miles), and cost.
\end{abstract}


VOL. II. TRANSMISSION OF POWER

\section{INTRODUCTION}

The law that created the Energy Research and Development Administration (ERDA) and the Nuclear Regulatory Commission (NRC) requires that NRC submit a report to Congress on Nuclear Energy Centers. One of the technical questions to be considered in the report is the question of transmission of power from a nuclear energy center. Among the transmission-related issues to be discussed are:

1. Current transmission systems

2. The impact of new technology

3. Projected U.S. transmission network by year 2000 for dispersed reactors

4. Projected U.S. transmission network by year 2000 for a11 reactors in nuclear energy centers

5. Dollar costs of each network

6. Environmental costs of each network

7. Reliability and stability of each network

The NRC has contracted with Oak Ridge National Laboratory to provide staff support for the NEC study. An interdisciplinary group headed by C. C. Burwell is providing support for NRC. In turn, ORNL subcontracted with the Institute for Energy Analysis for a study of the transmission requirements of an NEC. Since a transmission system (as well as many other impacts of an energy center) depends on the geometric pattern of generators and load centers, it 1s best to choose a surrogate site, that is, an actual set of load centers and energy center sites to serve those load centers. After a surrogate site was chosen by other members of the ORNL team, work began on the design of a transmission system for two cases. Case A considers three plans, independent of any existing facilities: a single energy center with 40 reactors producing power by year 2020, four energy centers with a total of 40 reactors, and ten energy centers with a total of 40 reactors. Case $B$ considers two plans, including existing facilities such as $500-\mathrm{kV}$ transmission lines and power plants: 27 dispersed sites only; and one energy center with 13 dispersed sites. 
This paper is a preliminary report on the analyses done by the Institute. It is not clear how the analysis of the surrogate site will fit into the NRC report to Congress. This report is, therefore, written primarily for internal use by the staff of ORNL and IEA.

The theory and design of power transmission systems is a mature branch of electrical engineering. A brief review of the theory is given in Sect. 2 of this report. Although technological progress will surely be made in this field in the next 45 years, the technical feasibility of nuclear energy centers does not depend on a breakthrough in transmiosion technology. Although UHV (1000-1500 kV) transm1ssion systems may be possible within ten years and DC transmission systews are available now, only 500- and 765-kV transintssion lines have been considered for the surrogate site analysis. For the surrogate site with all power coming from a single site (Case $A$ ), the average distance to a load center is 106 miles. Under current practice, the maximum load on a $765-\mathrm{kV}$ line that is not too long is equal to 4.8 gigawatts (GW) ( $4800 \mathrm{MW})$, which is the nominal generating capacity of the typical 4-unit cluster of nuclear reactors consldered in this study; a second line would be needed for a 4-unit cluster for reliability. For a 40-reactor energy center, twenty $765-\mathrm{kV}$ transmission lines might be needed. Using UHV ac or dc, the number of lines might be reduced. But consider the example of a service area with five load centers. For reliability at least two lines must go to each load center. Thus, the absolute minimum number of lines is ten. If ten lines are required, fifty or one hundred lines would be excessive, but twenty lines is probably not too many. For the final design, eçonomic studies could examine the tradeoffs between fewer than twenty lines using UHV ac or dc and the reliability of twenty lines.

The prospect of twenty lines in parallel on 110-ft towers that are $140 \mathrm{ft}$ wide seems to be a monstrous environmental insult. However, the lines will not be in parallel; for reliability, each line will probably be on a separate corridor, or perhaps there will be two lines on a single corridor. The lines will have their highest density at the generator. Consider a cluster of 4 reactors served by two lines, and assume that each 765-kV line has a 300-ft right-of-way. If the 4-reactor clusters are 
spaced such that there are 4000 acres for 4 reactors, then the transmission right-of-way will cut less than $1 \%$ of the perimeter of the 4-unit cluster. Because the lines will be directed away from the center, they may. cut the same side of the 4-unit cluster; the two lines will cut less than $4 \%$ of one side of the cluster. Two $765-\mathrm{kV}$ transmission 1 ines, each 100 miles long, require a total right-of-way of about 7.300 acres. Thus, the land required for the transmission system is more than the land required for the nuclear energy center. Clearly, the land use impact of the transmission system will be substantial. However, consider a 40reactor energy center with twenty 100-mile 765-kV transmission lines. For this idealized service area, which represents a circle of 100-mile radius, the energy center and transmission system occupy $148 \mathrm{sq}$ miles. The primary energy system occupies $1 / 213$ th of the total area. . Commitment of $0.05 \%$ of the land to the primary energy system is probably not an unacceptable environmental insult; it is comparable to the current impact of roads.

Section 3 is a discussion of the methodology of surrogate site analysis and a presentation of preliminary results. The methodology developed to design a transmission system for a site requires an interdisciplinary team working on the following tasks:

1. Generating site selection. After developing appropriate. criteria, several potential.sites were chosen, and an estimate is made of the maximum amount of power that each site can. support.

2. Load centers. The surrounding area was divided into load centers and projected demand was estimated. A reasonable number of load centers for a 48-GW energy center is four to six.

3. Development plan. A plan was developed for the sequence of development of a single energy center and the location and order of development of dispersed energy centers.

4. Transmission system. An optimum dispatch of power from energy centers to load centers was found, and a transmission system was designed to carry the optimum dispatch. 
5. Transmission corridors. Given the load centers and energy centers that are to be interconnected, land use planners should choose transmission corridors and substation locations.

These tasks are not independent; an appropriate design philosophy is to have several iterations to converge to a solution. This report is preliminary; at least one iteration on each task has been completed, but the process has not converged to an optimum solution.

Section 4 gives a comparison of transmission system costs for a nuclear energy center at the surrogate site and for an equivalent amount of power from dispersed energy, centers. Section 4 also has a brief review of other studies of transmission systems for energy centers. The least expensive transmission system results when each load center receives most of its power from a single nearby energy center. Clearly, a single large nuclear energy center cannot be near several load centers simultaneously, and the resulting transmission system will be more extensive and expensive than the minimum system. Will the transmission system for the dispersed energy centers be substantially less than for a single energy center? There is no simple answer. Some studies indicate that the dispersed transmission system will cost $23 \%$ as much as the clustered system, whereas other studies indicate that the dispersed system will cost $95 \%$ as much as the clustered system. Today, an energy center with a capacity of $48 \mathrm{GW}(48,000 \mathrm{MW})$ would provide $10 \%$ of the country's power and would have a substantial transmission penalty. In year 2020, dispersed 4.8-GW (4800-MW) energy centers may be too small for the load centers, and the penalty for a 48-GW $(48,000-\mathrm{MW})$ energy center would be much less. Consider a load center with a demand of $14 \mathrm{GW}$. The power could be supplied by an energy center over three $765-\mathrm{kV}$ lines if the load center is less than 100 miles from the energy center. For reliability, a fourth line would be needed. If the power for the load center came from three dispersed 4.8-GW energy centers, six lines would be needed. For this example, the dispersed system has a transmission penalty of $50 \%$. Thus, the transmission penalty for an energy center depends on the size of the load centers and the location of the dispersed 
sites. For the surrogate site, the cost of the transmission system is about $3 \%$ of the total cost of the energy. Thus, a $50 \%$ reduction in transmission cost for a dispersed system may not have a significant influence on the choice between clustered and dispersed energy centers. 


\section{TRANSMISSION LINES AND SYSTEMS}

\subsection{Introduction}

Transmission line theory is a mature branch of electrical engineering with an extensive 1iterature. This chapter provides a brief overview of transmission line theory as well as properties and planning of power transmission systems.

The name transmission line (TL) is usually reserved for lines composed of two or more conductors, which support a propagating transverse electromagnetic (TEM) wave and which are characterized by distributed parameters: resistance, inductance, conductance, and capacitance, all per unit length. In the case of power $\mathrm{TL}$, since at $60 \mathrm{~Hz}$ the wavelength is $3100 \mathrm{miles,}$, frequently lumped-parameter representation is used. For line lengths representing a significant fraction of the wavelength ( $2 \%$ or more), corrections, taking into account the distributed nature of $\mathrm{TL}$, are made.

Another characteristic in dealing with power TL is that, because the frequency is fixed, inductance and capacitance are usually referred to, not in henries or farads, but in terms of their reactances in ohms, or volt-amperes reactive. Inductors are associated with a sink (of volt-amperes reactive), and capacitors are associated with a source. 1

Power TL are generally either single- or three-phase, the latter being more prevalent. To permit heavier loading of the line, the number of conductors per phase rather than the size (cross-section) of a single conductor is increased. This has the advantage of reducing the inductance and increasing the capacitance, thereby reducing volt-ampere requirements. This can be seen in the phasor diagrams of $\mathrm{Fig} .1 \mathrm{~b}$ and $1 c$, representing the current-voltage relations of the system shown in Fig. $1 a$.

Requiring a given amount of volt-amperes delivered to the load (fixed magnitude of $\bar{V}_{R}$ and $\dddot{I}_{R}$ ), a smaller sending voltage $V_{S}$ is required when $\mathrm{X}_{L}$ is reduced and $\mathrm{X}_{C}$ is increased, as shown in Figs. $1 b$ and $1 c$. In the ideal case $X_{L}=X_{C}$ so that the source needs to produce only real power, which is further clarified below. 


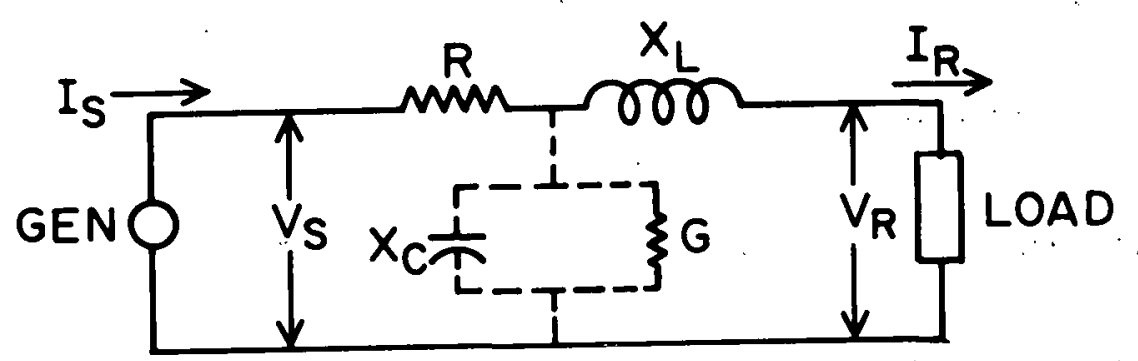

$a$

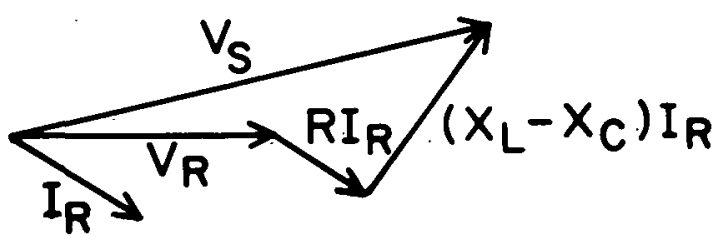

$b$

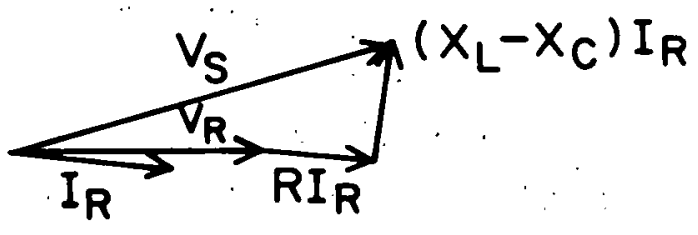

c.

Fig. 1. Transmission system and phasor diagrams.

\subsection{Power Consideration}

The standard convention in power engineering is $I I=V I *$, where $I I$ is the power, $V$ the voltage, and $I^{*}$ is the complex conjugate of the current $I$. In the case of the short $T L$, the current at the receiving end is $I_{R}=\left(V_{S}-V_{R}\right) / Z$, where $z=R+j X_{L}$ (for short lines, $X_{C}$ and $G$ are so small that they are frequently neglected). The complex power at the receiving end is

$$
\Pi_{R}=V_{R} I_{R}^{*}=V_{R}\left(V_{S}^{*}-V_{\underline{R}}^{*}\right) / Z^{*}
$$

Let $\mathrm{T}$ be the ratio of the sending voltage and the receiving voltage, that is, $T=V_{S} / V_{R}=T \exp (j \delta)$, where $\delta$, the phase angle between the sending and receiving voltages, is called the power angle. Given that 
$\theta$ is the angle of the complex impedance $z$, that is, $z=|z| \exp (j \theta)$, the complex power at the receiving end may be written

$$
\Pi_{R}=\frac{\left|V_{R}\right|^{2}}{|z|}(|T| \exp [j(\theta-\delta)]-\exp j \theta)
$$

so that the real and imaginary parts of the complex power are

$$
\begin{aligned}
& P_{R}=\frac{\left|\mathrm{V}_{\mathrm{R}}\right|^{2}}{|\mathrm{Z}|}(|\mathrm{T}| \cos (\theta-\delta)-\cos \theta), \\
& \mathrm{Q}_{\mathrm{R}}=\frac{\left|\mathrm{V}_{\mathrm{R}}\right|^{2}}{|\mathrm{z}|}(|\mathrm{T}| \sin (\theta-\delta)-\sin \theta) .
\end{aligned}
$$

Since the complex impedance is largely inductive, the angle $\theta$ is nearly $90^{\circ}$. Assuming that $\theta=90^{\circ}$,

$$
\begin{aligned}
& \mathrm{P}_{\mathrm{R}}=\frac{\left|\mathrm{V}_{\mathrm{R}}\right|^{2}|\mathrm{~T}|}{|\mathrm{z}|} \sin \delta, \\
& \mathrm{Q}_{\mathrm{R}}=\frac{\left|\mathrm{V}_{\mathrm{R}}\right|^{2}}{|\mathrm{z}|}(|\mathrm{T}| \cos \delta-1) .
\end{aligned}
$$

A common convention in power calculations is in Lerus of power factor: the cosine of the phase angle between the voltage and current. In terms of the phase voltage $v_{p}$ and current $I_{p}$, the complex power per phase is

$$
S_{p}=V_{p} I_{p}^{*}=\left|V_{p}\right|\left|I_{p}\right|\left(\cos \theta_{p}+J \sin \theta_{p}\right)=P+j Q,
$$

where the subscript $p$ denotes per phase quantitieg and $\theta_{p}$ is the angle between the phase voltage and phase currenc. In a three-phase system, the total real power is

$$
S=3 V_{p} I_{p}^{*}=3\left|V_{L} \| I_{L}\right| \cos \theta_{L}-P
$$


where the subscript $I$ denotes line-to-line quantities. Equation (8) holds for elther delta- or Y-connection; in the latter, $I_{L}=I_{p}$ and $V_{L}=\sqrt{3} V_{p}$, and in the former, $V_{L}=V_{p}$ and $I_{L}=\sqrt{3} I_{p}$. Power factor of one implies $\theta_{p}=0$.

Voltage regulation is determined at the receiving end as a percentage difference between no-load and full-load voltage. Thus,

$$
\text { Percent regulations }=100\left(\frac{\left|\mathrm{v}_{\mathrm{R}, \mathrm{NL}}\right|-\left|\mathrm{v}_{\mathrm{R}, \mathrm{FL}}\right|}{\mathrm{v}_{\mathrm{R}, \mathrm{FL}}}\right) .
$$

In the case of a long TL, it is convenient to describe the loading of the line in terms of surge-impedance loading (SIL), which is determined as follows. Voltage and current on a long $\mathrm{TL}$ are related to each other by

$$
\begin{aligned}
& V_{S}=V_{R} \cosh \gamma \ell+Z_{c} I_{R} \sinh \gamma \ell, \\
& I_{S}=I_{R} \cosh \gamma \ell+\left(V_{R} / Z_{c}\right) \sinh \gamma \ell,
\end{aligned}
$$

where the subscripts $S$ and $R$ have the same meaning as before; $Z_{c}$ is the characteristic impedance of the line; and $\gamma=\alpha+j \beta$ is the complex propagation constant. When the line is terminated by its characteristic impedance (usually denoted by $z_{0}=\sqrt{\mathrm{L} / \mathrm{C}}$ in the case of a lossless line), input impedance into the line at any point is equal to $\sqrt{\mathrm{L} / \mathrm{C}}$ : the ine appears infinite and supports no reflections. When the line is so loaded (hy its characteristic impedance).

$$
\left|I_{L}\right|=\frac{\left|V_{L}\right|}{\sqrt{3} \mid \sqrt{L / C})}
$$

and

$$
\text { ST.L }=3\left|v_{L}\right| \frac{\left|V_{L}\right|}{\sqrt{3}|\sqrt{L / C}|}=\frac{\left|V_{L}\right|^{2}}{\sqrt{L / C}}
$$

because the load is a pure resistance. When $\mathrm{V}_{\mathrm{L}}$ is in volts, SIL is in watts; when $V_{L}$ is expressed in kilowatts, SIL is in megawatts, or 
megawatt-amperes, because unity power factor is assumed. Power is frequently expressed in units of SIL, that is, a number denoting the ratio between the power carried on the line to SIL. The power handling capability is commonly determined with the aid of the curve shown in Fig. 2, whose derivation was based partly on theoretical and partly on heuristic considerations $^{2}$ although some belleve it to be too conservative. ${ }^{3}$

In the above equations, the current is the total current per phase, or per line, which depends upon the number of conductors. Changing the number of conductors per phase (keeping constant the cross-sectional area), the intra- and interphase spacing, etc., can substantialiy change the current capacity of a line." In the case of a short line in which the thermal limit applies, the current-carrying capacity per line may. be assumed proportional to the number of conductors in a bundle. The specific load which is usually assigned to short lines is mostly a matter of judgment based on experience.

Typical values of $z_{0}$ for power lines lie between 200 and 400 ohms (see also Ref. 4).

\subsection{Load Flow Studies}

Load flow studies are conducted to determine the operation of a transmission system under various circumstances. A load flow study is the determination of the voltage, current, real power, and reactive power in the system. Consider a system with $N$ independent nodes, that is, $\mathrm{N}$ buses that can be either load or generator buses. The expression for current $I_{k}$ at node $k$ is

$$
I_{k}=\sum_{n=1}^{N} Y_{k n} v_{n} \text {, }
$$

where the $Y_{k n}$ are the self and mutual admltrances of the nodes, and $V_{n}$ is the voltage at node $n$. Since the complex power at node $n, S_{n}$, is the product of the voltage, $V_{n}$, and the complex conjugate of the current $I_{n}^{*}\left(S_{n}=V_{n} I_{n}^{*}=P_{n}+j Q_{n}\right)$, knowledge of the rirrent and voltage at each node constitutes a complete solution for a load flow study. If the voltage, both the magnitude and phase angle, were known at each node, 
ORNL-DWG 75-14980

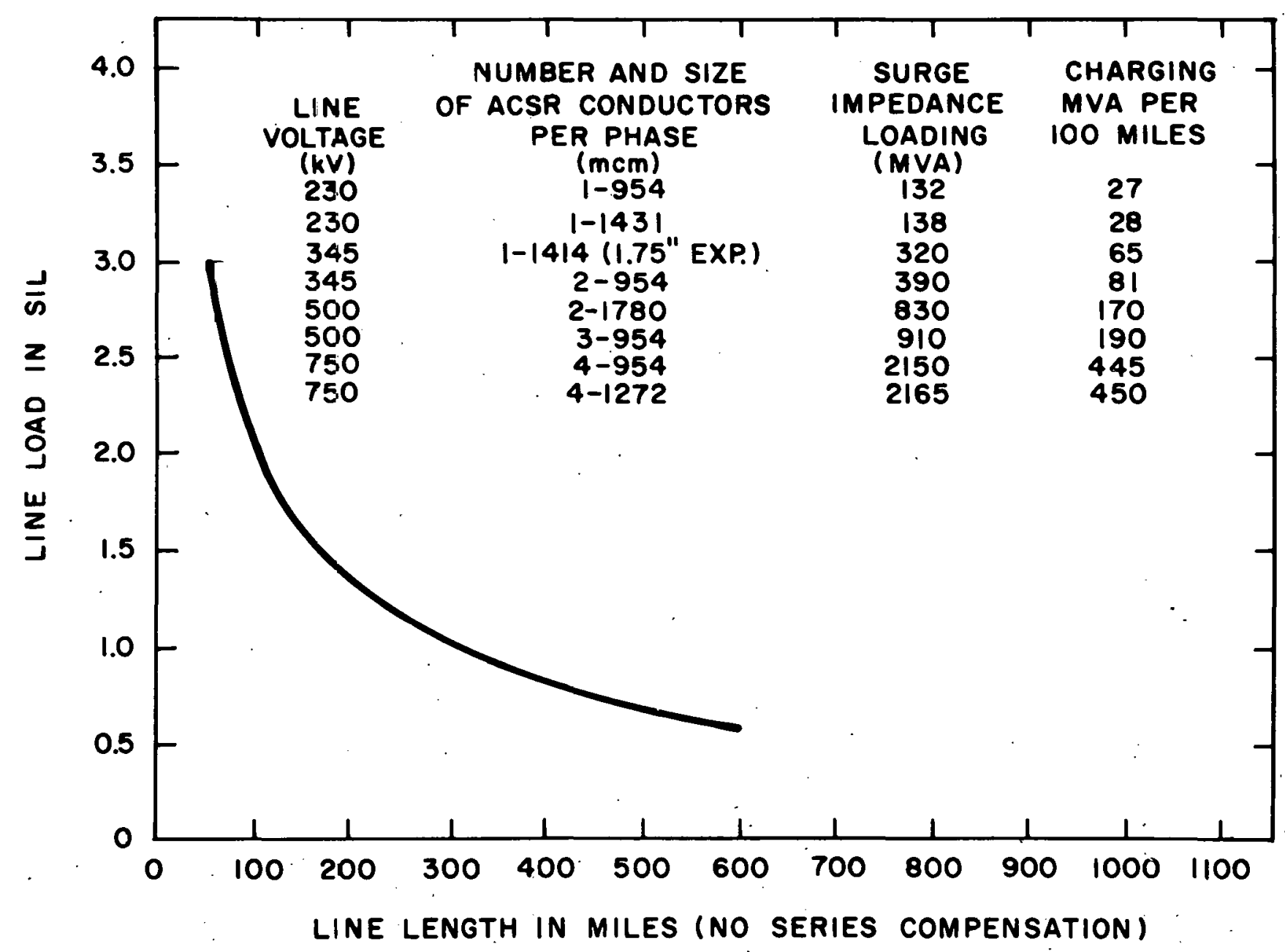

Fig. 2. Transmission line capability. 
Eq. (13) would yield the currents and thus the solution to the load flow problem.

Usually at a load bus, only the real and reactive power are given, with both $I_{n}$ and $v_{n}$ to be determined; whereas at a generator bus, the real power and the voltage magnitude are given. At one generator bus, the swing bus, the voltage magnitude and phase angle are given, but the current is not; thus, the power from the swing bus is determined by the load flow study. Determination of all the voltages and currents for this system, with its complex initial conditions, requires an iterative. method of solution.

\subsection{Transmission Planning}

Transmission line theory and design represent well-developed and established aspects of the power industry. This is not the case with future planning primarily because of the large number of uncertain variables such as growth and changes in demand; variations in Federal, state, and local regulations; rights-of-way; and environmental and social costs and impacts. The difficulty in establishing definite economic advantages of specific transmission schemes - as a result of these variables - makes the problem unwieldy even with computerized techniques.

Although load flow studica reached a high level of accuracy more than 15 years ago, $\$$ there is a lack of consensus on the reliability of a specific method of planning, except for the unanimous agreement regarding the overall difficulty of the problem. The only existing agreement with respect to particulars of planning is that dc load flow considerations are acceptable in the case of long-range (ten or more years) analyses. 6 An excellent review on the use of computers in planning, with a fairly comprehensive bibliography, points out the local (geographical) character of much of the planning considerations. ${ }^{7}$ Techniques involve use of linear programming, 8 power flow models, 9,10 dynamic programing, 11 and still other methods. ${ }^{12-14}$ As a result of the review of the existing literature and discussions with systems planners in several utility companies, a linear programming model seems adequate for the purpose of this study. 


\subsection{IEA Linear Programming System for Transmission Expansion Planning}

Consider a system with $\mathrm{J}$ generating stations and $\mathrm{K}$ load centers. Let $D_{i j}$ be the transmission distance from generator $i$ to load center $j$. Let $G_{i}$ be the capacity of generating center $i$, let $L_{j}$ be the demand at load center $j$, and let $G_{i j}$ be the power from generator $i$ to load center j. For the optimum dispatch of power, sufficient power is dispatched from each generator to the load centers to satisfy the demand at each load center without exceeding the generating capacity of the generators, and the power is dispatched to minimize the miles of transmission. The following linear programing problem analogous to the transportation problem will yield the optimum dispatch of power:

$$
H=\sum_{j=1}^{K} \sum_{i=1}^{J} D_{i j} G_{i j}=\text { minimum, }
$$

subject to the constraints

$$
\begin{array}{ll}
L_{j}=\sum_{i=1}^{J} G_{i j} & j=1, k, \\
G_{i} \geqslant \sum_{j=1}^{k} G_{i j} & i=1, j .
\end{array}
$$

A computer program that solves this dispatch problem has been the principal design tool in this study. 


\section{SURROGATE SITE ANALYSIS}

\subsection{Introduction}

Every point in the continental United States is in the service area of an electrical utility, public or private. Within the service area of each utility are load centers. The utilities operate and construct generating stations. Complex distribution and transmission systems are connecting the load centers and the generating station. The distribution system delivers power to the final consumer, and the transmission system moves bulk power around and between the service areas. Transmission and distribution systems are hierarchical depending on voltage (and thus power transmission capacity), and the hierarchical levels interconnect through transformers at substations.

The goal of utility planners is to design a system that will meet the needs of a service area reliably and with minimum cost to the customer and the environment. The goal of this study is somewhat different: it is to contrast the electrical power distribution system that has no NECs with the system that might develop if nuclear energy centers (NECs) are established. In other words, the task represents a differential analysis. To avoid being too hypothetical, several "real" surrogate sites were chosen for analysis. In the case of utilities, the service area is given and fixed. The urflictes then estluale llie growth of demand to plan additions to the power generating capacity for that area. In this study the sequence is reversed: A site was chosen first; then the rate of development of the energy center was chosen to guarantee a stable work force; finally, a service area (which may contain pieces of several existing utility service areas) was defined, an area which would be large enough to demand the base load power from the NEC as we11 as frum utlier sources.

This study is being conducted by a large team with many of the tasks performed in parallel. The problems are complex and a suitable method for their solution is iteration. At each iteration, the best information from the team members is used as input. Some of the input data used in this report have been subsequently revised by other members of the team, and where appropriate, the tentative nature of the input data will be 
noted. The results: reported here follow several iterations, but they do not yet represent a final solution.

Three cases, without currently existing transmission facilities, were considered for five load centers (Case A):

1. A maximum of forty reactors on a single site,

2. A maximum of forty reactors on four sites - ten reactors per site,

3. A maximum of forty reactors on ten sites - four reactors per site,

and two cases, including existing transmission facilities, were considered for six load centers (Case B):

1. Dispersed sites,

2. Center site, with few dispersed sites.

\subsection{Case A}

In each case, the construction sequence for the forty reactors is the same (see Table 1). The first reactor achieves full power operation in June 1987, and the fortieth reactor achieves full power operation in June 2020. The construction rate is one reactor per year from 1987 to 2000 and one reactor every nine months after 2000. To minimize disruption of the labor force, each site is fully developed before the next site is. begun. Each reactor has a capacity of $1200 \mathrm{MW}(1.2 \mathrm{GW})$ of electric power.

\subsubsection{Load centers and demand}

The definition of the load centers presented a minor difficulty. Initially, the largest standard metropolitan statistical areas (SMSAs) within 300 miles of the surrogate site were chosen. Because there are gaps between the SMSAs, however, the surrounding demand must be allocated to SMSAs. It seemed more appropriate, therefore, to choose the BEA economic areas* as defined by the Office of Business Economics of

* Choice suggested by R. J. Olsen, who made the demand projections. 
Table 1. Reactor full power sequence ${ }^{a}$

\begin{tabular}{|c|c|c|c|}
\hline $\begin{array}{l}\text { Number of } \\
\text { reactors }\end{array}$ & Date & $\begin{array}{l}\text { Number of } \\
\text { reactors }\end{array}$ & Date \\
\hline 2 & June 1988 & 22 & July 2006 \\
\hline 4 & June 1990 & 24 & February 2008 \\
\hline 6 & June 1992 & 26 & August 2009 \\
\hline 8 & June 1994 & 28 & March 2011 \\
\hline 10 & June 1996 & 30 & September 2012 \\
\hline 12 & June 1998 & 32 & April 2014 \\
\hline 14 & June 2000 & 34 & October 2015 \\
\hline 16 & December 2001 & 36 & May 2017 \\
\hline 18 & July 2003 & 38 & November 2018 \\
\hline 20 & January 2005 & 40 & June 2020 \\
\hline
\end{tabular}

the Department of Commerce. These areas cover all parts of the continental United States, and population projections by BEA area are readily available. The areas are named for the largest SMSA within the region or, where there is no SMSA, for the largest city. In this study the city so named represented the load center for each region. The developed capacity projections 15 indicated that the five $B E A$ regions nearest the Kentucky Lake surrogate site had large enough demand to use all of the power from the NEC. (Subsequently, Olsen adjusted his projections, 16 and a different number of BEA regions was needed for the next iteration.) Five load centers were chosen as a convenient, yet representative, study ohjective.* The load centers and their allocated capacity, as given in Ref. 15, are shown in Table 2. Figure 3 shows the service area for the Kentucky Lake Surrogate Site. (Figure 3 includes the Chat tanooga BEA Region, which was in the service area in the preceding iteration and contains one of the dispersed sites.)

\footnotetext{
* In a recent study by National Ėlectric Reliability Counci, , 17 four sites were studied with three to six load centers served by each.
} 
Table 2. Load centers and their share of the allocated capacity

\begin{tabular}{|c|c|c|c|c|c|}
\hline \multirow{2}{*}{$\begin{array}{l}\mathrm{BEA} \\
\text { region }\end{array}$} & \multirow[b]{2}{*}{ Name } & \multicolumn{2}{|c|}{ Latitude } & \multicolumn{2}{|c|}{ Longitude } \\
\hline & & Degrees & Minutes & Degrees & Minutes \\
\hline \multicolumn{6}{|c|}{ Load centers } \\
\hline 46 & Memphis, TN & 35 & 7.5 & 90 & 3.4 \\
\hline 47 & Huntsville, AL & 34 & 43.9 & 86 & 35.2 \\
\hline 49 & Nashville, TN & 36 & 9.8 & 86 & 46.7 \\
\hline 55 & Evansville, IN & 37 & 58.2 & 87 & 34.5 \\
\hline 115 & Paducah, KY & 37 & 4.6 & 88 & 36.9 \\
\hline
\end{tabular}

\begin{tabular}{|c|c|c|c|c|c|c|}
\hline $\begin{array}{l}\mathrm{BEA} \\
\text { region }\end{array}$ & 1980 & 1985 & 1990 & 1995 & 2000 & 2020 \\
\hline & \multicolumn{5}{|c|}{ Allocated share of capacity ${ }^{a}$} & . \\
\hline 46 & $\begin{array}{l}7.082 \\
6.989\end{array}$ & $\begin{array}{l}8.650 \\
8.483\end{array}$ & $\begin{array}{l}11.180 \\
11.300\end{array}$ & $\begin{array}{l}13.610 \\
13.603\end{array}$ & $\begin{array}{l}16.632 \\
16.737\end{array}$ & $\begin{array}{l}30.645 \\
30.884\end{array}$ \\
\hline 47 & $\begin{array}{l}2.860 \\
2.822\end{array}$ & $\begin{array}{l}3.731 \\
3.659\end{array}$ & $\begin{array}{l}4.919 \\
4.972\end{array}$ & $\begin{array}{l}6.389 \\
6.385\end{array}$ & $\begin{array}{l}7.970 \\
8.020\end{array}$ & $\begin{array}{l}16.344 \\
16.472\end{array}$ \\
\hline 49 & $\begin{array}{l}6.129 \\
6.048\end{array}$ & $\begin{array}{l}7.802 \\
7.652\end{array}$ & $\begin{array}{l}10.286 \\
10.396\end{array}$ & $\begin{array}{l}12.777 \\
12.770\end{array}$ & $\begin{array}{l}15.939 \\
16.040\end{array}$ & $\begin{array}{l}31.326 \\
31.570\end{array}$ \\
\hline 55 & $\begin{array}{c}2.515 \\
(2.232)\end{array}$ & $\begin{array}{c}3.035 \\
(2.832)\end{array}$ & $\begin{array}{c}3.919 \\
(3.655)\end{array}$ & $\begin{array}{c}4.793 \\
(4.446)\end{array}$ & $\begin{array}{c}5.822 \\
(5.394)\end{array}$ & $\begin{array}{c}10.281 \\
(9.601)\end{array}$ \\
\hline 115 & $\begin{array}{c}1.782 \\
(1.581)\end{array}$ & $\begin{array}{c}2.162 \\
(2.006)\end{array}$ & $\begin{array}{c}2.613 \\
(2.437)\end{array}$ & $\begin{array}{c}3.195 \\
(2.964)\end{array}$ & $\begin{array}{c}3.882 \\
(3.597)\end{array}$ & $\begin{array}{c}6.705 \\
(6.261)\end{array}$ \\
\hline
\end{tabular}

$a_{\text {The numbers in italics represent revised projections }}{ }^{16}$ in the Southeastern Electric Reliability Council (SERC) region; those in parentheses represent projections in the East Central Area Reliability Coordination Agreement (ECAR) region. 


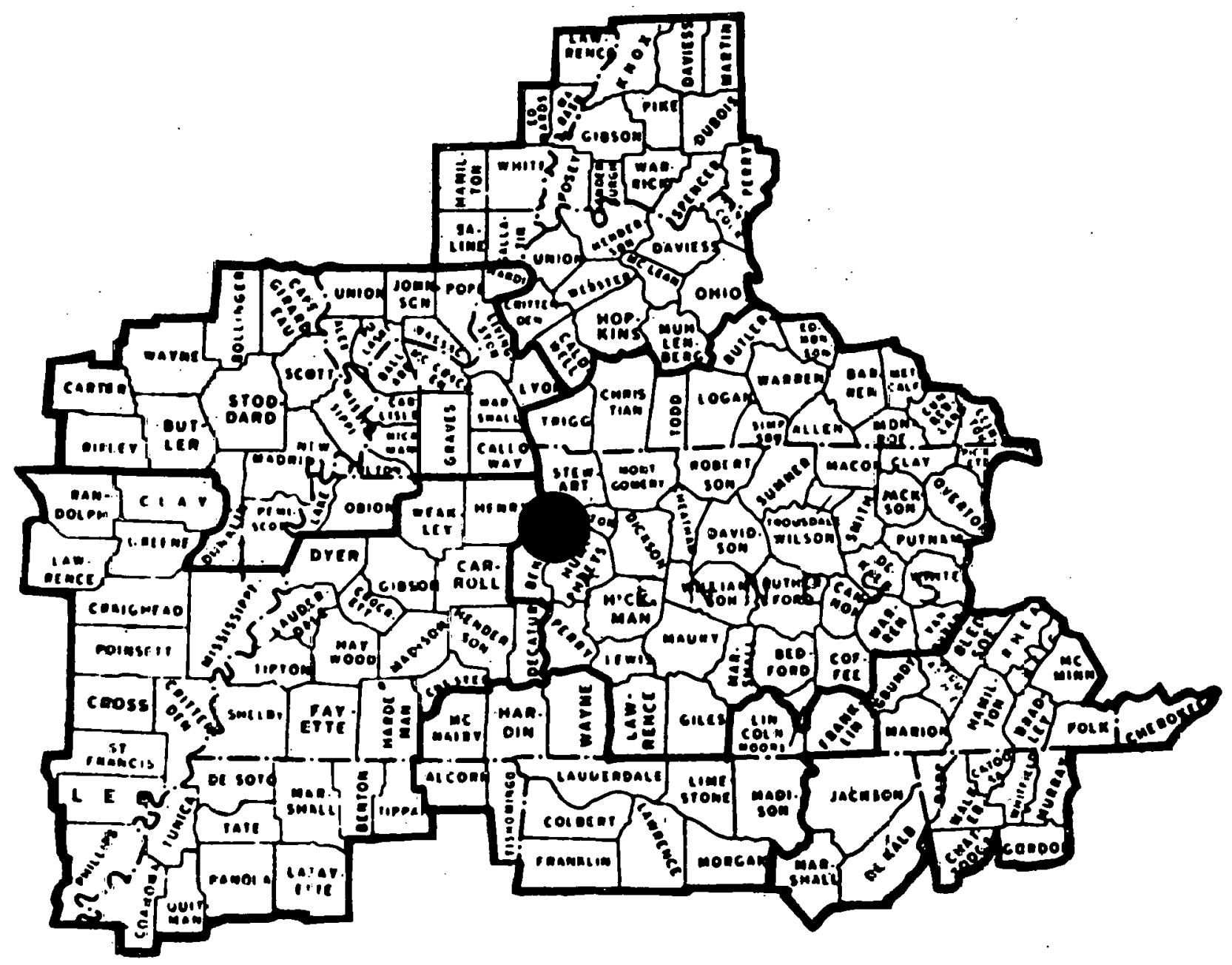

Fig. 3. Service area for Kentucky Lake Surrogate Site. 


\subsubsection{Dispersed sites.}

Sixty possible sites, each capable of supporting 4 reactors, were chosen within a 300-mile radius of the Kentucky Lake Surrogate Site. 18 The sites were chosen after the region had been analyzed by means of coarse screening techniques. The primary considerations were the availability of an adequate supply of water and avoidance of the New Madrid Fault area. (Details may be found in the appendix.) After the service. area for the surrogate site was chosen, ten potential generating sites were selected within that service area. The ten sites are identified in Table 3 and shown in Fig. 4. The Kentucky Lake Surrogate Site, McKinnon, Tennessee, is site number 1 . The ten sites include three which are under development by TVA. For each site, it will be assumed that there is no development before 1986 .

Table 3. Dispersed sites for generators

\begin{tabular}{|c|c|c|c|c|c|c|}
\hline \multirow[b]{2}{*}{ Site } & \multirow[b]{2}{*}{ Name } & & \multicolumn{2}{|c|}{ Latitude } & \multicolumn{2}{|c|}{ Longitude } \\
\hline & & & Degrees & Minutes & Degrees & Minutes \\
\hline 1 & McKinnon, TN & & 36 & 12.5 & 87 & 55.0 \\
\hline 2 & Cumberland City, TN & ק & 36 & 23.3 & 87 & 38.1 \\
\hline 3 & Eastport, MS & & 34 & 53.2 & 88 & 6.1 \\
\hline 4 & $\begin{array}{l}\text { Bellefonte-Hollywood, AL } \\
\text { (TVA) }\end{array}$ & & 34 & 40.3 & 86 & 2.1 \\
\hline 5 & Penton, MS & & 34 & 52.0 & 90 & 17.0 \\
\hline 6 & Cadiz, $\overline{\mathrm{KY}}$ & & 36 & 51.8 & 87 & 50.1 \\
\hline 7 & Hartsville, TN (TVA) & & 36 & 23.7 & 86 & 9.8 \\
\hline 8 & Perryville, TN & : & 35 & 37.2 & 88 & 2.4 \\
\hline 9 & $\begin{array}{l}\text { Browns Ferry-Rogersville, } \\
\text { (TVA) }\end{array}$ & $\mathrm{AL}$ & 34 & 49.6 & 87 & 17.5 \\
\hline 10 & Sherard, MS & & 34 & .12 .6 & 90 & 42.6 \\
\hline
\end{tabular}

\subsubsection{Differential analysis}

The concern of this study lies in the differences between siting baseload nuclear power plants in energy centers and in dispersed generating 


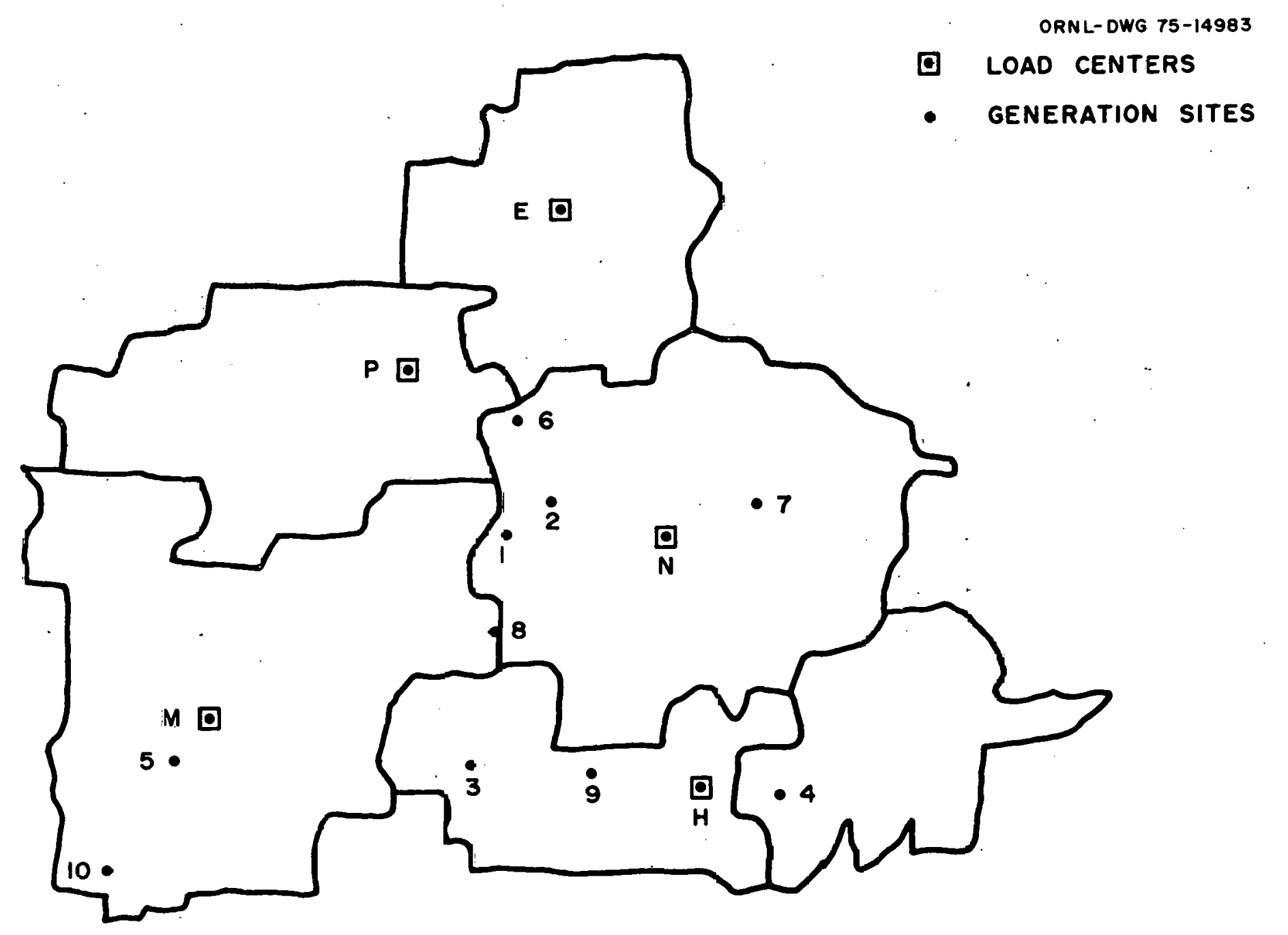

Fig. 4. Load center and dispersed generating sites for Kentucky Lake Surrogate Site. 
sites. Although there are approximations involved, the differences were estimated directly by means of differential analysis. Both a centered and a dispersed siting plan will have an existing system of transmission lines and power plants in 1987, but for the differential analysis of Case A the assumption will be made that there is no existing system of transmission lines and power plants before 1987. Although there will be fossil and peaking units in addition to the base load nuclear units for both a centered and a dispersed siting plan, for purposes of the differential analysis it will be assumed that no other sources of power exist in the service area. Also, even though there are interconnections with adjacent load centers that can be used to export or import power, no such interconnections with adjacent areas will be used in the differential analysis. The final assumption in the differential analysis is that all bulk power is transmitted over $765-\mathrm{kV}$ lines; therefore, only the miles of $765-\mathrm{kV}$ transmission lines for the centered and dispersed system will be estimated.

Since the energy center has base load units, the transmission system must be capable of moving all the power to the load centers. Thus, the total demand from the load centers should be equal to the total capacity of the energy center. The number of reactors in Table 1 multiplied by 1.2 GW per reactor gives the total demand by a11 load centers. This total has been allocated to load centers on the basis of the capacity projection of $01 \operatorname{sen}^{15}$ (see Table 2) corrected for retire-" ments. (The details are in the appendix.) The resulting demand projection is shown in Table 4 for the date (shown in Table 1) at which each second reactor is completed. (The total demand is $40 \mathrm{MW}$ less than the total capacity to guarantee that the linear programming: problem is feasible.)

\subsubsection{Sensitivity analysis}

Sensitivity analysis implies the study of each assumption in the differential, analysis. A comprehensive check would consist of adding all the neighboring BEA regions, including the existing system in 1986, estimating retirements in the period 1986-2000 based on the existing plants in 1986, and including all new capacity additions (nuclear, fossil, and peaking) in the period 1986-2000. For this larger system, the same 
Table 4. Demand from energy centers by load centers

\begin{tabular}{lcccccr}
\hline Year & Nashville & Paducah & Evansville & Huntsville & Memphis & Total \\
\hline 1988 & 0.76 & 0.16 & 0.28 & 0.36 & 0.81 & 2.36 \\
1990 & 1.54 & 0.31 & 0.56 & 0.73 & 1.63 & 4.76 \\
1992 & 2.28 & 0.50 & 0.84 & 1.15 & 2.39 & 7.16 \\
1994 & 3.02 & 0.70 & 1.11 & 1.59 & 3.14 & 9.56 \\
1996 & 3.78 & 0.89 & 1.38 & 2.00 & 3.91 & 11.96 \\
1998 & 4.57 & 1.08 & 1.65 & 2.38 & 4.68 & 14.36 \\
2000 & 5.35 & 1.27 & 1.91 & 2.77 & 5.46 & 16.76 \\
2001 & 6.13 & 1.45 & 2.18 & 3.17 & 6.23 & 19.16 \\
2003 & 6.92 & 1.62 & 2.43 & 3.59 & 7.00 & 21.56 \\
2005 & 7.72 & 1.79 & 2.68 & 4.01 & 7.77 & 23.96 \\
2006 & 8.50 & 1.96 & 2.93 & 4.42 & 8.54 & 26.36 \\
2008 & 9.31 & 2.12 & 3.18 & 4.85 & 9.30 & 28.76 \\
2009 & 10.10 & 2.29 & 3.43 & 5.27 & 10.07 & 31.16 \\
2011 & 10.91 & 2.45 & 3.61 & 3.11 & 10.83 & 33.56 \\
2012 & 11.70 & 2.62 & 3.92 & 6.13 & 11.59 & 35.96 \\
2014 & 12.52 & 2.77 & 4.15 & 6.58 & 12.34 & 38.36 \\
2015 & 13.32 & 2.94 & 4.39 & 7.01 & 13.10 & 40.76 \\
2017 & 14.14 & 3.09 & 4.62 & 7.46 & 13.84 & 43.16 \\
2018 & 14.95 & 3.25 & 4.86 & 7.90 & 14.60 & 45.56 \\
2020 & 15.78 & 3.40 & 5.09 & 8.36 & 15.34 & 47.96 \\
\hline
\end{tabular}

three cases which were analyzed previously by means of differential analysis (one, four, and ten sites) and the two sets of answers could be compared. In Case B, limited sensitivity analysis has been performed for the surrogate site.

\subsubsection{Transmission corridors}

The selection of detailed transmission corridors and substations is not solely an engineering problem; it is a complex land use planning problem that should involve environmentalists, land use planners, and the public. The planning process should be iterative; the engineer determines the need for a transmission line from point A to point $B$; the land use planning process must then locate the substation locations $A$ and $B$ and choose a corridor between them. The engineer may then revise his design if the corridor located by the planning process is too expensive. This, in turn, may require that the land use planning process 
should consider the alternative design, etc. In this study, the transmission corridors, based on engineering data on the number of transmission lines between generators and load centers, were planned by J. S. Suffern.

\subsubsection{Analytical tools}

A computer program was devised to solve the IEA Linear Programming problem described in Section 2. Given the locations of the load centers and generators, the generating capacity of each generator, and the demand from each load center, the computer program dispatches power from generators to load centers to minimize the transmission of power. Table 5 shows a sample of the computer printout for the 10-site case, each site with 4 reactors. The total generating capacity is $48 \mathrm{GW}$ and the total demand is $47.97 \mathrm{GW}$, leaving an excess capacity of $30 \mathrm{MW}$. Table 5 and Fig. 4 illustrate the tradeoffs between minimizing distance and satisfying demand. From Table 4, the demand from Paducah is $3400 \mathrm{MW}$. Site 6, Cadiz, is closest to both Evansville and Paducah, but it does not have enough power to satisfy both demands. Although Paducah is closer to Cadiz, all the power from Cadiz flows to Evansville. Site 1, McKinnon, is closer to Paducah than Site 2, Cumberland City, and the demand of Paducah is satisfied by McKinnon while the remaining demand of Evansville, $290 \mathrm{MW}$, is satisfied by Cumberland City.

Table 5 indicates that the total gigawatt-miles for the dispersed system is 2974 and the total gigawatt-miles for the center is 5103 . Thus, the dispersed system seems to effect considerable savings. This, however, represents the dispatch of power not a reliable transmission system. The real savings can be determined only by comparing the miles of transmission lines that include redundancy at least for a single contingency. In such a case, the final savings may not be as great as the difference in dispatch gigawatt-miles for the two systems implies. 
Table 5. Optimum dispatch of power for

dispersed system - ten 4-reactor sites - in 2020

McKinnon, Tennessee 48 GW Apri1 21, 1975

Multiple-site output

Total gigawat $t$-miles $=2974$

Central gigawatt-miles $=5103$

$\begin{array}{ll}\text { Name of generator - McKinnon, Tennessee } \\ \text { Dispatch } & \begin{array}{c}\text { Generator capacity }=4.8 \\ \text { Name of load center }\end{array} \\ 1.40 & \text { Nashville, lennessee } \\ 3.40 & \text { Yuducah, Kentucky } \\ 0.0 & \text { Evansville, Ind iana } \\ 0.0 & \text { Huntsville, Alabama } \\ 0.0 & \text { Memphis, Tennessee }\end{array}$

Excess capacity $=0.0$

Generator capacity $=4.8$

Name of generator - Cumberland City, Tennessee

Dispatch
4.51
0.0
0.29
0.0
0.0

Name of load center

Nashville, Tennessee

Paducah, Kentucky

Evansville, Indiana Huntsvilie, Alabama

Memphis, 'Tennessee

Excess capacity $=0.0$

Generator capacity $=4.8$

Name of generator - Eastport, Mississippi

\section{Dispatch}

0.0

0.0

0.0

0.0

4.80
Name of load cencer

Nashville, Tennessee

Paducah, Kentucky

Evansville, Indiana

Huntsville, Alabama

Memphis, Tennessee

Excess capacity $=0.0$ 
Table 5 (continued)

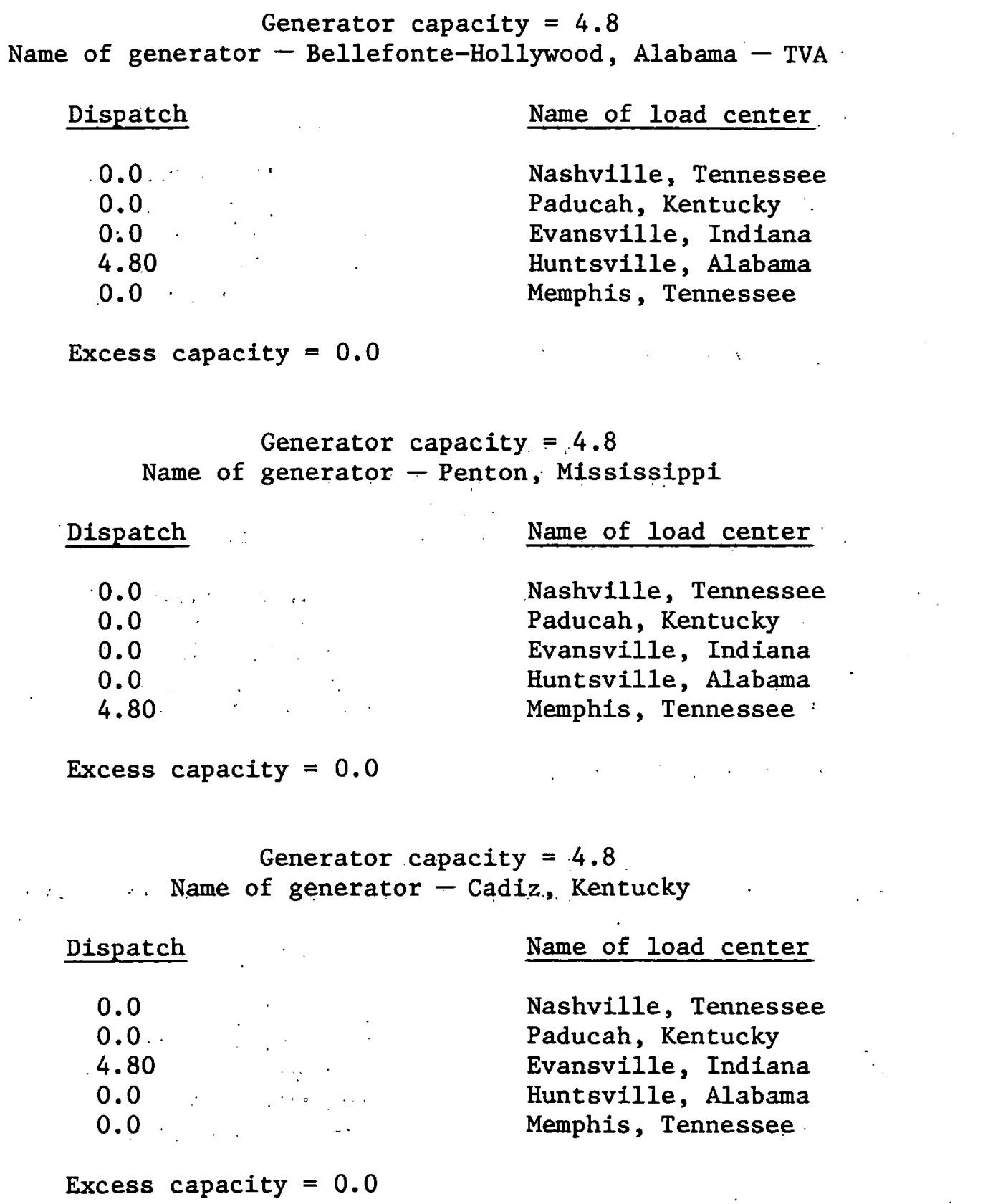


Table 5 (continued)

Generator capacity $=4.8$

Name of generator - Hartsville, Tennessee - TVA

Dispatch

4.80

0.0

0.0

0.0

0.0
Name of load center

Nashville, Tennessee

Paducah, Kentucky

bivansville, Indiana

Huntsville, Alabama

Memphis, Tennessee

Excess capacity $=0.0$

Generator capacity $=4.8$

Name of generator - Perryville, Tennessee

Dispatch

3.86

0.0

0.0

0.0

0.94
Name of load center

Nashville, Tennessee

Paducah, Kentucky

Evansville, Indiana

Huntsville, Alabama

Memphis, Tennessee

Excess capacity $=0.0$

Generator capacity $=4.8$

Name of generator - Browns Ferry-Rogersville, Alabama - TVA

Dispatch

1.21

0.0

0.0

3.56

0.0
Name of load center

Nashville, Tennessee

Paducah, Kentucky

Evansville, Indiana

Huntsville, Alabama

Memphis, Tennessee

Excess capacity $=0.03$ 
Table 5 (continued)

\author{
Generator capacity $=4.8$ \\ Name of generator - Sherard, Mississippi \\ Dispatch \\ Name of load center \\ 0.0 \\ 0.0 \\ 0.0 \\ 0.0 \\ 4.80 \\ Nashville, Tennessee \\ Paducah, Kentucky \\ Evansville, Indiana \\ Huntsville, Alabama \\ Memphis, Tennessee \\ Exçess capacity $=0.0$
}

\title{
3.2.7 Transmission system for one energy center at the Kentucky Lake Surrogate Site
}

In the case of a single energy center, the optimum dispatch of power is simply to satisfy the demand of each load center. Table 6 and Fig. 5 show the transmission system for a fully developed energy center with 40 reactors delivering 48 GW of power in 2020. The designated demand for each load center comes from Table 4. The distances from the surrogate site to the load centers are represented by straight line (actually, great circle) distances. (For the next iteration, the transmission corridors designed by the land use planners would be used.) . On the basis of the methods described in Section 2, the capacity of a 765-kV line of the appropriate length has been estimated. The minimum number of lines, $\mathrm{L}^{*}$, represents the demand divided by the capacity per line. The transmission system was designed by rounding $L^{*}$ to the next highest integer and adding an extra line to provide spare capacity if one of the lines should fail (single contingency). As an example, the demand for Nashville from the energy center in 2020 will be $15.78 \mathrm{GW}$. With the capacity of a 64-mile transmission line of about $6.129 \mathrm{GW}$; L* is 2.57 . Thus, three lines can carry the load, but four lines are needed for redundancy. 
Table 6. One energy center at Kentucky Lake Surrogate Site McKinnon, Tennessee, 40 reactors, $48 \mathrm{GW}$ - in 2020

\begin{tabular}{lrrrrr}
\hline Load center & Load & Miles & GW/line & L* & Lines \\
\hline Nashville & 15.78 & 64 & 6.129 & 2.57 & 4 \\
Paducah & 3.40 & 71 & 5.789 & 0.59 & 2 \\
Evansville & 5.09 & 123 & 4.338 & 1.17 & 3 \\
Huntsville & 8.36 & 127 & 4.243 & 1.97 & 3 \\
Memphis & 15.34 & 142 & 3.926 & 3.91 & 5 \\
\hline
\end{tabular}

$L^{*}=$ Load $\div(\mathrm{GW} /$ line $)$

\subsubsection{Transmission system and development plan for ten dispersed energy centere}

Table 5 shows the optimum dispatch of power from 10 dispersed energy centers to the load centers in 2020. Table 7 lists the capacity (GW/line) for a $765-\mathrm{kV}$ line from each generator to the load centers the generator will serve. Based on the capacities in Table 7, a transmission system shown in Fig. 6 has been designed to carry the dispatch of power shown in Table 5, including a single contingency provision. For example, the demand of Evansville is satisfied by power from Cadiz (6) and Cumberland City (2) while the power for Paducah comes from McKinnon (1). A single 765-kV line from Cadiz (6) to Evansville can carry $5.5 \mathrm{GW}$, which exceeds the demand of Evansville (5.09 GW). Thus, the power from Cumberland City (2) to Evansville can be transmitted to Cadiz (6), and the total load can be transmitted to Evansville rather than sending the power directly from Cumberland City (2) to Evansville. Two lines are needed from Cadiz (6) to Evansville. A single line connects Cumberland City (2) and Cadiz (6); the second path is from Cumberland City (2) to Mckinnon (1) to Cadiz (6). The line from McKinnon (1) to Cadiz also provides a second path for the power from Mckinnon (1) to Paducah.

The transmission system in Fig. 6 carries 290 MW from Cumberland City (2) to Cadiz (6) to Evansville. Since the $765-\mathrm{kV}$ line from Cumberland City (2) to Cadiz (6) could carry 6625 MW, it is substantially underloaded at $290 \mathrm{MW}$. More extensive systems studies, including load-flow analyses, would be needed to choose the best alternative to 


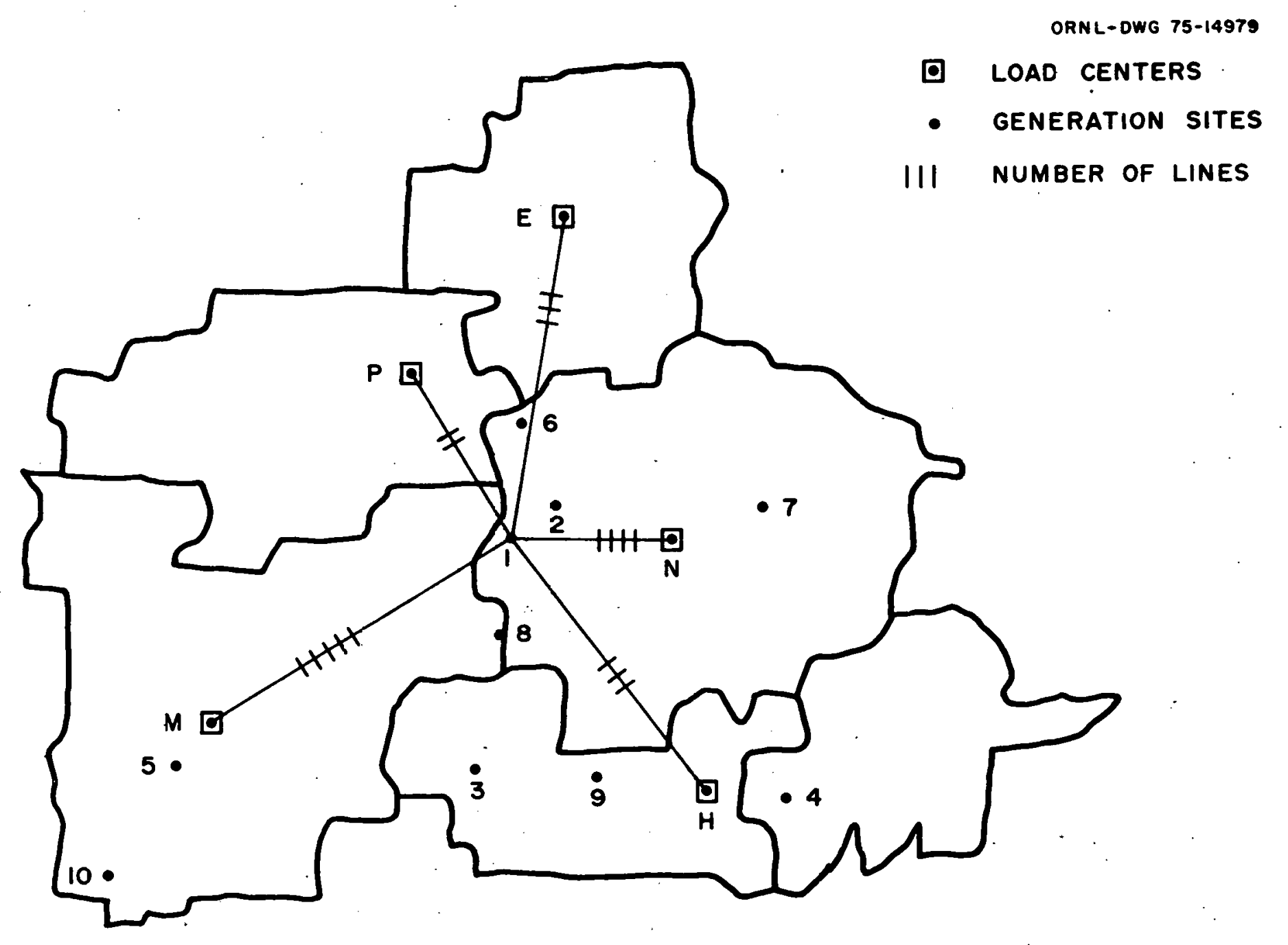

Fig. 5. One energy center at Kentucky Lake Surrogate Site (McKinnon, Tennessee), having 40 reactors and producing $48 \mathrm{GW}$, in 2020 . 
Table 7. Dispersed generators - 1-generator sites, each with 4 reactors and producing $4.8 \mathrm{GW}-$ in 2020

\begin{tabular}{ccccccc}
\hline \multicolumn{2}{c}{ Dispatch } & & & & \\
From & To & Load & Miles & GW/line & L* & Lines \\
\hline 1 & N & 1.40 & 64 & 6.129 & 0.23 & 1 \\
1 & P & 3.40 & 71 & 3.789 & 0.59 & 2 \\
2 & N & 4.51 & 50 & 6.625 & 0.68 & 1 \\
2 & E & 0.29 & 109 & 4.575 & 0.06 & 1 \\
3 & M & 4.80 & 112 & 4.508 & 1.06 & 2 \\
4 & II & 4.80 & 32 & 6.625 & 0.72 & 2 \\
5 & M & 4.80 & 22 & 6.625 & 0.72 & 3 \\
6 & E & 4.80 & 78 & 5.498 & 0.87 & 2 \\
7 & N & 4.80 & 38 & 6.625 & 0.72 & 2 \\
8 & N & 3.86 & 80 & 5.422 & 0.71 & 2 \\
8 & M & 0.94 & 119 & 4.360 & 0.22 & 1 \\
9 & N & 1.21 & 97 & 4.878 & 0.24 & 2 \\
9 & H & 3.56 & 41 & 6.625 & 0.54 & 2 \\
10 & M & 4.80 & 73 & 5.701 & 0.84 & 2 \\
\hline L* & Load $\div$ (GW/1ine) & & & &
\end{tabular}

serve Evansville. Among the alternatives are: a different dispatch of power, a lower voltage connection between Cumberland City and Cadiz (e.g., 345- or $230-\mathrm{kV}$ ), or an increased generating capacity at Cadiz.

In addition to designing a transmission system for a fully developed system in 2020 with 40 reactors at ten sites, an optimum sequence of development for the ten dispersed energy centers was obtained. Table 8 shows the sequence chosen, obtained by examining the energy center at three stages in its development - 10 reactors in 1996, 20 reacturs lin 2005, and 30 reactors in 2012 - and by consldering projected changco in demand.

The IEA Program was used to work out the details shown in Table 8 (i.e., choosing between Browne Eerry (9) and Cumherland City (2) in 1990, choosing between Cadiz (6) and Hartsville (7) in 2001, etc).

\subsubsection{Transmission system and development plan for four energy centers}

The first task is to choose the four energy centers from among the ten dispersed energy centers. In 2020 the demand from Memphis and Nashville is greater then the 12-GW capacity of one of the four energy centers. 


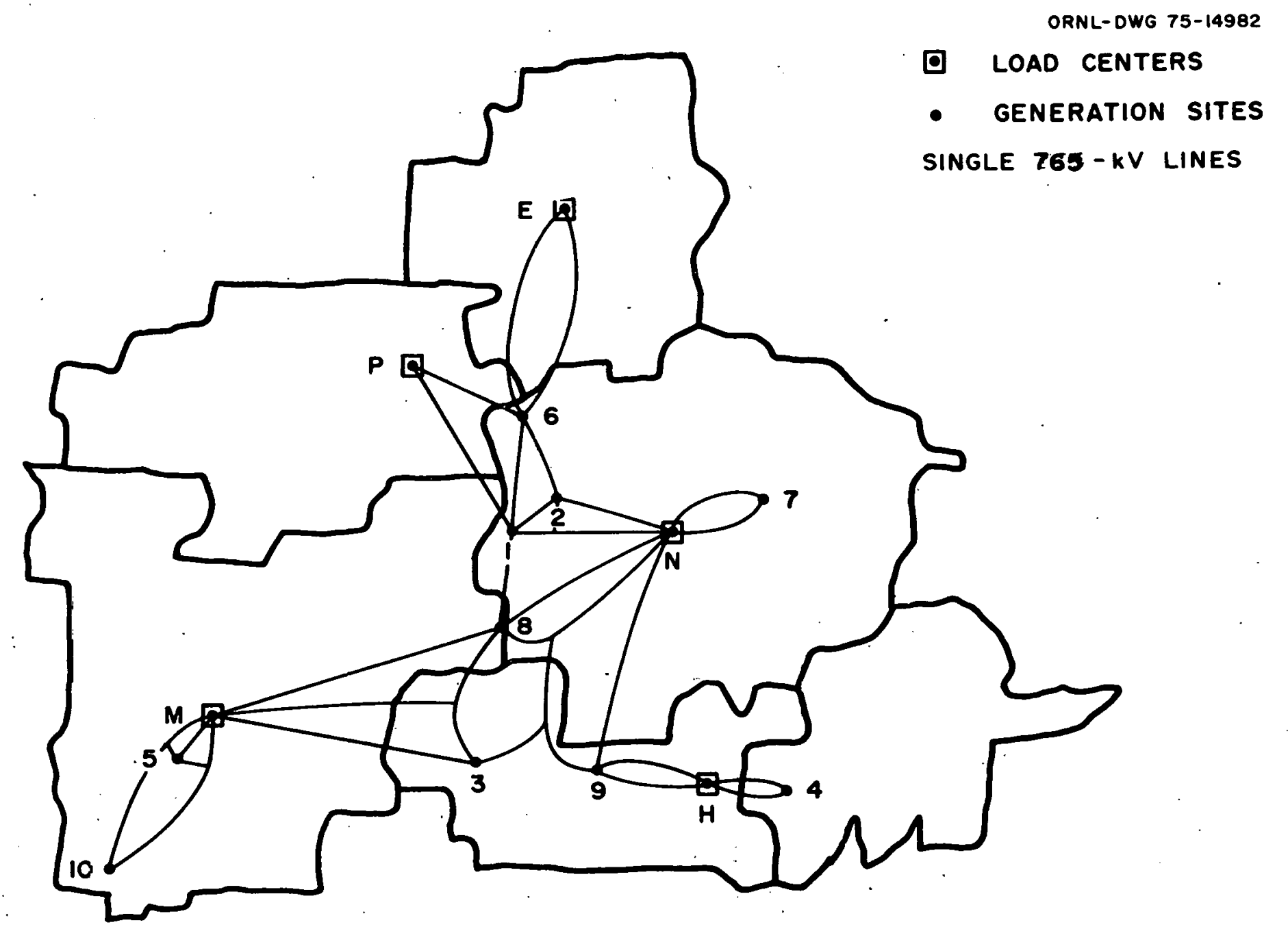

Fig. 6. Transmission system for ten dispersed sites. 
Table 8. Optimum sequence for ten dispersed sites

\begin{tabular}{rrl}
\hline Order & Site & Completion date \\
\hline 1 & 2 & June 1990 \\
2 & 9 & June 1994 \\
3 & 5 & June 1998 \\
4 & 6 & December 2001 \\
5 & 7 & January 2005 \\
6 & 10 & February 2008 \\
7 & 4 & March 2011 \\
8 & 1 & Apri1 2014 \\
9 & 3 & May 2017 \\
10 & 8 & June 2020 \\
\hline
\end{tabular}

Penton (5) is the best choice for the Memphis energy center; the Nashville energy center could be either Hartsville (7) or Cumberland City (2). The IEA computer program was used to make an optimum choice for the four energy centers. The results are shown in Table 9. The sites for the four energy centers are Penton (5), Cadiz (6), Hartsville (7), and Browns Ferry (9). The total number of dispatch gigawatt-miles for the four energy centers is less than one-haif the gigawatt-miles for the single energy center and significantly less than the gigawatt-miles for the ten dispersed energy centers. (The following note of caution must be inserted. Although the four energy centers are chosen to minimize the total gigawattmiles, the ten energy centers were chosen at random. Four energy centers chosen at random would probably not give fewer gigawatt-miles than the ten energy centers. However, just as a 4-reactor energy center makes sense at Hartsville in 1985, a 10- or 12-reactor energy center makes sense at Hartsville in 2020. Perhaps the optimum system is to have lhe energy centers grow to meet the load; in 2020 Penton (5) and Hartsville (7) would have more than 10 reactors, and Cadiz (6) and Browns Ferry (9) would have less than 10 reactors.)

The capacity of $765-\mathrm{kV}$ transmission lines from the energy centers to the load centers is given in Table 10. On the basis of Table 10, a transmission system for the four energy centers has been designed and is shown in Fig. 7. Because of light loading, only one line is shown from Browns Ferry (9) to Nashville. As in the case of the line from Cumberland 
Table 9. Optimum dispatch of power from four energy centers, each having 10 reactors and producing $12 \mathrm{GW}$, in $2020^{a}$

\begin{tabular}{|c|c|c|}
\hline $\begin{array}{l}\text { Name of } \\
\text { generator } b\end{array}$ & $\begin{array}{l}\text { Name of } \\
\text { load center }\end{array}$ & Dispatch \\
\hline Penton, MS (5) & Memphis, TN & 12.00 \\
\hline Cadiz, KY (6) & $\begin{array}{l}\text { Nashville, TN } \\
\text { Paducah, KY } \\
\text { Evansville, IN }\end{array}$ & $\begin{array}{l}3.51 \\
3.40 \\
5.09\end{array}$ \\
\hline Hartsville, TN (7) (TVA) & Nashville, TN & 12.00 \\
\hline $\begin{array}{l}\text { Browns Ferry-Rogersville, AL } \\
\text { (9) (TVA) }\end{array}$ & $\begin{array}{l}\text { Nashville, TN } \\
\text { Huntsville, AL } \\
\text { Memphis, TN }\end{array}$ & $\begin{array}{l}0.27 \\
8.36 \\
3.34 \\
47.97^{c}\end{array}$ \\
\hline
\end{tabular}

Table 10. Four energy centers (Penton, Cadiz, Hartsville, and Browns Ferry), each having 10 reactors and producing $12 \mathrm{GW}$, in 2020

\begin{tabular}{llrrrrr}
\hline $\begin{array}{c}\text { Dispatch } \\
\text { generator }\end{array}$ & Load center & Load & Miles & GW/line & L* & Lines \\
\hline & & & & & & \\
Penton (5) & Memphis & 12.00 & 22 & 6.625 & 1.81 & 3 \\
Cadiz (6) & Nashville & 3.51 & 76 & 5.577 & 0.63 & 2 \\
Cadiz (6) & Paducah & 3.40 & 46 & 6.625 & 0.51 & 2 \\
Cadiz (6) & Evansville & 5.09 & 78 & 5.498 & 0.93 & 2 \\
Hartsville (7) & Nashville & 12.00 & 38 & 6.625 & 1.81 & 3 \\
Browns Ferry (9) & Nashville & 0.27 & 97 & 4.878 & 0.06 & 1 \\
Browns Ferry (9) & Huntsville & 8.36 & 41 & 6.625 & 1.26 & 3 \\
Browns Ferry (9) & Memphis & 3.34 & 158 & 3.645 & 0.92 & 2 \\
\hline
\end{tabular}

$L^{*}=$ Load $\div$ (GW/line) . 


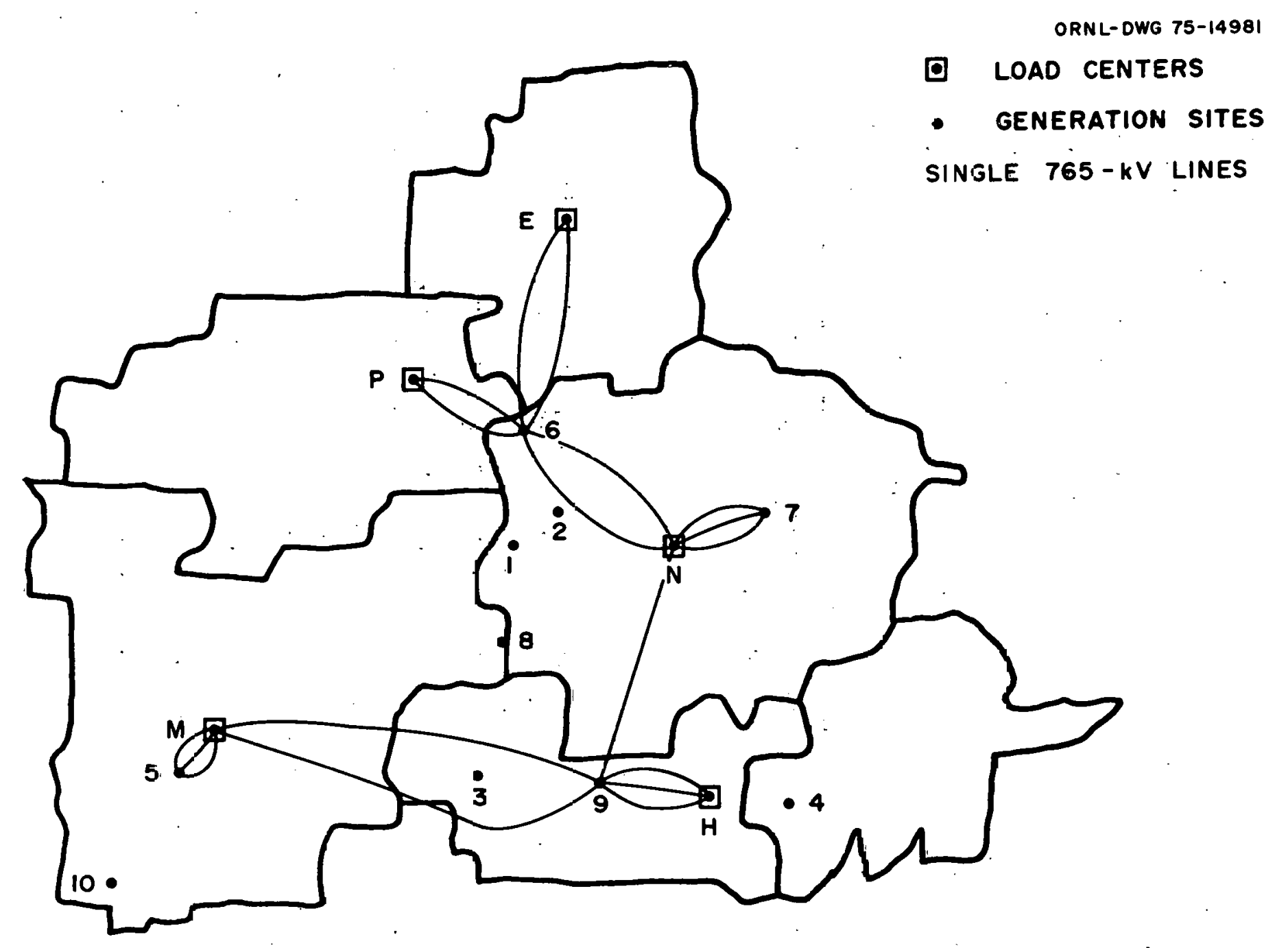

Fig. 7. Transmission system for four energy centers. 
City (2) to Evansville for the dispersed system, systems studies would be needed to choose the best way to supply $270 \mathrm{MW}$ of power to Nashville. The present dispatch of power from Browns Ferry is probably not the best solution.

The IEA Linear Programming Computer Program was used to find an optimum time sequence for the development of the four energy centers shown in Table 11. All possible development sequences were considered in 1996, 2005, and 2012; that is, after the completion of one, two, and three centers. In 1966 the optimum site is Cadiz (6). In 2005 the optimum sites are Penton (5) and Hartsville (7). Thus, the second. optimum is not compatible with the first. In 2012 , the optimum sites are Penton (5), Cadiz (6), and Browns Ferry (9). Considering the total gigawatt-miles in 1996, 2005, and 2012 for all possible development sequences, the best sequence is shown in Table 11 .

Table 11. Optimum sequence for four energy centers

\begin{tabular}{ccl}
\hline Order & Site & Completion date \\
\hline 1 & 6 & June 1996 \\
2 & 5 & January 2005 \\
3 & 9 & September 2012 \\
4 & 7 & June 2020 \\
\hline
\end{tabular}

\subsubsection{Comparison of the transmission system in 2020 for one energy} center, four energy centers, and ten dispersed energy centers

To summarize, the IEA Linear Programing Computer Program dispatches the power to the load centers to minimize the distance the power must travel measured in gigawatt-miles. The total number of gigawatt-miles for the three types of energy centers are shown in Table 12. For one center the power travels $5103 \mathrm{GW}$-miles, for four centers the power travels $2429 \mathrm{GW}$-miles ( $48 \%$ of the one-center tota1), and for ten centers the power travels $2974 \mathrm{GW}$-miles (58\% of the one-center total). With the caveat noted previously, the four-center system has the smallest: power dispatch. 
Table 12. Comparison of transmission system for one energy center, four energy centers, and ten dispersed centers

\begin{tabular}{ccccc}
\hline $\begin{array}{c}\text { Number of } \\
\text { centers }\end{array}$ & $\begin{array}{c}\text { Linear Programing } \\
\text { gigawatt-miles }\end{array}$ & $\begin{array}{c}\text { Percent of } \\
\text { the one-center } \\
\text { total }\end{array}$ & $\begin{array}{c}765-\mathrm{kV} \\
\text { miles }\end{array}$ & $\begin{array}{c}\text { Percent of } \\
\text { the one-center } \\
\text { total }\end{array}$ \\
\hline 1 & 5103 & 100 & 1858 & 100 \\
4 & 2429 & 48 & 1116 & 60 \\
10 & 2974 & 58 & 1727 & 93 \\
\hline
\end{tabular}

Another comparison can be made of the estimate of the total miles of $765-\mathrm{kV}$ transmission required for each type of energy center (see Table 12). (The length of the transmission system in Table 12 is based on straight-line distances. An estimate using corridöris chosen by means of land use planning will be given in the next chapter.) Because of redundancy required for reliability, the four-energy-center system loses some of its transmission distance advantage over the single energy center (60 vs $48 \%$ ); but the dispersed system loses almost all its advantage over the single energy center (93 vs 58\%). Cost comparison of the three transmission systems will be made in the next chapter.

\subsection{Case B}

\subsubsection{Introduction}

This part of the study takes into consideration power plants and 500-kV transmission lines existing and/or planned through the ear1y 1980s, as indicated in the 1974 reports to the Federal Power Commission. Plants with capacities smaller than $200 \mathrm{MW}$ were omitted. The plants which were included were phased out in accordance with the expected lifetime for the type - 20 years for gas turbine, 40 years for steam, and 60 years for hydroelectric. Dates of plant completion and respective capacicles were obtained from the directory. 19

Load centers and generation sites are shown in Fig. 8, which, except for the addition of Chartanooga, cuver's the same area as the regions in part $A$ of the study. The centers and sites have been renumbered to correspond to bus numbers used by General Electric in a parallel 


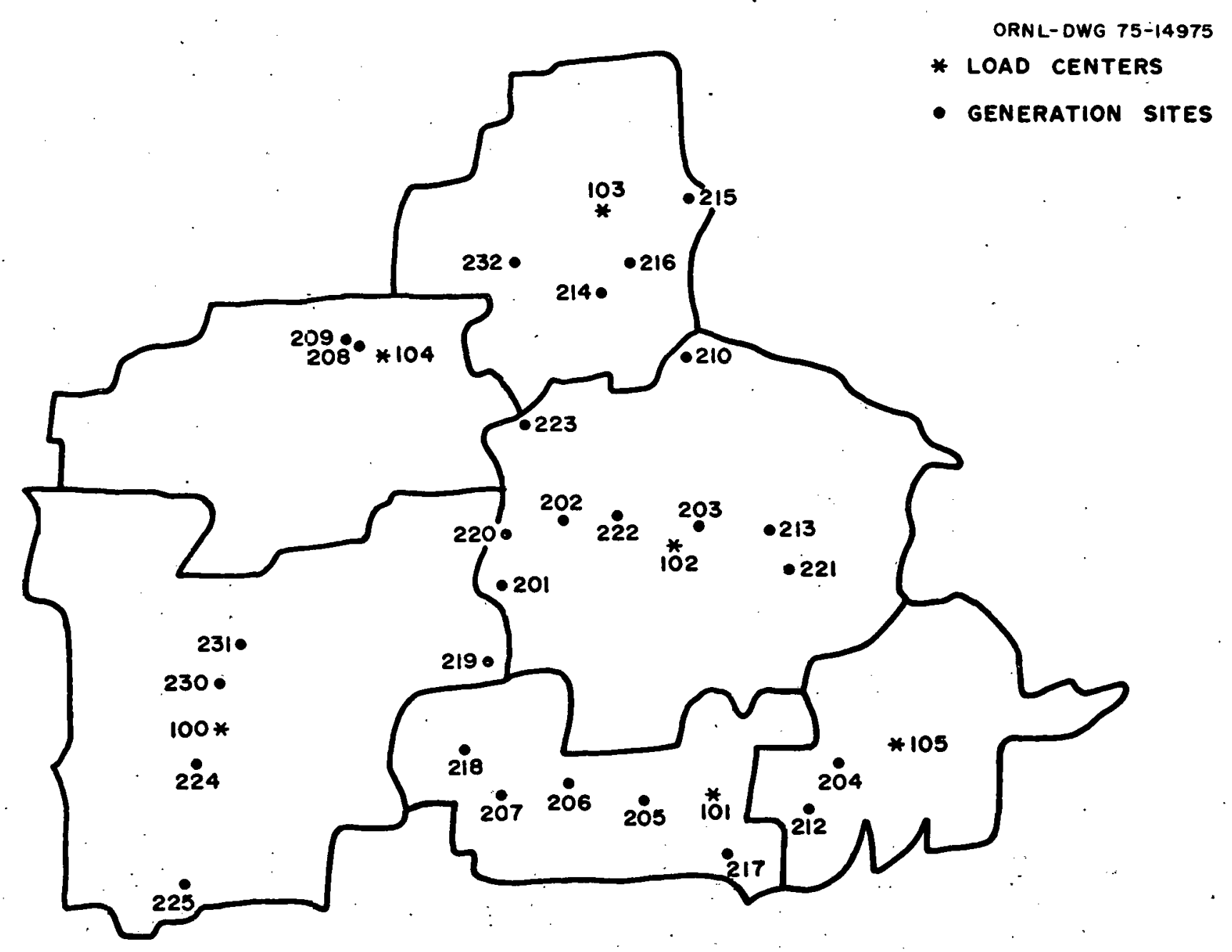

Fig. 8. Load centers and generation sites (Case B). 
study. The load centers and their demands are listed in Table 13; the generating sites and their capacities are listed in Table 14 for the dispersed case and in Table 15 for the center case.

Table 13. Load centers and demand $a$

\begin{tabular}{|c|c|c|c|c|c|c|}
\hline \multirow[b]{2}{*}{$\begin{array}{l}\text { Bus } \\
\text { number }\end{array}$} & \multirow[b]{2}{*}{ Name } & \multicolumn{2}{|c|}{ Position } & \multirow{2}{*}{$\begin{array}{l}1985 \\
\text { load } \\
\text { (MW) }\end{array}$} & \multirow{2}{*}{$\begin{array}{l}2005 \\
\text { load } \\
\text { (MW) }\end{array}$} & \multirow{2}{*}{$\begin{array}{l}2020 \\
\text { load } \\
\text { (MW) }\end{array}$} \\
\hline & & Latitude & Longitude & & & \\
\hline 100 & Memphis & 35.125 & 90.057 & $-5,476$ & $-15,377$ & $-25,737$ \\
\hline 101 & Huntsvil1e & 34.732 & 86.587 & $-3,049$ & $-8,001$ & $-13,727$ \\
\hline 102 & Nashville & 36.163 & 86.778 & $-6,377$ & $-15,833$ & $-26,308$ \\
\hline 103 & Evansville & $3 \overline{7} .9 \overline{7} 0$ & 87.575 & $-1,737$ & $-5,192$ & $-8,001$ \\
\hline 104 & Paducali & 37.077 & 88.615 & $-3,372$ & $-5,143$ & $-6,918$ \\
\hline \multirow[t]{2}{*}{105} & Chat tanooga & 35.043 & 85.310 & 0 & $-1,848$ & $-6,483$ \\
\hline & & & & $-20,011$ & $-51,394$ & $-8 \overline{7}, 174$ \\
\hline
\end{tabular}

See Appendix $C$ for derivation.

The existence of $500-\mathrm{kV}$ lines, shown in Fig. 9, modifies the approach to the solution of optimum path. In absence of lines, as was assumed in Case A, it was simply a matter of accepting the Linear Programing solution. In this case, the recommendations of the Linear Programming run have to be weighed against alternatives in the use of the existing lines because these were not entered into the program. Using the results of the dual solution for selection cricerion, different runs were made for cases in which different plants were down. The resulting changes in power-flow pattern suggested an optimum coupling between the existing and new lines.

Power carrying capacity of Linés shorter than about 50 miles is limited thermally and, according to Fig. 2, should carry about 3 SIL although some consider this much too conservative. ${ }^{3}$ The SIL of a $500-\mathrm{kV}$ 1.ine varics from about 0.7 to $1.0 \mathrm{GW}$ for characteristic (surge) impedances of 350 to 250 ohms, respectively. Short lines can, therefore, safely carry $3 \mathrm{GW}$. With very few exceptions, the lines in the dispersed case fall into this category. Wherever longer lines are needed, their capacity will be determined on the basis of an SIL of $1 \mathrm{GW}$ and the curve of Fig. 2. In view of the conservative character of this curve, the results would still apply if the surge impedance of the TL were greater than 250 ohms. 
Table 14. Generating stations and capacity dispersed case

\begin{tabular}{|c|c|c|c|c|c|c|}
\hline \multirow[b]{2}{*}{$\begin{array}{c}\text { Bus } \\
\text { number }\end{array}$} & \multirow[b]{2}{*}{ Name } & \multicolumn{2}{|c|}{ Position } & \multirow{2}{*}{$\begin{array}{c}1985 \\
\text { capacity } \\
\text { (MW) }\end{array}$} & \multirow{2}{*}{$\begin{array}{c}2005 \\
\text { capacity } \\
\text { (MW) }\end{array}$} & \multirow{2}{*}{$\begin{array}{c}2020 \\
\text { capacity } \\
\text { (MW) }\end{array}$} \\
\hline & & Latitude & Longitude. & & & \\
\hline 201 & Johnsonville & 36.033 & 87.983 & 1,338 & 2,400 & 4,800 \\
\hline 202 & Cumberland & 36.383 & 87.650 & 2,550 & 2,550 & 4,800 \\
\hline 203 & Gallatin & 36.317 & 86.400 & 1,088 & 2,400 & 4,800 \\
\hline 204 & Widows Creek & 34.883 & 85.767 & 1,832 & 2,688 & 6,000 \\
\hline 205 & Browns Ferry & 34.633 & 86.950 & $3 ; 195$ & 4,395 & 4,800 \\
\hline 206 & Wilson Dam & 34.783 & 87.583 & 630 & 630 & 0 \\
\hline 207 & Colbert & 34.733 & 87.867 & 1,841 & 507 & 4,000 \\
\hline 208 & Shawnee & 37.150 & 88.783 & 1,540 & 3,600 & 3,600 \\
\hline 209 & Joppa & 37.217 & 88.833 & 1,100 & 0 & 0 \\
\hline 210 . & Paradise & 37.250 & 86.983 & 2,771 & 4,700 & 3,600 \\
\hline 212 & Bellefonte & 34.725 & 85.975 & 2,426 & 4,800 & 6,000 \\
\hline 213 & Hartsville & 36.395 & 86.163 & 4,820 & 4,800 & 4,800 \\
\hline 214 & Sebree & 37.605 & 87.527 & 300 & 300 & 0 \\
\hline 215 & Coleman & 37.903 & 86.753 & 455 & 4,055 & 4,800 \\
\hline 216 & Owensboro & 37.768 & 87.113 & 465 & 0 & 0 \\
\hline 217 & Morgan City & 34.472 & 86.568 & 0 & 0 & $.4,800$ \\
\hline 218 & Eastport & 34.887 & 88.102 & 0 & 4,800 & 4,800 \\
\hline 219 & Perryville & 35.620 & 88.040 & 0 & 0 & 4,800 \\
\hline 220 & Mckinnon & 36.317 & 87.907 & 0 & 4,800 & 4,800 \\
\hline 221 & Smithville & 35.960 & 85.813 & 0 & 0 & 4,800 \\
\hline 222 & Cumberland City & 36.388 & 87.635 & 0 & 4,800 & 4,800 \\
\hline 223 & Cadiz & 36.863 & 87.835 & 0 & 0 & 4,800 \\
\hline 224 & Penton & 34.867 & 90.283 & 4,800 & 4,800 & 4,800 \\
\hline 225 & Marks & 34.258 & 90.273 & 0 & 4,800 & 4,800 \\
\hline 230 & Wilson & 35.572 & 90.043 & 0 & 4,800 & 4,800 \\
\hline $231^{\prime}$ & Luxura & 35.757 & 89.028 & 0 & 0 & 4,800 \\
\hline \multirow[t]{2}{*}{232} & Uniontown & 37.775 & 87.932 & $\begin{array}{r}0 \\
\end{array}$ & 0 & $\begin{array}{r}2,400 \\
\end{array}$ \\
\hline & & & & 31,151 & 66,625 & 102,400 \\
\hline
\end{tabular}


Table 15. Generating stations and capacity center case

\begin{tabular}{|c|c|c|c|c|c|c|}
\hline \multirow[b]{2}{*}{$\begin{array}{c}\text { Bus } \\
\text { number }\end{array}$} & \multirow[b]{2}{*}{ Name } & \multicolumn{2}{|c|}{ Position } & \multirow{2}{*}{$\begin{array}{c}1985 \\
\text { capacity } \\
(\mathrm{MW})\end{array}$} & \multirow{2}{*}{$\begin{array}{c}2005 \\
\text { capac1ty } \\
\text { (MW) }\end{array}$} & \multirow{2}{*}{$\begin{array}{c}2020 \\
\text { capacity } \\
\text { (MW) }\end{array}$} \\
\hline & & Latitude & Longitude & & & \\
\hline 201 & Johnsonville & 36.033 & 87.983 & 1,338 & 0 & 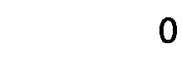 \\
\hline 202 & Cumberland & 36.383 & 87.650 & 2,550 & 2,550 & 4,800 \\
\hline 203 & Gallatin & 36.317 & 86.400 & 1,088 & 0 & 0 \\
\hline 204 & Widows Creek & 34.883 & 85.767 & 1,832 & 2,680 & 6,000 \\
\hline 205 & Browns Ferry & 34.633 & 86.950 & 3,195 & 3,195 & 4.800 \\
\hline 206 & Wilson Dam & 34.783 & 87.583 & 630 & 630 & 0 \\
\hline 207 & Colbert & 34.733 & 87.867 & 1,841 & 507 & 4,000 \\
\hline 208 & Shawnee & 37.150 & 88.783 & 1,540 & 3,600 & 3,600 \\
\hline 209 & Joppa & 37.217 & 88.833 & 1,100 & 0 & 0 \\
\hline 210 & Paradise & 37.250 & 86.983 & 2,771 & 1,110 & 0 \\
\hline 212 & Bellefonte & 34.725 & 85.975 & 2,426 & 4,800 & 6,000 \\
\hline 213 & Hartsville & 36.395 & 86.163 & 4,820 & 4,800 & 4,800 \\
\hline 214 & Sebree & 37.605 & 87.527 & 300 & 300 & 0 \\
\hline 215 & Coleman & 37.903 & 86.753 & 455 & 4,055 & 4,800 \\
\hline 216 & Owensboro & 37.768 & 87.113 & 465 & 0 & 0 \\
\hline 217 & Morgan City & 34.472 & 86.568 & 0 & 0 & 0 \\
\hline 218 & Eastport & 34.887 & 88.102 & 0 . & 0 & 0 \\
\hline 219 & Perrybille & 35.620 & 88.040 & 0 . & 0 & 0 \\
\hline 220 & Mckinnon & 36.317 & 87.907 & 0 & 24,000 & 48,000 \\
\hline 221 & Sm1thville & 35.960 & .85 .813 & 0 & 0 & 0 \\
\hline 222 & Cumberland City & 36.388 & 87.635 & 0 & 0 & 0 \\
\hline 223 & Cadiz & 36.063 & 87.835 & 0 & 0 & 0 \\
\hline 224 & Penton & 34.867 & 90.283 & 4,800 & 4,800 & 4,800 \\
\hline 225 & Marks & 34.258 & 90.273 & 0 & 4,800 & 4,800 \\
\hline 230 & Wilson & 35.572 & 90.043 & 0 & 4,800 & 4,800 \\
\hline 231 & Luxora & 35.757 & 89.928 & 0 & 0 & 4,800 \\
\hline \multirow[t]{2}{*}{232} & Uniontown & 37.775 & 87.932 & $\begin{array}{r}0 \\
\end{array}$ & 0 & 2,400 \\
\hline & & & & 31,151 & 66,627 & 103,600 \\
\hline
\end{tabular}




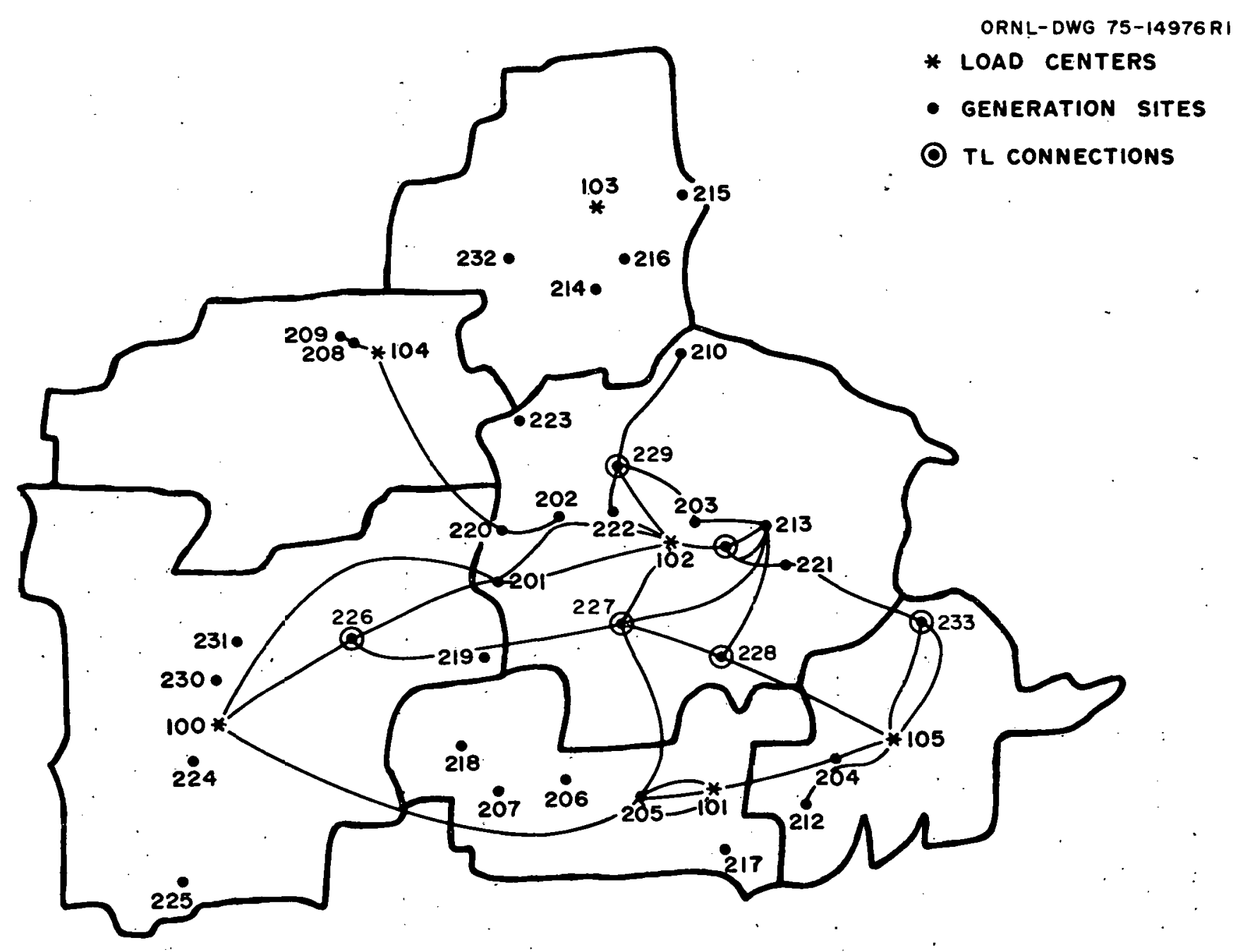

Fig. 9. Transmission system for Case B using 500-kV lines. 


\subsubsection{Dispersed cases}

1985

Figure 10 shows the power dispatch for 1985, and Fig. 11 shows the required additions to the transmission network for 1985 .

One of the Linear Programing recommended dispatches is from Sebree (214) to Evansville (103). Since the capac1ty of Sebree is only $0.3 \mathrm{GW}$ and Paradise (210) has excess capacity, it is better to ship the power from Paradise since a TL from there is needed anyway. This line will pass Owensboro (216) and will carry an additional $0.455 \mathrm{GW}$ from there. In view of the very light loading of all these lines, provision for contingency is made by running a TL from Paradise (210) Lu Culeman (215). This is particularly desirable because this line will provide for contingency in subsequent years.

To satisfy Memphis (100) requirements, three lines are established from Penton (224) including contingency - in view of the short distance (22 miles), this is deemed adequate. In addition, a short IL connecting to the existing network is established from Colbert (207).

No additional lines are needed to satisfy Huntsville (101), Chattanooga (105), or Paducah (104) requirements because of the existing network, which amply provides for single contingencies. This is not quite obvious in the case of Paducah, but can be seen as follows: If the line from Shawriee (208) or Joppa (209) is down, supplemental power (either the 1.5 or $1.1 \mathrm{GW}$, respectively) can be shipped via the line from McKinnon (220) and supplied from Johnsonville (201) and Cumberland (202). Should this be inadequate, excess power available at Gallatin (203) can be delivered to McKinnon through Nashville.(102) via the additional line established there. One line is added from Hartsville (213) to Nashville.

A total of 280 miles of 'il are added, with d puwer cairying capacity of $3 \mathrm{GW}$ per line because of short distances. 


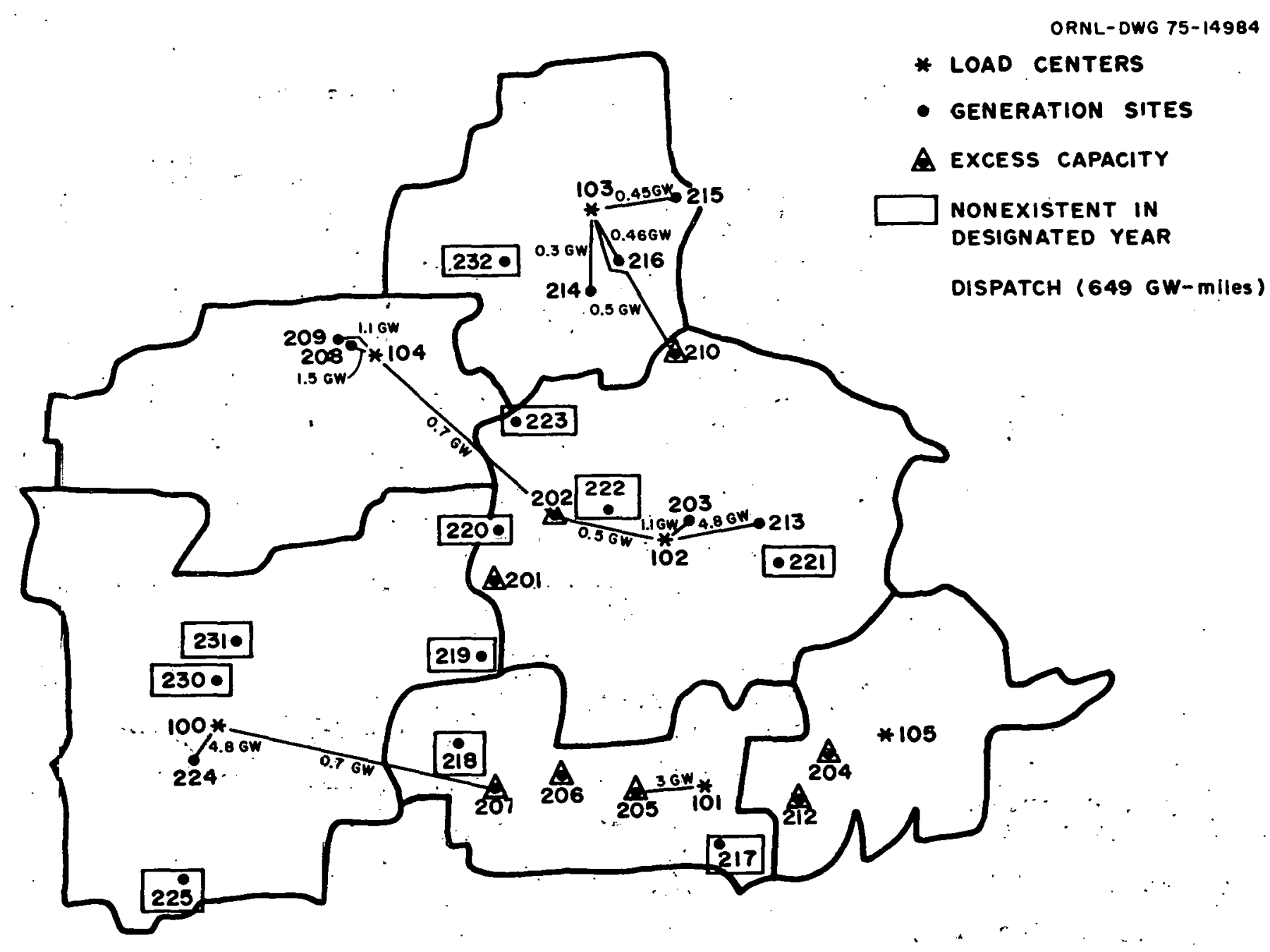

Fig. 10. Power dispatch for dispersed case -1985. 


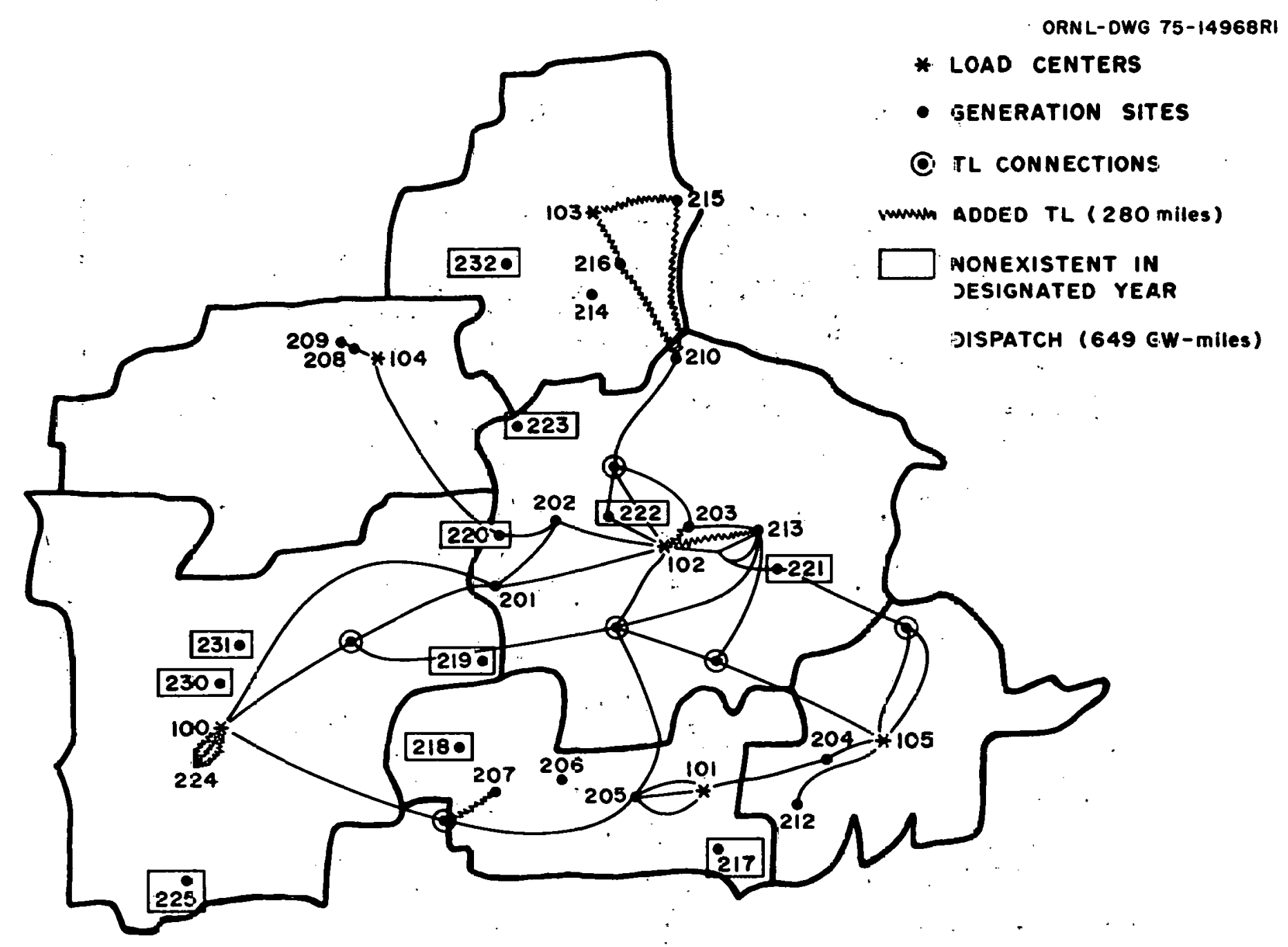

Fig. 11. Additions to the transmission network for dispersed case -1985 . 
$\underline{2005}$

Figure 12 shows the power dispatch for 2005; Fig. 13 shows the additions to the transmission network for 2005. The 1985 additions are drawn as part of existing network. Additional TL is established between Coleman (215) and Evansville (103) to cover single contingencies. Should the line from Paradise (210) to Evansville through Owensboro break down, power can be carried via Coleman because the distance from Coleman to Evansville is only 45 miles. A contingency line is added between Shawnee (208) and Paducah (104), as well as one from McKinnon (220) to Paducah. This line is routed through Cadiz (223) because of the anticipated needs in 2020. This routing adds 18 miles of $\mathrm{TL}$ in 2005, but saves an entire Ine of 46 miles. A 20-mile link is added between McKinnon and Johnsonville (201) to facilitate contingency routings. At Memphis (100), one line is provided between Marks (225) and Penton (224) and two between Marks and Memphis: This saves about 18 miles and can be used because of the short distance between Penton and Memphis (22 miles). Two links are added between Wilson (230) and Memphis directly, and the other through tying in to the existing line, thus saving about 10 miles. The power from Eastport (218) to Memphis is routed through Colbert (2017) and existing network to result in a savings of about 95 miles of TL. In . case of contingency, the $1 \mathrm{GW}$ of power to Memphis can be obtained either from Johnsonville or McKinnon via Johnsonville. A line is added between Bellefonte (212) and Huntsville (101); no other contingency lines are required because of the possibility of routing from Bellefonte through Widows Creek (204). No additions are required for Nashville and Chattanooga:

A total of 459 miles of TL are added.

$\underline{2020}$

Figure 14 shows the power dispatched in 2020 with Fig. 15 showing the TL additions. Note that with the sequential planning not many additional miles of TL are needed even though the projected demand increased by about $70 \%$. In spite of the Linear Programing dispatch of $2.4 \mathrm{GW}$ from Uniontown (232) to Evansville, that station is not 


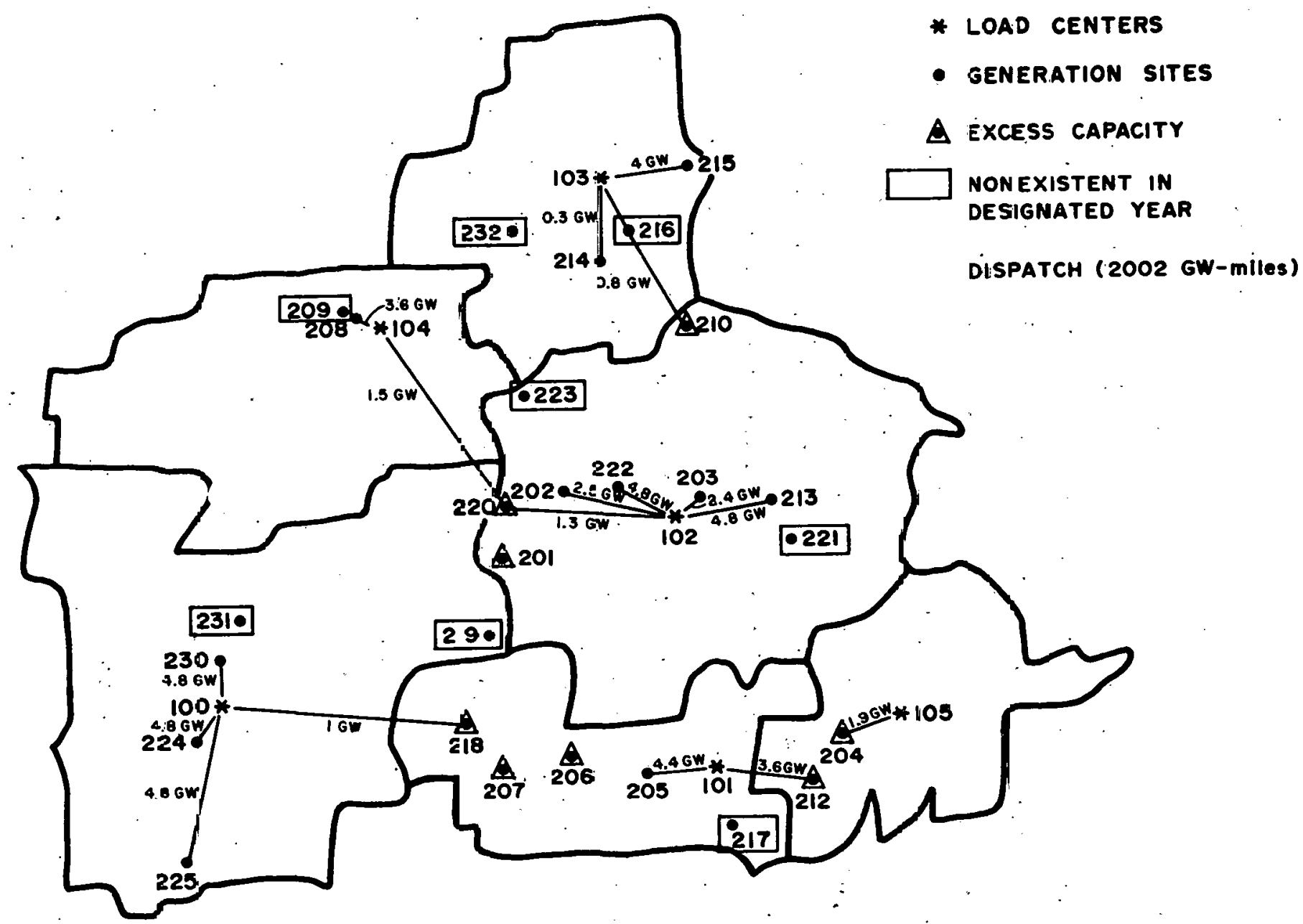

Fig. 12. Power dispatch for dispersed case - 2005. 


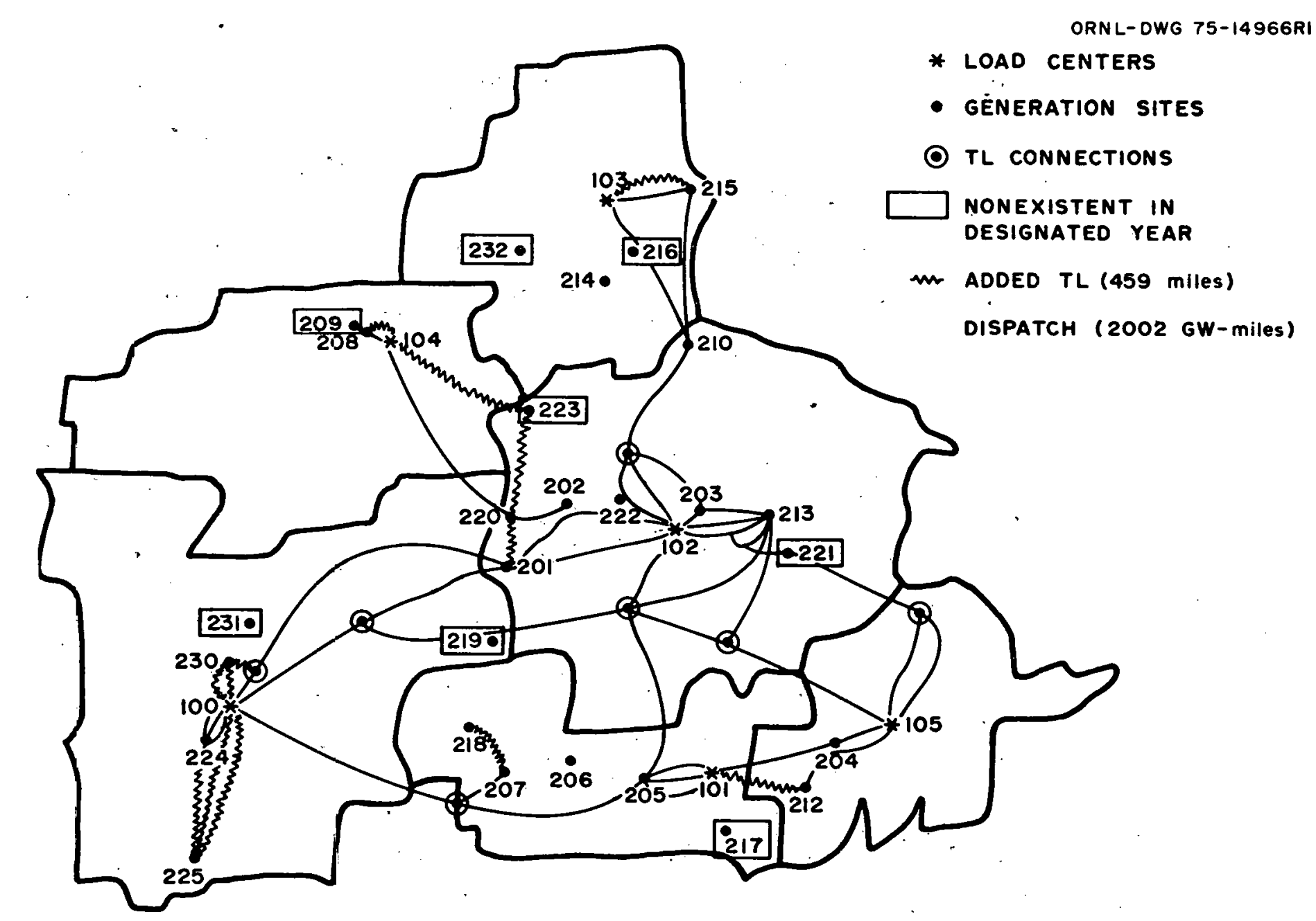

Fig. 13. Additions to the transmission network for dispersed case -2005 . 


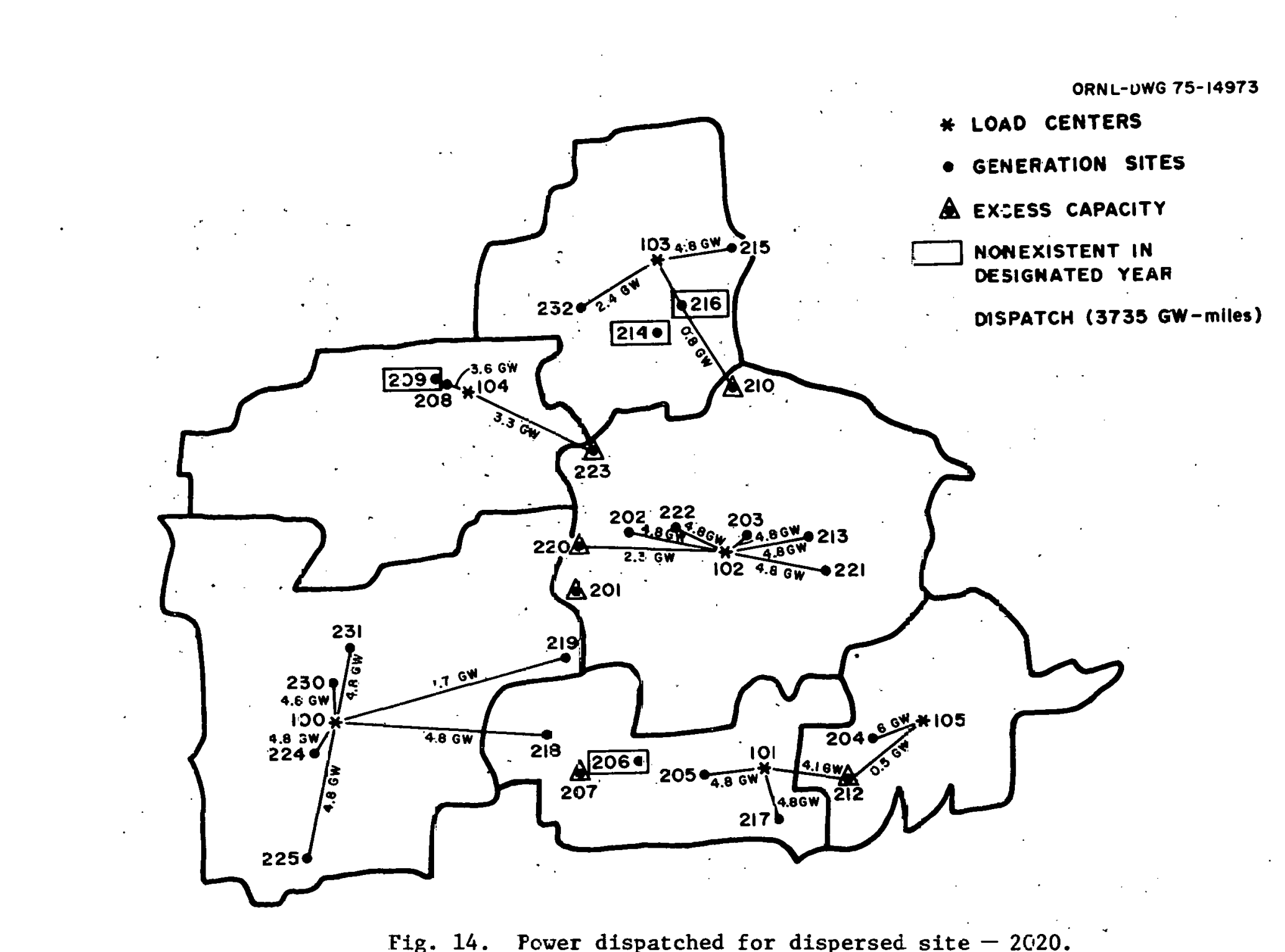




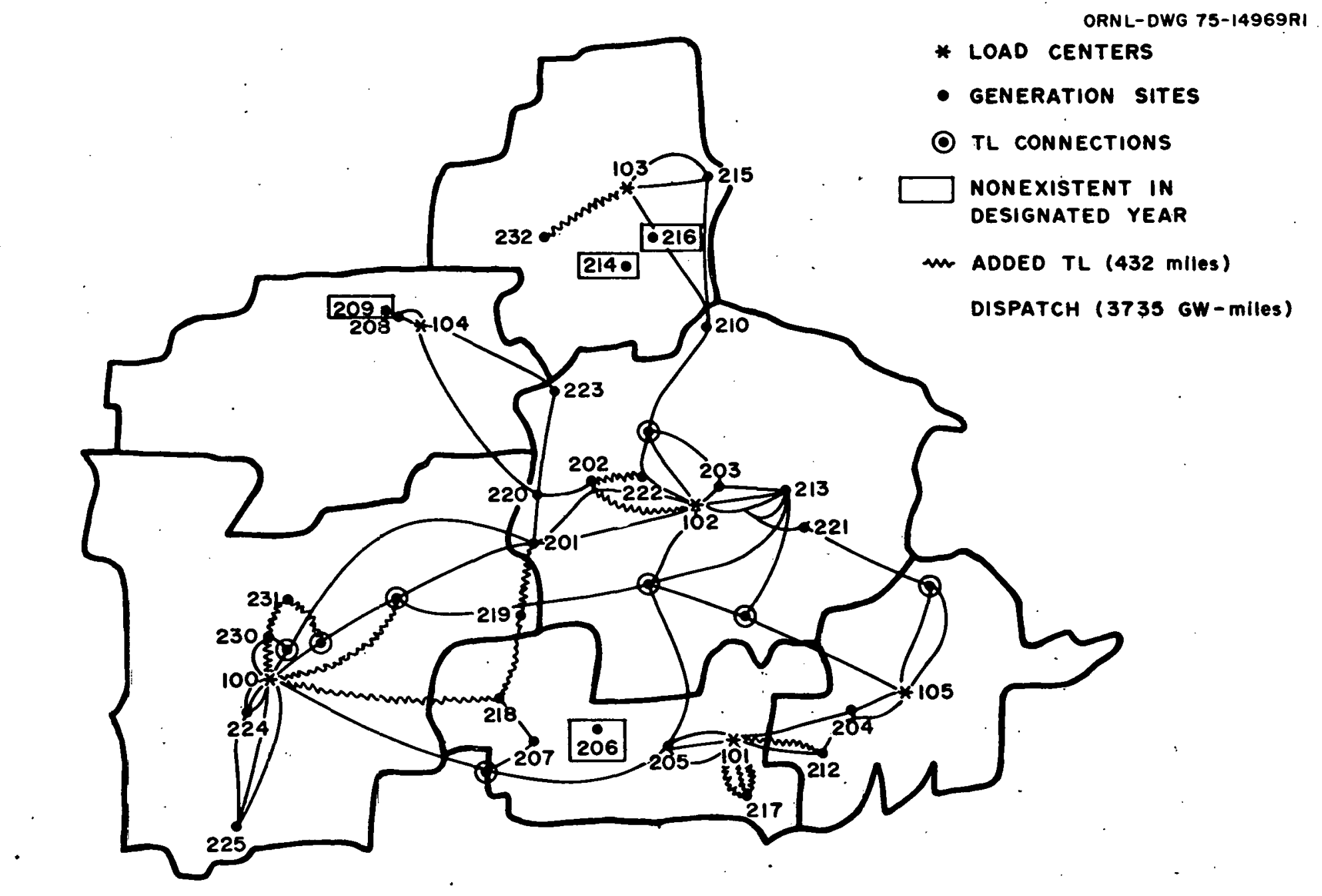

Fig. 15. Additions to the transmission network for dispersed case -2020 . 
required because Coleman (215) and Paradise (210) can handle Evansville's demand of $8 \mathrm{GW}$, including contingency provisions with lines already established. Three lines are established from Luxora (231) to supply Memphis: one to Wilson (230), one tying in to one of the existing but not fully utilized lines, and one directly to Memphis. Another line is added between Wilson and Memphis. To provide for contingencies, Eastport (218) is connected directly with Memphis and also with Perryville.(219), and Perryville is connected with Johnsonville (201). A link is also provided between Cumberland (202) and Cumberland City (222), and between Cumberland and Nashville. Three lines are provided between Morgan City (217) and Huntsville (101), and one is added between Bellefonte (212) and Huntsville (101).

A total of 408 miles of TL are added. Under some conditions, a line may have to carry $3.2 \mathrm{GW}$. Th1s, apparent1y, is quite acceptable. ${ }^{3}, 20$ It is also worth noting that, instead of developing Uniontown (232), it would be more economical to install one of the reactors at Coleman and the other either at Paradise or at Owensboro. To tie Uniontown to the network, one 24-mile-long TL is required. This increases the added length of TL to 432 miles.

\subsubsection{Center case}

$\underline{2005}$

Figure 16 shows the power dispatched in 2005, and Fig. 17, which includes the 1985 network (see Fig. 11), shows the TL added. Quite evidently, the center case TL planning is simplified by the absence of a large number of generating sites. The connections here are much more direct than in the dispersed case and do not require so much explanation. No additional contingency is provided between Paradise (210) and Evansville (103) because raradise will be phased out and because the lint is lightly loaded. Connections between McKinnon (220) and Paducah (104) and between Shawnee (208) and Paducah are straightforward. The links between Johnsonville (201), McKinnon (220), and Cumberland City (222), and between McKinnon and Nashville (102) are added to the existing network for contingency. One line is established from Marks (225) to 


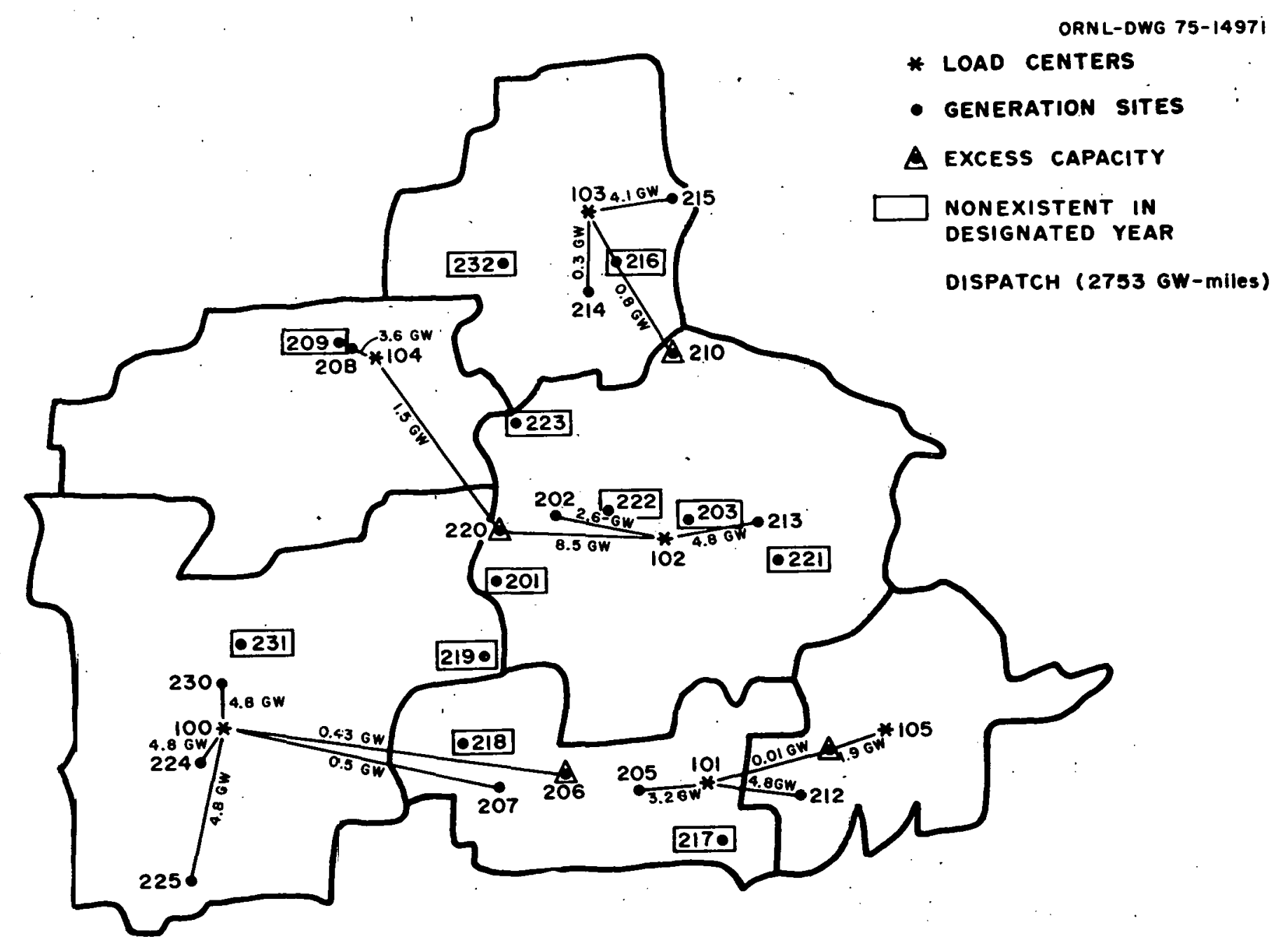

Fig. 16. Power dispatched for center case -2005 . 


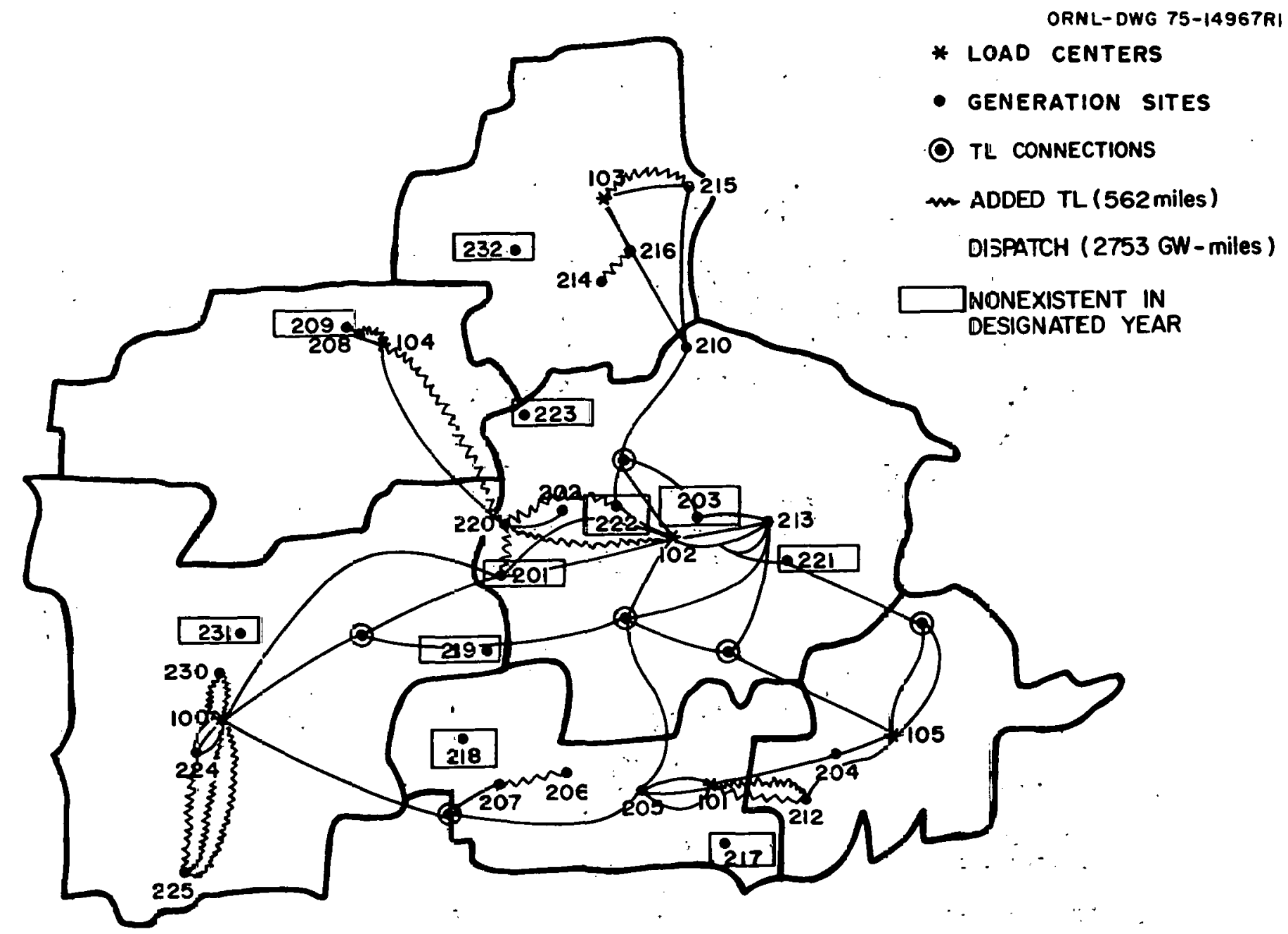

Fig. 17. Additions to the transmission network for the center case -2005 . 
Penton (224), two from Marks to Memphis (100), and two from Wilson (230) to Memphis because there is enough excess capacity at McKinnon to take care of a double contingency. For similar reasons, there is only one TL connecting Wilson Dam (206) to Colbert (207). The links between Bellefonte (212) and Huntsville (101) are added to take care of contingency. A total of 562 miles of TL are added.

2020

Figure 18 shows the power dispatched in 2020, and Fig. 19 the TL added.* As in the above case, additions are straightforward. Five lines are added between McKinnon (220) and Nashville; one is added bétween McKinnon and Johnsonville (201); and one, between Cumberland (202) and Nashville. Power from McKinnon to Nashville can be sent on nine lines. Contingencies in supplying Chattanooga (105) can be handled by diverting power from Mckinnion (220) through the existing network. This will increase transmission losses, but only during contingency. Two lines are added between Luxore (231) and Memphis (100); one, between Luxore and Wilson (230); and one, between Wilson Dam (206) and Huntsville (101).

A total of $534 \mathrm{TL}$ miles are added. Table 16 compares miles of added TL for the dispersed and center cases.

Distances between generating plants and load centers are shown in Table 17. Distances between selected plants, are shown in Fig. 20.

\section{Internal connections at a nuclear energy center}

The National Electric Reliability Council (NERC) study ${ }^{17}$ recommends that the 4-reactor clusters in an NEC "must be separated from each other within the energy center." In this study the units will be physically

* Through oversight, the total capacity of the system added up to $1.2 \mathrm{GW}$ more than the corresponding dispersed case. Some runs with the 1.2 GW subtracted showed that the length of added transmission lines may increase by 15 to 115 miles, depending upon the location of the generating site whose capacity was reduced by $1: 2 \mathrm{GW}$. 
ORNL-OWG 75-14970

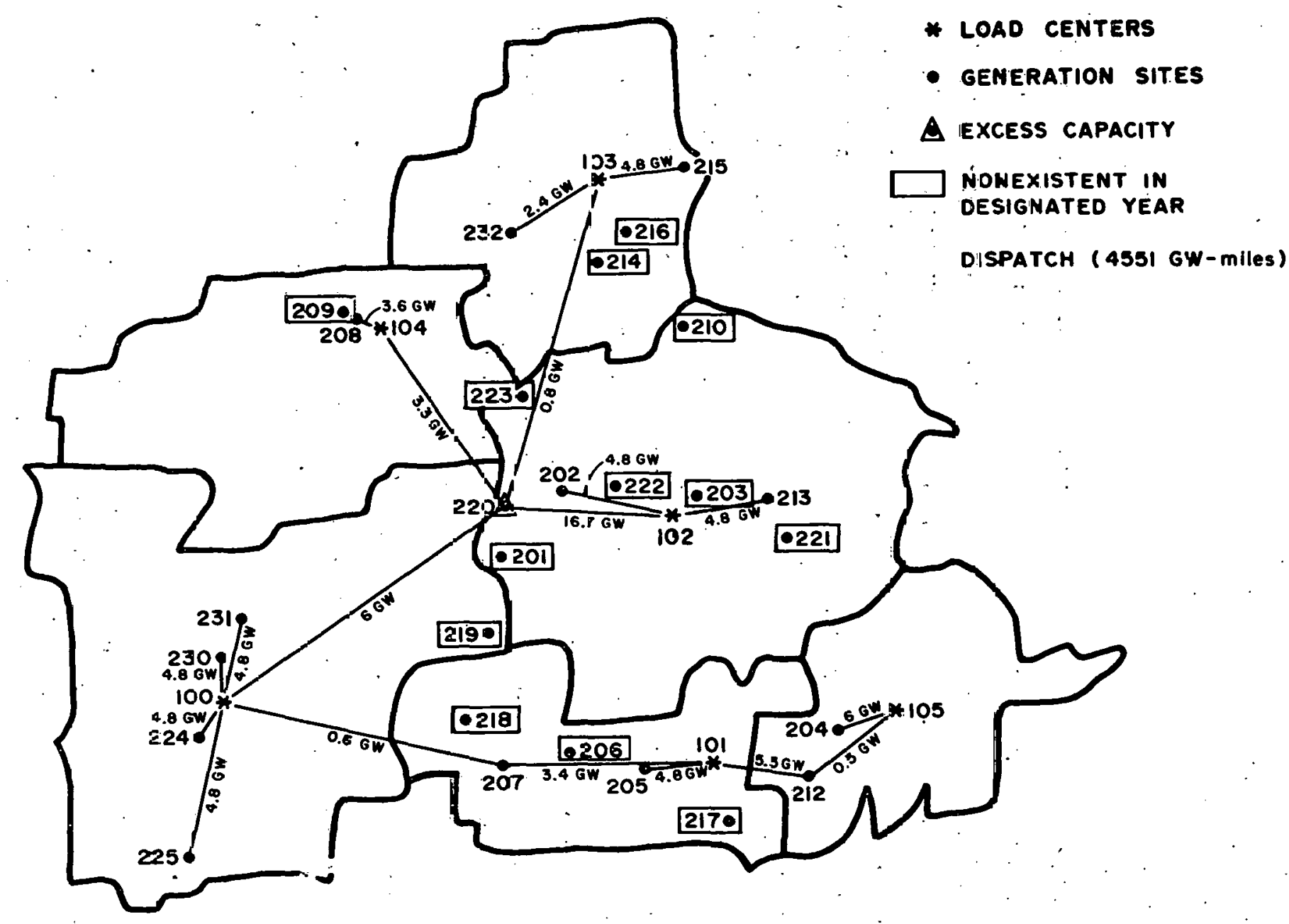

Fig. 18. Power dispatched for center case - 2020. 


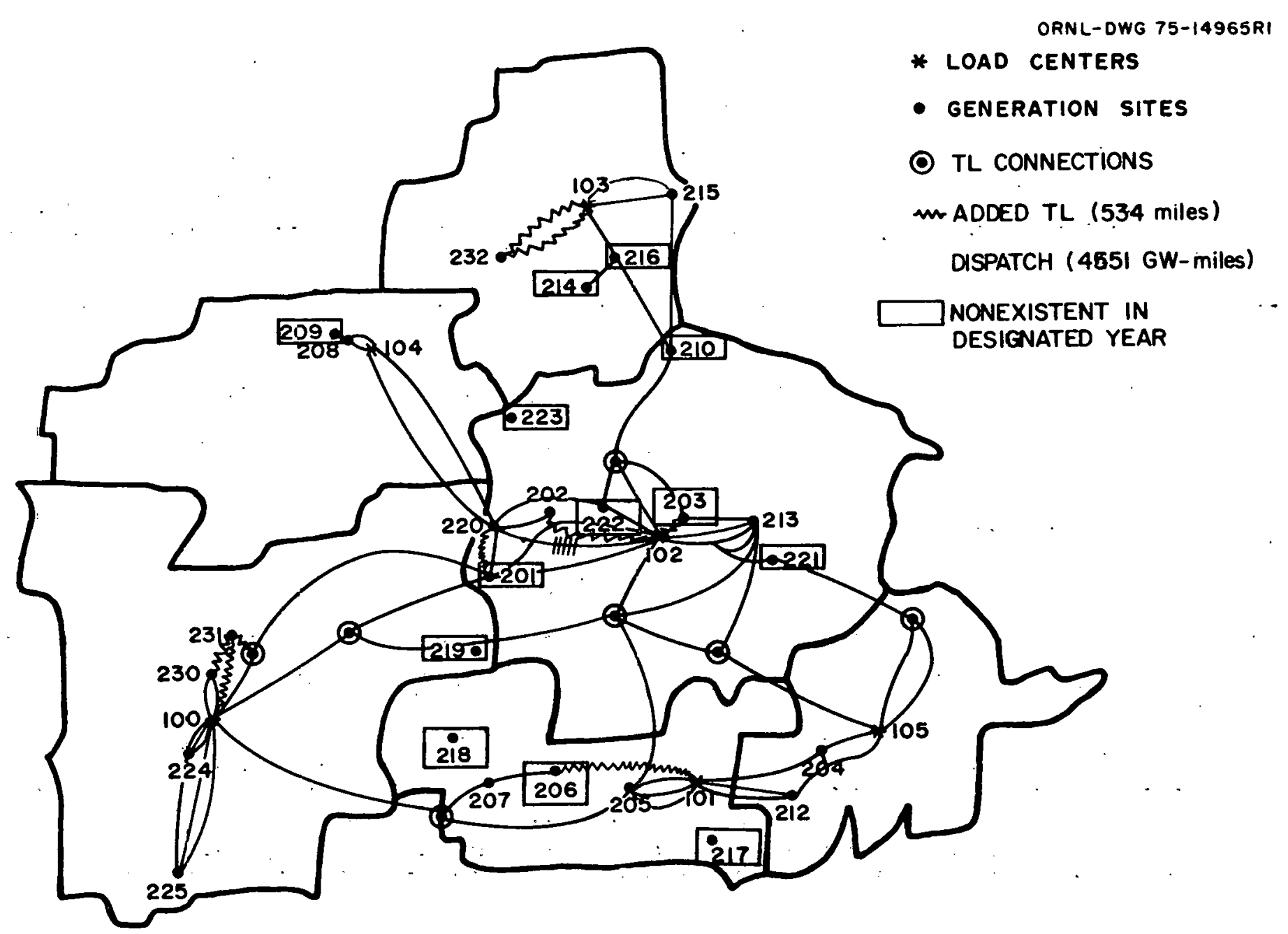

Fig. 19. Additions to the transmission network for the center case -2020 . 
Table 16. Comparison of tranamission systems and costs for dispersed and center cases designed by the Institute for Enerzy. Analysis (IEA) and tine Jeneral Electric Company (GE)

\begin{tabular}{|c|c|c|c|c|c|c|c|c|c|c|c|c|c|}
\hline \multirow{3}{*}{$\begin{array}{l}\text { Transmission } \\
\text { line voltage } \\
\quad(\mathrm{kV})\end{array}$} & \multicolumn{6}{|c|}{ Fully: dispersed } & \multicolumn{7}{|c|}{ Large center } \\
\hline & \multirow{2}{*}{$\begin{array}{l}\text { Dispatch } \\
\text { (GW-mIles) }\end{array}$} & \multicolumn{2}{|c|}{ M1les } & \multicolumn{2}{|c|}{ Terminals } & $\begin{array}{l}\text { Millions of } \\
19 ? 4 \text { dollars } b\end{array}$ & \multirow{2}{*}{$\begin{array}{l}\text { Dispatch } \\
\text { (GW-miles) }\end{array}$} & \multicolumn{2}{|c|}{ Miles } & \multicolumn{2}{|c|}{ Terminals: } & \multicolumn{2}{|c|}{$\begin{array}{c}\text { Millions of } \\
1974 \text { dollars } b\end{array}$} \\
\hline & & $\overline{\text { IEA }}$ & $\overline{\mathrm{GE}}$ & $\overline{\text { IEA }}$ & $G$ & $\begin{array}{ll}I E_{A} & G E\end{array}$ & & $\overline{\text { IFA }}$ & $\mathbf{G E}$ & $\overline{\text { IEA }}$ & GE & $\overline{\text { IEA }}$ & $\overline{G E}$ \\
\hline . & . & & & & & Iear 2005 & . & & $\cdots$ & & & & \\
\hline \multirow[t]{2}{*}{500} & 2002 & 459 & 1238 & 25 & BO & 419 & 2753 & 562 & 1300 & 30 & 72 & 176 & 413 \\
\hline & $\because$ & & & & & Year 2020 & & r & & & & & \\
\hline 500 & 3.35 & . 891 & 2690 & 51 & 148 & 851 & 4551 & 1096 & 1493 & 52 & 84 & 328 & 477 \\
\hline 765 & & & $\therefore$ & $\because$ & & ". & $\because$ & & 1288 & & 42 & & 546 \\
\hline CEA result. & & & & - & & & & & & & & & \\
\hline $\begin{array}{l}b_{\text {GE estinate }} \\
\text { for } 765-\mathrm{kV}\end{array}$ & $\begin{array}{l}\text { ases : } \\
\text { ne. }\end{array}$ & $0100 / \mathrm{mi}$ & Le and & $\$ 2 . \Xi$ & millic & $n / t \geq r m i n a l$ for & 500-kV line; & $\$ 300,0$ & $00 / \mathrm{mil}$ & $e$ and & $\$ 3.8$ & ailli & \\
\hline
\end{tabular}

GE estinate bases: $\$ 190,0,00 / \mathrm{mile}$ and $\$ 2 . \equiv \mathrm{million} / \mathrm{t} \equiv$ rminal for $500-\mathrm{kV}$ ine; $\$ 300,000 / \mathrm{mile}$ and $\$ 3.8 \mathrm{million} / \mathrm{terminal}$ 
separated. For the flexible dispatch of power when units undergo maintenance or a forced outage, it is assumed that there will be a system of internal connections allowing switching to various combinations of reactors.

The NERC study also recommends that transmission lines be on separate corridors and that underground cable be considered in the proximity of the energy center. A separate study is needed to evaluate the optimum separation of corridors and the length of underground cable required. In this study, only overhead transmission lines were assumed on separate corridors after leaving the energy center. 
Table 17. Great-circle distances in miles

\begin{tabular}{|c|c|c|c|c|c|c|c|}
\hline \multirow[b]{2}{*}{ Generating site } & \multicolumn{7}{|c|}{ Load center } \\
\hline & $\begin{array}{l}\text { Memphis } \\
(100)\end{array}$ & $\begin{array}{l}\text { Huntsville } \\
(101)\end{array}$ & $\begin{array}{l}\text { Nashville } \\
\quad(102)\end{array}$ & $\begin{array}{l}\text { Evarssville } \\
\quad(1(13)\end{array}$ & $\begin{array}{c}\text { Paducah } \\
\text { (104) }\end{array}$ & & $\begin{array}{c}\text { Chattanooga } \\
\text { (105) }\end{array}$ \\
\hline Johnsonville (201) & 132 & 119 & 68 & 136 & 80 & r & 165 \\
\hline Cumberland (202) & 161 & 129 & 51 & 110 & 72 & & 161 \\
\hline Gallatin (203) & 221 & 110 & 24 & 131 & 133 & - & 107 \\
\hline Widows Creek (204) & 243 & 48 & 105 & 236 & 220 & & 28 \\
\hline Browns Ferry (205) & 179 & 22 & 106 & 233 & 193 & & 97 \\
\hline Wilson Dam (206) & 142 & 57 & 106 & 220 & 169 & & 130 \\
\hline Colbert (207) & 127 & 73 & 116 & 224 & 167 & & 147 \\
\hline Shawnee (208) & 157 & 207 & 130 & 87 & 11 & & 242 \\
\hline Joppa (209) & 160 & 213 & 135 & 86 & 16 & & 247 \\
\hline Paradise (210) & 226 & 175 & 76 & 59 & 91 & & 179 \\
\hline Bellefonte (212) & 233 & 35 & 109 & 241 & 220 & & 44 \\
\hline Hartsville (213) & 235 & 117 & 38 & 134 & 144 & & 105 \\
\hline Sebree $(214)$ & 222 & 205 & 108 & 25 & 70 & & 216 \\
\hline Coleman (215) & 266 & 219 & 120 & 45 & 117 & & 213 \\
\hline Owensboro (216) & 245 & 212 & 112 & 29 & 95 & & 213 \\
\hline Morgan City (217) & 203 & 18 & 117 & 248 & 213 & & . 82 \\
\hline Eastport (218) & 112 & 87 & 115 & 215 & 154 & & 158 \\
\hline Perryville (219) & 119 & 102 & 80 & 154 & 106 & & 159 \\
\hline McKinnon (220) & 146 & 132 & 64 & $\mathbb{1 1 6}$ & 66 & & 117 \\
\hline Smithville (221) & 245 & 95 & 56 & 170 & 174 & & .69 \\
\hline Cumberland City (222) & 161 & 129 & 50 & 109 & 72 & & 160 \\
\hline Cadiz (223) & 173 & 163 & 76 & 78 & 46 & & 189 \\
\hline Penton (224) & 22 & 210 & 217 & 252 & 179 & & 282 \\
\hline Marks (225) & 61 & 212 & 237 & 297 & 216 & & 287 \\
\hline Wilson (230) & 31 & 204 & 187 & 215 & 131 & & 269 \\
\hline Luxora (231) & 44 & 201 & 178 & 201 & 117 & & 265 \\
\hline Uniontown (232) & 218 & 223 & 128 & 24 & 61 & & 239 \\
\hline
\end{tabular}




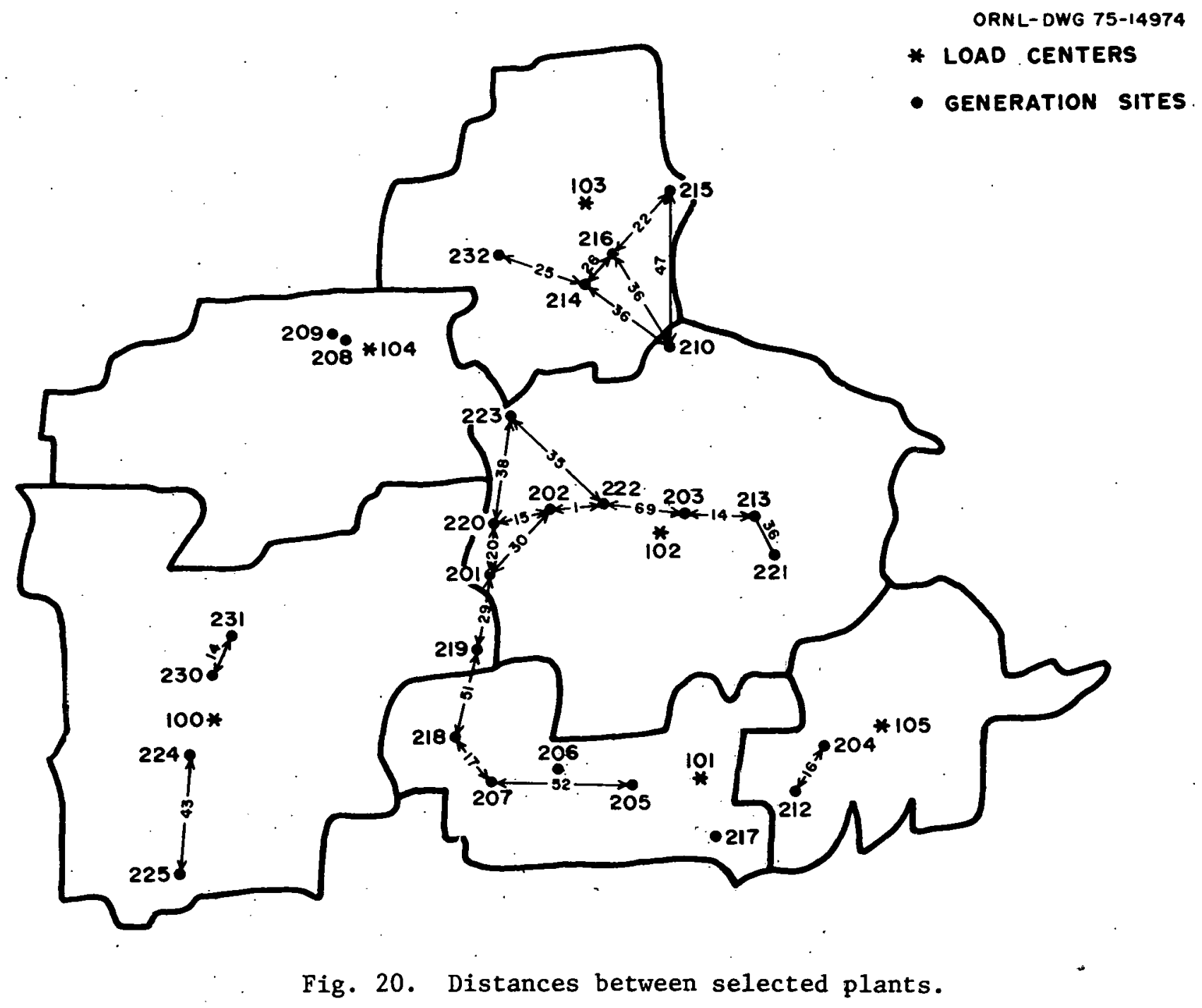




\section{COSTS AND DISCUSSION OF RESULTS}

\subsection{Introduction}

This section gives an estimate of the costs of the transmission systems (Case A) developed in Section 3 for the Kentucky Lake Surrogate Site and compares the staff's results with the energy center studies by the National Electric Reliability Council 17 and General Electric. ${ }^{21}$ Since the NERC report is a summary without details and the GE report has not been released, our comparative studies will be brief and approximate.

\subsection{Transmission System Coste for One Energy Centcr, Four Energy Centers, and Tell Energy Centers}

The transmission line distances given in Section 3 (Case A) were straight line:distances. The design of transmission line corridors is a land use planning problem. Operating under severe constraints, land use planners at Oak Ridge National Laboratory have made preliminary choices for transmission corridors. The corridors have been selected to avoid areas that would obviously not be good locations from an environmental standpoint but have not been screened in detail. The results are shown in Table 18. In all cases, the miles of transmission line have increased over the straight line distance, but the increases have been approximately proportional to length; thus, relative length of transmission for each type of energy center is unchanged.

The cost of each system has been estimated on the basis of the length of the 765-kV transmission 1ines. Substation costs, which should be approximately the same for each system, were not included. Every utility files an annual report with the Federal Power Commission which includes the cost of all transmission lines built during the year. In 1973 Appalachian Power Company built 169.34 miles of $765-\mathrm{kV}$ line at a cost of $\$ 40,298,353$, giving an average cost of $\$ 237,973 / \mathrm{mIle}$. In 1974 Appalachian Power Company built 236.67 miles of $765-\mathrm{kV}$ line at a cost of $\$ 59,171,453$, giving an average cost of $\$ 250,017 / \mathrm{mile}$. Assuming that the increase in cost trom 1973 to 1974 was due to inflation and that the same rate of inflation will prevail in 1975, the average cost 
of a $765-\mathrm{kV}$ transmission line in 1975 will be $\$ 263,000 / \mathrm{mlle}$. Using this value of cost per mile, the cost for the transmission systems for one, four, and ten energy centers has been estimated (see Table 18).

Table 18. Transmission system costs for one, four, and ten energy centers $a$

\begin{tabular}{|c|c|c|c|c|}
\hline $\begin{array}{l}\text { Number of } \\
\text { centers }\end{array}$ & $\begin{array}{l}\text { Miles of } \\
765-\mathrm{kV} \text { lines }\end{array}$ & $\begin{array}{l}\text { Percent of } \\
\text { one-center } \\
\text { total }\end{array}$ & $\begin{array}{c}\text { Cost } \\
\text { (million } \$)\end{array}$ & $\begin{array}{c}\text { Savings } \\
\text { (million } \$ \text { ) }\end{array}$ \\
\hline 1 & 2000 & 100 & 526 & 0 \\
\hline 4 & 1216 & 61 & 320 & 206 \\
\hline 10 & 1903 & 95 & 500 & 26 \\
\hline
\end{tabular}

The cost of the $765-\mathrm{kV}$ transmission system for one 40-reactor energy system is estimated at $\$ 526 \mathrm{mfllion.} \mathrm{For} \mathrm{comparison,} \mathrm{if} \mathrm{a} \mathrm{nuclear} \mathrm{reactor}$ costs $\$ 450 / \mathrm{kW}$, then a $1200-\mathrm{MW}$ reactor will cost $\$ 540$ million. Thus, the transmission system will be about $3 \%$ of the cost of the energy center. (Substation costs have not been included. Excluding transformers, the substation costs for circuit breakers, land, reactive power control, etc., are approximately $\$ 8$ to $\$ 10$ million per line. 21 For an energy center with 17 transmission lines, the substations might cost $\$ 200$ to $\$ 300$ million.) As shown in Table 18, the transmission costs of dispersed energy centers are less than the costs of a single energy center. With four energy. centers, the transmission costs are $61 \%$ of the central center; with ten energy centers, the transmission costs are $95 \%$ of the central center. In the staff's opinion, the costs for four energy centers may be too low, and the costs for ten energy centers may be too high.

As mentioned in Section 3, the sites of the four energy centers were chosen to minimize transmission costs, whereas the Surrogate Site and the ten dispersed energy centers were not chosen to minimize transmission costs. Furthermore, the transmission systems were designed to meet the demand in 2020 and were not designed to meet the demand over 
the development period of the system from 1986 to 2020. As designed in Section 3, the transmission system for four energy centers has a single north-south link from Browns Ferry to Nashville. However, for the first ten years, all the power comes from Cadiz in the north and will require a stronger transmission link. For these two reasons, the transmission costs for the case of four energy centers may be too low.

For the optimum power dispatch, the ten-energy-center case has $58 \%$ as many gigawatt-miles as the one-center case. However, the ten-center case has $95 \%$ of the $765-\mathrm{kV}$ circuit miles for the one-center case. Thus, the 765-kV lines are not as heavily loaded for the ten-center case, and perhaps a lower voltage of transmission would be appropriate. If a lower voltage were used and the miles of transmission did not increase, then the cost would be reduced.

\subsection{The National Electric Reliability Council Study}

In the recent study of nuclear energy centers by the National Electric Reliability Council, 17 four generalized types of energy centers were studied - Coastal, Remote; Inland, and Western. The Coastal site might be on the New Jersey coast near major load centers. The Remote site might be in upstate New York, several hundred miles from a major load center. The Inland site might be in the TVA region with several load centers within a 200 -mile radius. The Western site might be in the California desert with several load centers within a 200-mile radius. The demand pattern is for the year 2000, and the centers develop from 1985 to 2000. The NERC study does not plan the development of the center - it only designs a transmission system for the fully developed center. The NERC report is short and does not present all the details of the studies. The studies do not use the same transmission voltage; the Coastal study uses $500-\mathrm{kV}$ lines, the Remote study uses $765-\mathrm{kV}$ lines, the Inland study uses $500-\mathrm{kV}$ lines and UHV (1100 to $1300 \mathrm{kV}$ ), and the Western study uses $765-\mathrm{kV}$ lines. To compare the NERC study with the staff's study, a common measure of transmission is needed. Cost is one possible common denominator; however, the NERC study does not have cost data, and our study has not developed cost estimates for 500-kV and 1000to $1300-\mathrm{kV}$ transmission lines. Another possible common measure is to 
estimate the load capacity of lines at other voltages and convert to equivalent miles of $765-\mathrm{kV}$ line. This approach was chosen.

For the Coastal study, the distances are short, and the lines are assumed to be at the thermal limit. Thus, the capacity of the lines is proportional to voltage, that is, 1000 miles of $500-\mathrm{kV}$ line is equivalent to 654 miles of $765-\mathrm{kV}$ line. For the Inland study, the lines are assumed to be long enough to have the carrying capacity proportional to the surge impedance loading (SIL), which depends on voltage squared. Thus, 1000 miles of $500-\mathrm{kV}$ line is equivalent to 388 miles of $765-\mathrm{kV}$ 1ine, and 1000 miles of $1200-\mathrm{kV}$ line is equivalent to 2464 miles of $765-\mathrm{kV}$ line. For the Western study, no total was given for miles of $765-\mathrm{kV}$ line, and the length of the lines on the figure in the report were measured to estimate the mileage. Staff estimates of miles of $765-\mathrm{kV}$ equivalent transmission line are shown in Table 19 . The ratio of miles of $765-\mathrm{kV}$ line and capacity, as well as the cost in dollars per kilowatt, is given. (The cost estimate is based on $\$ 263,000 / \mathrm{mile.})$

The ratio in miles per gigawatt will increase as sites become more remote from load centers, and they will decrease as the demand of the load centers increases. For the Kentucky Lake study, the ratio is 42 miles/GW for a single energy center in 2020. For the NERC study, the ratio is $55 \mathrm{miles} / \mathrm{GW}$ for the Coastal study and ranges from 100 to 142 miles/GW for the other studies with a single energy center. (The remote site has the lowest ratio. A remote site in the East is a typical central site in the rest of the country.) The Coastal site is near large metropolitan centers, which is not true for the Kentucky Lake Surrogate Site. Thus, all the NERC studies seem to require about twice as many miles of transmission per gigawatt as the Kentucky Lake site. The primary reason for this difference is probably that the NERC studies are for 2000, whereas this study is for 2020, by which time the demands of the load centers will have increased substantially. If this hypothesis is true and accounts for the factor of two, the agreement between the staff study and the NERC studies would be quite good. (In the next iteration, the staff will design the time evolution of the transmission system.) For the Inland site, two energy centers require about half as many miles of transmission lines as a single center. 
Simllarly for our study, four energy centers require about half as many miles of transmission lines as a single center. However, for the Inland study, the dispersed case has $23 \%$ as many miles of transmission line as the central site in strong contrast to our dispersed case. Because there is no figure in the NERC report for the dispersed Inland study, further analysis of the differences cannot be provided.

Table 19. Comparison of the Kentucky Lake Surrogate Site transmission system and the four studies by the National Electric Reliability Council

\begin{tabular}{ccccc}
\hline Study & $\begin{array}{c}\text { Capacity } \\
(\mathrm{GW})\end{array}$ & $\begin{array}{c}\text { Equivalent length } \\
\text { of } 765-\mathrm{kv} \text { miles }\end{array}$ & Ration \\
\hline
\end{tabular}

Kentucky Lake Surrogate Study

$\begin{array}{llllrr}\text { One center } & 48 & 2000 & 42 & 11 & 2020 \\ \text { Four center } & 48 & 1216 & 25 & 7 & 2020 \\ \text { Ten center } & 48 & 1903 & 40 & 10 & 2020\end{array}$

National Electric Reliability Council

\begin{tabular}{|c|c|c|c|c|c|c|}
\hline Coastal & 12 & & 654 & 55 & 14 & 2000 \\
\hline Remote & 13 & & 1300 & 100 & 26 & 2000 \\
\hline Inland (1) & 25 & & 3071 & 123 & 32 & 2000 \\
\hline Inland (2) & 25 & & 1241 & 50 & 13 & 2000 \\
\hline Inland (7) & 25 & & 698 & 28 & 7 & 2000 \\
\hline Western & 20 & & 2839 & 142 & 37 & 2000 \\
\hline
\end{tabular}

\subsection{The General Electric Study}

There are two parts to the General Electric study on energy centers that was sponsored by the National Science Foundation ${ }^{21}$ : the first was a study of energy centers in New York State, and the second was a study of a network of 59. energy centers serving the whole country. For New York State, the cost of the transmission system for dispersed siting is $\$ 19 / \mathrm{kW}$; for two energy centers, the cost is $\$ 29 / \mathrm{kW}$. For the United States with 59 energy centers, the incremental cost ranges from $\$ 7.6$ to $\$ 21.2 / \mathrm{kW}$ (see Table 20). 
Table 20. Transmission system costs for the General Electric energy park study

\begin{tabular}{lcc}
\hline \multicolumn{1}{c}{ Region } & $\begin{array}{c}\text { Average distance } \\
\text { (miles) }\end{array}$ & $\begin{array}{c}\text { Incremental } \\
(\$ / \mathrm{kW})\end{array}$ \\
\hline Northeast & 59 & 7.6 \\
East Central & 95 & 13.3 \\
Southeast (500-kV) & 110 & 12.5 \\
Southeast (765-kV) & 110 & 15.2 \\
West Central & 117 & 14.9 \\
South Central & 128 & 21.2 \\
West & 142 & 18.4 \\
\hline Assumptions: 20 reactors per energy center; $26-\mathrm{GW}$ \\
capacity; 1974 dollars.
\end{tabular}

A tentative conclusion from this comparative study is that our transmission system has fewer miles of 765-kV line per gigawatt of capacity than the systems studied by NERC and GE and that the difference is probably due to the later date of our,study, which results in a greater demand from the load centers. The three studies have more similarities than differences. A second conclusion is that the ratio of miles of transmission for a dispersed system to miles of transmission for a single energy center will usually be less than one, but the ratio may range from 23 to $95 \%$. If the dispersed sites are near the load centers, the ratio will be low, If the dispersed sites are not near the load centers, the ratio will be higher.

The fundamental difference between cases $A$ and $B$ is the incorporation of the existing transmission network and power plants in the latter, which substantially reduces the dispatch gigawatt-miles (compare Tables 12 and 16).

Table 16 summarizes the result of the analysis indicating that dispersed sites require about $20 \%$ fewer miles of TL than does the center case. The General Electric analysis also indicates that a transmission penalty is associated with the large energy center mode, but percentage comparisons have less meaning because the GE design includes both 500and $765-\mathrm{kV}$ components. 
The miles of icircuits added by:General. Electric's program, listed in Table 16 for comparison, are substantially larger than the miles projected by IEA. There are two primary reasons for it. The GE program operates largest units first (nuclear plants are operating continuously) for reasons of economy; and the network design - in addition to single-line contingencies - includes also a generator-out contingency.

These differences can be appreciated by sensitivity analysis for some outages (see Tables 21 and 22): outages of one generator in dispersed cases increase the dispatch gigawatt-miles by a larger percentage than outages of two generators in the center cases. For instance, for dispersed sites the ourage of Penton Increases gigawat-miles by about $90 \%$ in 1985 ; by $22 \%$ in 2005 , and by about $13 \%$ in 2020 ; whereas for a center, removal of two generators increases gijgàiate-miles by abour $7 \%$ in 2005 and by about $18 \%$ in 2020 .

Table 21. Dispatch gigawatt-miles with outages for dispersed sites

\begin{tabular}{lccc}
\hline Generator out & $\begin{array}{c}1985 \\
\text { (gigawatt-miles) }\end{array}$ & $\begin{array}{c}2005 \\
\text { (gigawatt-miles) }\end{array}$ & $\begin{array}{c}2020 \\
\text { (gigawatt-miles) }\end{array}$ \\
\hline $\begin{array}{l}\text { Gallatin (203) } \\
\text { Widows Creek (204) }\end{array}$ & & 2100 & 3937 \\
Browns Ferry (205) & 696 & & 3993 \\
Shawnee (208) & 744 & 2166 & 3903 \\
Hartsville (213) & 781 & 2210 & 3943 \\
$\begin{array}{l}\text { Morgan City (217) } \\
\text { Penton (224) }\end{array}$ & 1231 & & 4214 \\
Uniontown (232) & & 2450 & 3821 \\
$\quad$ Without outages & 649 & 2002 & 3735 \\
\hline
\end{tabular}


Table 22. Dispatch gigawatt-miles with outages for center case

\begin{tabular}{|c|c|c|}
\hline Generator out & $\begin{array}{c}2005 \\
\text { (gigawatt-miles) }\end{array}$ & $\begin{array}{c}2020 \\
\text { (gigawatt-miles) }\end{array}$ \\
\hline Shawnee (208) and Penton (224) & 2993 & 5346 \\
\hline Widows Creek (204) and Bellefonte (212) & 2793 & \\
\hline Without outages & 2753 & 4551 \\
\hline
\end{tabular}

Comparison of Figs. 21 through 25 with Figs. 11, 13, 15, 17 and 19 is also helpful in understanding the differences in miles of circuits added because of the different way that the existing circuits were utilized in each analysis (note also excess capacities indicated in the latter set of figures). These results indicate that changes in constraints and/or primary considerations influence substantially the design and the economics of transmission network and are not independent of the economics of specific plant operations. To quote from the GE Manual: "There are emotional, political, social and technical biases that seem to prevent total agreement on any plan submitted to 2 or:more planners." 22 


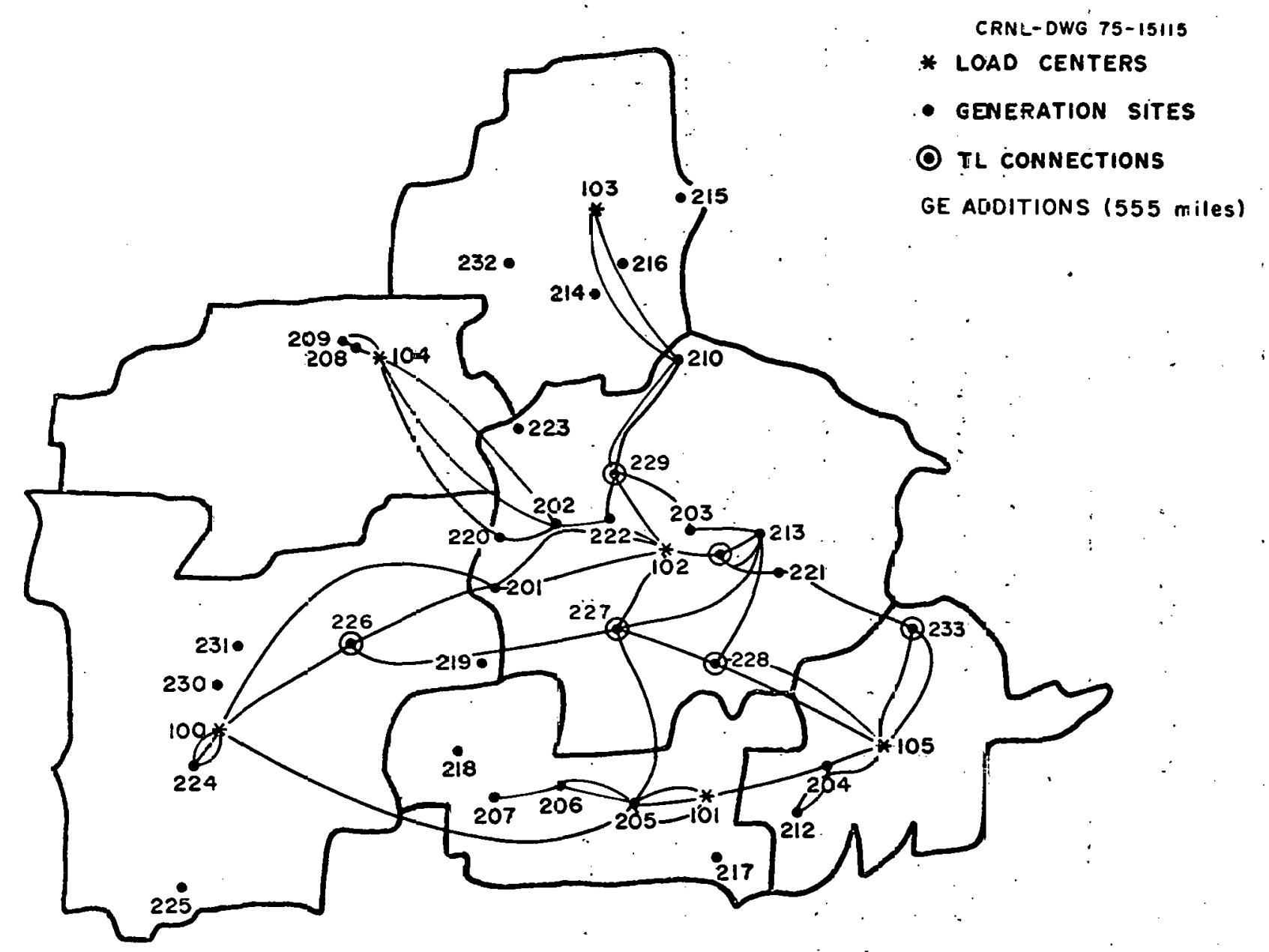

Fíg. 21. GE additions to the transmission network For dispersed :case -1985 . 


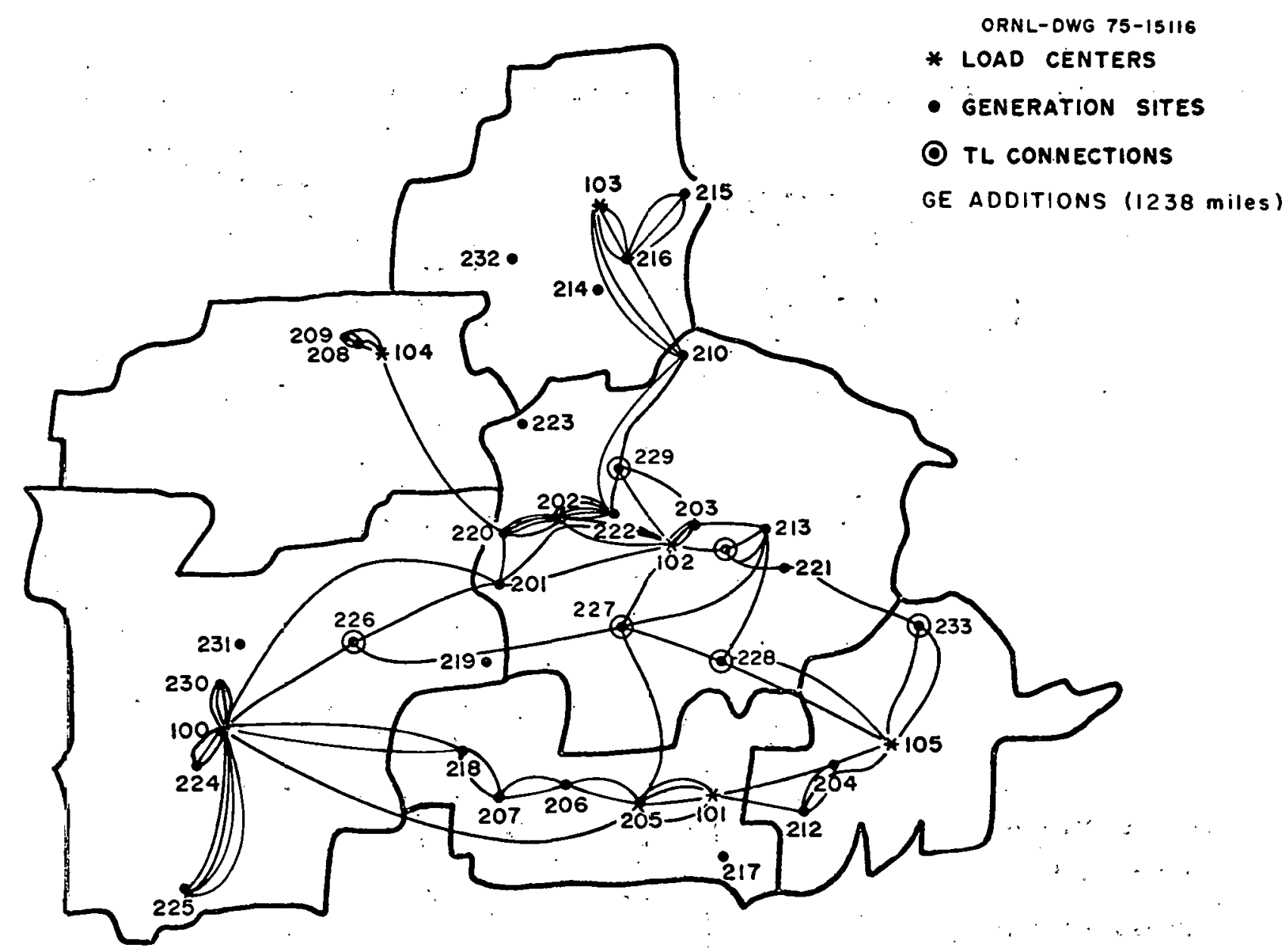

Fig. 22. GE additions to the transmission network for dispersed case -2005 . 


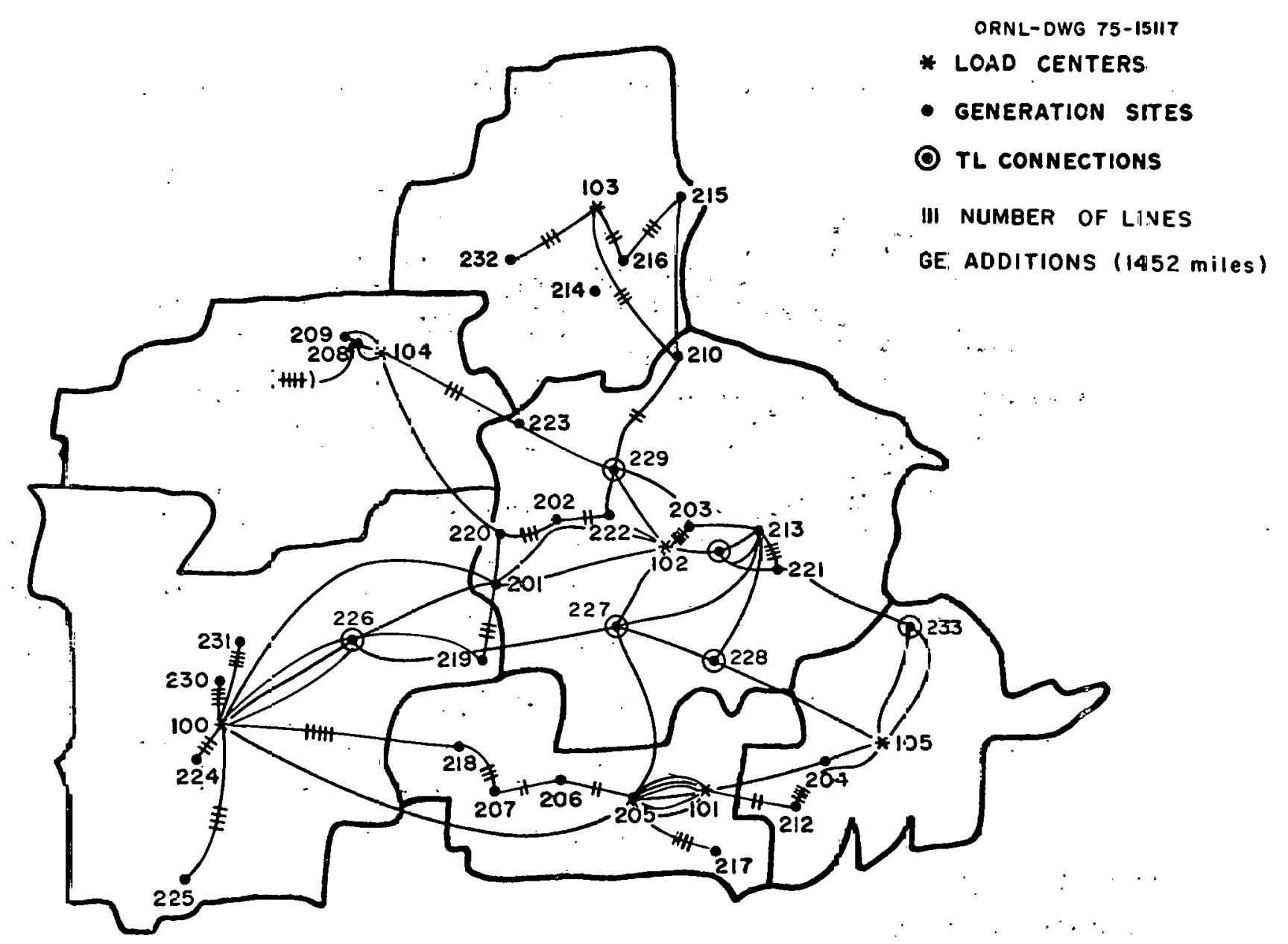

Iig. 23. GE additions to the transmission network for dispersed case -2020 . 


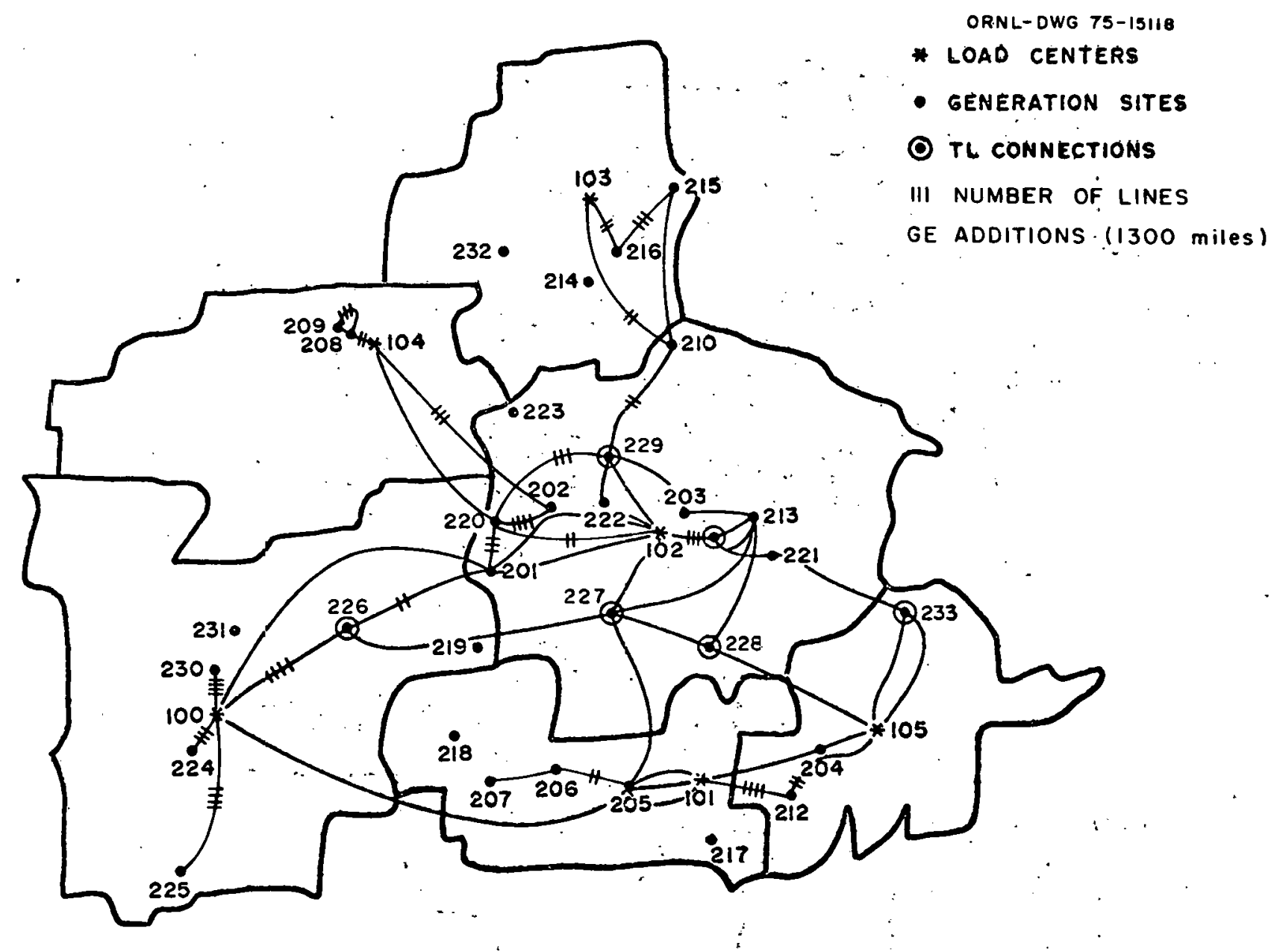

Fig. 24. GE additions to the transmission network ${ }^{+}$for center case -2005 . 


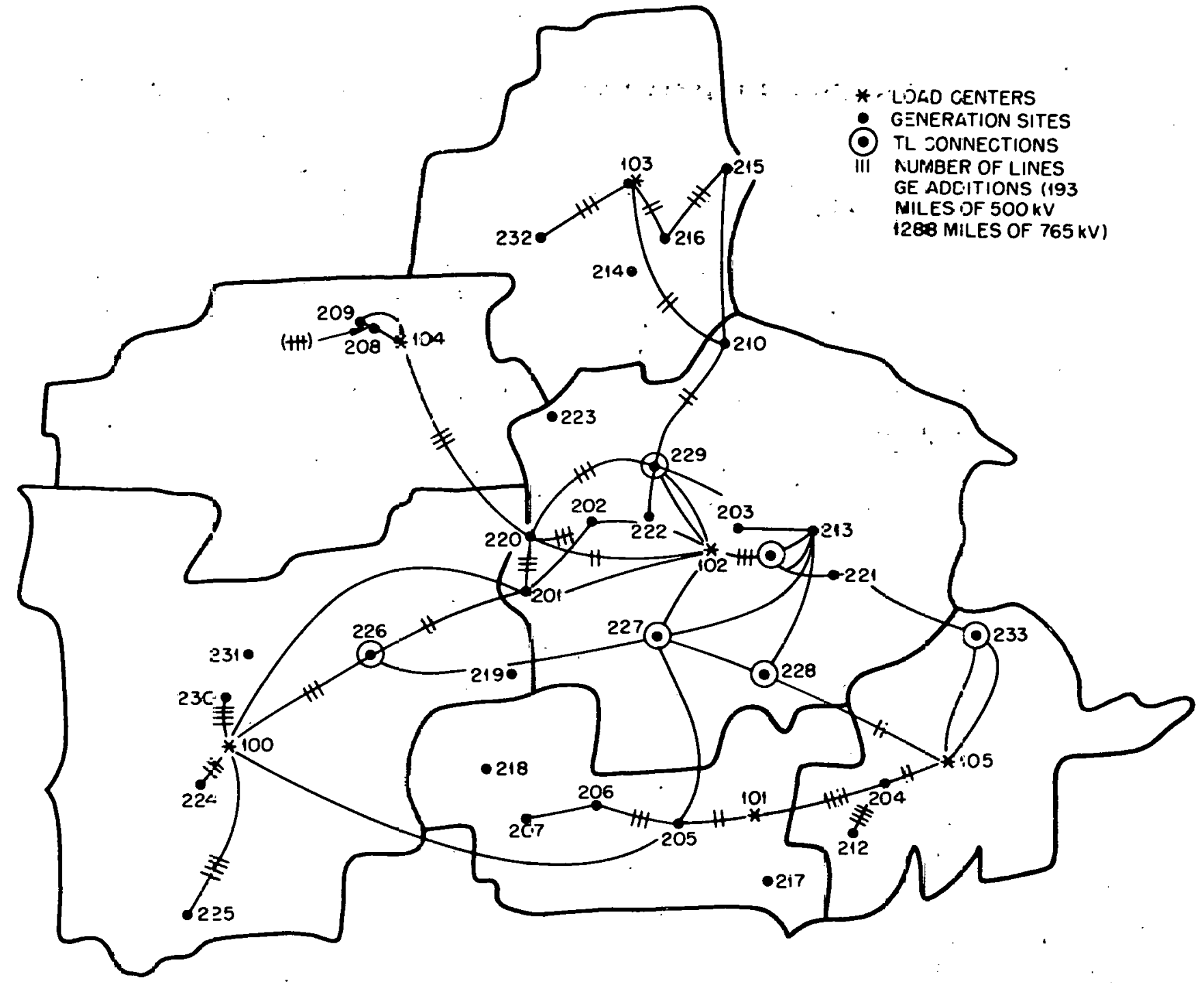

Fig. 25. GE additions to the transmission network for senter case -2020 . 


\section{REFERENCES}

1. W. D. Stevenson, Jr., EZements of Powers System Analysis, 3rd ed., McGraw-Hil1 Book Company, New York, 1975.

2. Electrical Transmission and Distribution Reference Book, 4th ed., Westinghouse, p. 481 .

3. L. L. Garver, private communication, Sept. 8, 1975.

4. A. F. Gabrielle et al., "Electrical Constants and Relative Capabilities of Bundled-Conductor Transmission Lines," IEEE Trons. PAS PAS-83: 78-92 (1974).

5. M. S. Dyrkacz and F. J. Maginniss, "A New Automatic Program for Load-Flow Studies on the IBM-704," AIEE Trans. 78 (III): 52-72 (1959).

6. W. R. Puntel et al., "An Automated Method for Long-Range Planning of Transmission Networks," 1973 Power Industry Computer Application (PICA) Conference paper 73CH0 740-1 PWR, Minneapolis, Minn., June $3-6,1973$.

7. V. G. Knight et al., "Computers in Power System Planning," Proc. IEEE $62(7): 872-883(1974)$.

8. L. L. Garver, "Transmission Network Estimation Using Linear Programming," IEEE Trans. PAS PAS-89 (7): 1688-1697 (1970).

9. J.-C. Kaltenbach, J. Peschon, and E. H. Gehrig, "A Mathematical Optimization Technique for the Expansion of Electric Power Transmission Systems," IEEE Trans. PAS, PAS-89 (1): 113-119 (1970).

10. J. Peschon, O. W. Bree, Jr., and L. P. Hajdn, "Optimal Power-Flow Solution for Power System Planning," Proc. IEEE 60(1): 64-70 (1972). 
11. E. R. Petersen, "A Dynamic Programming Model for the Expansion of Electric Power Systems," Management Science 20(4, II): 656-664 (1973).

12. T. P. Dusonchet and A. E1-Abiad, "Transmission Planning Using Discrete Dynamic Optimizing," IEEE PAS Summer Meeting Paper T72 474-5, San Francisco, CA July 9-14, 1975.

13. S. T. Y. Lee, K. L. Hicks, and E. Hnyilicza, "Transmission Expansion by Branch-and-Bound Integer Programming with Optimal CostCapacity Curves," IEEE PAS Winter Meeting Paper T74 143-4, New York, NY, Jain. 27 - Feb. 1, 1974.

14. C. C. Gonzaga et al., "Uptimal Planning of the Expunsiuni of a Power Transmission System," Proc. of the Symp. of Systems Approaches to Developing Countries, Internation Fed. of Automatic Control, Algers, Algeria, May 28-31, 1973, pp. 217-224.

15. R. J. Olsen, "Regional Need for Power Consistent with Water Resources Council Projections: Load Centers Within 300 Miles of the Kentucky Lake Surrogate Site," Memorandum to C. C. Burwell, Oak Ridge National Laboratory, Apr. 2, 1975.

16. L. G. Bray and R. J. Olsen, Revision and Extension of April 2, 1975 Memo, "Regional Need for Power Consistent with Water Resources Council Population Projections," Memorandum to NECSS Distribution, Oak Ridge National Laboratory, May 16, 1975.

17. National Electric Reliability. Council, Nuclear Energy Centers, An Assessment of Impact on Reliability of Electric Power Supply, Princeton, New Jersey, 1975.

18. G. Samuels, "Dispersed (4800 MWe) Sites Within 300 Miles of the Kentucky Lake Surrogate Site," Oak Ridge National Laboratory, May 2, 1975. 
19. Electrical World, Directory of Electrical Utilities, 1974-1975, 83rd ed., McGraw-Hill, Incorporated, 1974.

20. L. L. Garver, J. J. LaForest, and S. C. Robinson, "Transmission Costs as Affected by Energy Center Size," G.E. Report to NRC, Contract No. AT [49-24] 0151, July 1975.

21. Assessment of Energy Parks vs. Dispersed Electric Power Generating Facilities, Center for Energy Systems, General Electric Co., 777 14th St., N.W., Washington D.C. 20005, May 30, 1975.

22. Transmission Network Expansion Planning Program, G.E. Users Manual TP2, November 1972, January 1974, p. 2. 


\section{Appendix A \\ RETIREMENTS AND DEMAND PROJECTIONS}

The goal of this appendix is to show how the demand projections in Table 4 (Section 3) were derived. In his memorandum of April 2, 1975,15 Olsen allocated capacity to BEA regions. Capacity will be composed of base-load nuclear and fossil plants and peaking units; capacity will be greater than peak demand. Due to retirements, the cumulative additions in generating stations are not equal to the change in capacity. In 1980 the capacity projection for the five load centers $1 \mathrm{~s} 20 \mathrm{GW}$, and in 2020 the capacity projection is $95 \mathrm{GW}$; the increase in capacity is $75 \mathrm{GW}$. The new capacity that must be built between 1980 and 2020 is the sum of the increase in capacity, $75 \mathrm{cW}$, and the retirements. If the plants have a lifetime of 40 years, all the capacity in 1980 will be retired by 2020 ; thus, the cumulative new capacity between 1980 and 2020 will be $95 \mathrm{GW}$. If the staff knew the date at which each generator serving the load centers was built and could estimate the lifetime of each plant, it could estimate the retirement schedule directly. Because the data for a direct estimate are not available, the staff has developed an approximate retirement schedule. All plants are assumed to have a lifetime of 40 years, and the retirement rate is approximated by using an exponential function.

Let $A(t)$ be the additional power plants that begin producing power in year $t$, let $R(t)$ be the retirements in year $t$ and let $C(t)$ be the total capacity in-place at the end of year $t$. Then, the change in capacity is equal to the additions minus the retirements, that is,

$$
\Delta C(t)=C(t)-C(t-1)=A(t)-R(t) \text {. }
$$

Define the cumulative additions and retirements by

$$
\begin{array}{ll}
\operatorname{CA}(t)=\sum_{t^{\prime}=t^{*}}^{t} A\left(t^{\prime}\right) & t \geqslant t^{*}, \\
\operatorname{CR}(t)=\sum_{t^{\prime}=t^{*}}^{t} R\left(t^{\prime}\right) & t \geqslant t^{*},
\end{array}
$$


where $t^{*}$ is the initial year, and $C A(t)$ and $C R(t)$ are zero if $t$ is less than $t^{*}$. Because

$$
\sum_{t^{\prime}=t^{*}}^{t} \Delta C\left(t^{\prime}\right)=C(t)-C\left(t^{*}-1\right),
$$

the definitions of $\mathrm{CA}(t)$ and $\mathrm{CR}(\mathrm{t})$ imply that

$$
C(t)=C\left(t^{*}-1\right)+C A(t)-C R(t) \text {. }
$$

Assume that all plants retire after $\tau$ years, that is,

$$
R(t)=A(t-\tau)
$$

If all plants retire after $\tau$ years, then all plants in operation today were built within the last $\tau$ years, and the cumulative retirements over the next $\tau$ years are equal to today's capacity. These results can now be stated more formally as a theorem.

\section{Theorem:}

$$
\begin{aligned}
& \sum_{t^{\prime}=t+1-\tau}^{t} A\left(t^{\prime}\right)=C(t), \\
& \sum_{t^{\prime}=t+1-\tau}^{t} R\left(t^{\prime}\right)=c(t-\tau) .
\end{aligned}
$$

Proof:

Choose $t *$ far in the past, then $C(t *-1)=0$, and equation (4) becomes :

$$
\begin{aligned}
C(t) & =C A(t)-C R(t), \\
& =\sum_{t^{\prime}=t^{*}}^{t} A\left(t^{\prime}\right)-\sum_{t^{\prime}=t^{*}}^{t} R\left(t^{\prime}\right) .
\end{aligned}
$$


Because $R(t)=A(t-\tau)$,

$$
\begin{aligned}
C(t) & =\sum_{t^{\prime}=t^{*}}^{t} A\left(t^{\prime}\right)-\sum_{t^{\prime}=t^{*}}^{t} A\left(t^{\prime}-\tau\right), \\
& =\sum_{t^{\prime}=t^{*}}^{t} A\left(t^{\prime}\right)-\sum_{t^{\prime}=t^{*}-\tau}^{t-\tau} A\left(t^{\prime}\right), \\
& =\sum_{t^{\prime}=t+1-\tau}^{t} A\left(t^{\prime}\right) .
\end{aligned}
$$

Using equarion ( 5 ),

$$
\begin{aligned}
r(t-\tau) & =\sum_{t^{\prime}=t+1-2 \tau}^{t-\tau} A\left(t^{\prime}\right)=\sum_{t^{\prime}=t+1-\tau}^{t} A\left(t^{\prime}-\tau\right) \\
& =\sum_{t^{\prime}=t+1-\tau}^{t} R\left(t^{\prime}\right) .
\end{aligned}
$$

Assume that $\tau$ is 40 years. To approximate the retirement rate between 1980 and 2000, assume that $R$ has a uniform growth rate, that is,

$$
R(t)=R^{t-1980}
$$

Equation (7) has two unknowns, $R$ and $g$, and two conditions are needed to determine them. Equation (1) gives one condition and Eq. (6) gives a second, that is,

$$
\begin{aligned}
& \sum_{1981}^{2020} R(t)=R\left(\frac{g^{41}-g}{g-1}\right)=C(1980), \\
& R(2020)=A(1980)=\Delta C(1980)+R(1980) \\
& R\left(g^{40}-1\right)=\Delta C(1980) .
\end{aligned}
$$

Equations (8) and (9) can be solved to yleld

$$
g=C(1980) / C(1979)
$$




$$
R=\Delta C(1980) /\left(g^{40}-1\right)
$$

Equations (10) and (11) will be used to estimate the retirement correction on the next iteration, but were not used to derive the demand projections in Table 4.

To derive the correction for retirements used in this iteration, assume that the additions, retirements, and total capacity increase at the same exponential rate, that is,

$$
\begin{aligned}
& \mathrm{C}(\mathrm{t})=\mathrm{Cg}^{\mathrm{t}}, \\
& \mathrm{A}(\mathrm{t})=\mathrm{Ag}^{\mathrm{t}}, \\
& \mathrm{R}(\mathrm{t})=\mathrm{Rg}^{\mathrm{t}} .
\end{aligned}
$$

Using Eq. (1), two expressions for the change in capacity can be found, that is,

$$
\begin{aligned}
& \Delta C(t)=C(t)-C(t-1)=C^{t-1}(g-1), \\
& \Delta C(t)=A(t)-R(t)=A(t)-A(t-\tau)=\Delta C(t)=A g^{t}(1-\alpha),
\end{aligned}
$$

where $\alpha=g^{-\tau}$. Because these two expressions are equal,

$$
A=\frac{C(g-1)}{g(1-\alpha)}
$$

The cumulative new capacity is given by $\mathrm{Eq}$. (2), that is,

$$
C A(t)=\sum_{t^{\prime}=t^{*}}^{t} A\left(t^{\prime}\right)=\sum_{t^{\prime}=t^{*}}^{t} A g^{t^{\prime}} .
$$

If $t^{*}$ is far in the past, then $C A(t)$ is given by

$$
C A(t)=\frac{A g^{t+1}}{g-1}
$$


Using equation (12), CA(t) may be written

$$
\mathrm{CA}(\mathrm{t})=\frac{\mathrm{Cg}^{\mathrm{t}}}{1-\alpha}=\frac{\mathrm{C}(\mathrm{t})}{1-\alpha}
$$

Equation (13) was used to estimate the values of $\mathrm{CA}(t)$ that were used to derive the demand projections in Table 4. Values of $g$ and $\alpha$ for each of the five load. centers are shown in Table 23. The value of $g$ is the average growth rate from 1980 to 1990 , and $\alpha$ is given by $\alpha=g^{-\tau}$, where $\tau$ is 40 years.

lable 23. Values for $g$ and $\alpha$ for the load centers

\begin{tabular}{llllll}
\hline & Nashville & Paducah & Evansville & Huntsvi11e & Memphis \\
\hline g & 1.0531 & 1.0390 & 1.0454 & 1.0557 & 1.0467 \\
$\alpha$ & 0.12606 & 0.21631 & 0.16961 & 0.11428 & 0.16101 \\
\hline
\end{tabular}

Using the capacity projections in Table 2, Eq. (13) has been used to estimate the cumulative additions of new capacity for each load center that are shown in Table 24.

Table 24. Cumulative additions of new capacity by load center

\begin{tabular}{lrrrrr}
\hline Year & Nashville & Paducah & Evansville & Huntsville & Memphis \\
\hline 1985 & 8.927 & 2.759 & 3.677 & 4.212 & 10.310 \\
1990 & 11.770 & 3.334 & 4.719 & 5.554 & 13.326 \\
1995 & 14.620 & 4.077 & 5.772 & 7.213 & 16.222 \\
2000 & 18.556 & 4.953 & 7.011 & 8.998 & 19.824 \\
2020 & 35.845 & 8.556 & 12.381 & 18.453 & 36.526 \\
\hline
\end{tabular}


By means of exponential interpolations, Table 24 has been expanded to predict the cumulative additions for each year from 1985 to 2020 (see Table 25).

From Table 1, the development schedule for the nuclear energy center has the first reactor producing power on June 1, 1987. Using Table 25, Table 26 gives the cumulative additions of new capacity after 1986.

The demand by each load center from the base load nuclear power plants in the nuclear energy centers (see Table 27) is calculated from the development schedule in Tables 1 and 4. On June 1, 1990, the fourth reactor begins full-power operation and the energy center is supplying 4.8 GW. In 1990, the cumulative additions from base-load nuclear, fossil, and other sources is $7.233 \mathrm{GW}$. Thus, $66 \%$ of the new capactty in the service area from 1986 to 1990 will be base-load nuclear power from the energy center, which is close to our goal at $60 \%$. To estimate the demand by each load center, the total demand is assumed to be $40 \mathrm{MW}$ less than the total capacity, and the demand is apportioned on the basis of the capacity additions in Table 26. (Due to round-off, the demands by load centers in Table 27 in 1990 total to 4.77 rather than 4.76 GW.) Similarly, for each year shown in Table 1, the output of the energy center is allocated to load centers in proportion to the cumulative additions in Table 26. The cumulative additions in Table 26 from 1986 to 2020 are $80.291 \mathrm{GW}$, and $48 \mathrm{GW}$ is $60 \%$ of the cumulative additions.

As previously noted there are two sources of error in the demand projection in Table 27, and these errors will be corrected in the next iteration. The first source of error is that olsen has revised the demand projections used by the staff. 16 . The second source of error is that Eq. (13) was used rather than Eqs. (10) and (11). The magnitude of the second source of error can now be estimated. Equations (5) and (6) state that

$$
\begin{aligned}
& \sum_{t=1981}^{2020} A(t)=C(2020) \\
& \sum_{t=1981}^{2020} R(t)=C(1980)
\end{aligned}
$$


Table 25. Annual cumulative additions of new capacity by load center

\begin{tabular}{|c|c|c|c|c|c|c|}
\hline Year & Nashville & Paducah & Evansville & Huntsville & Memphis & Total \\
\hline 1985 & 8.927 & 2.759 & 3.677 & 4.212 & 10.310 & 29.885 \\
\hline 1986 & 9.435 & 2.865 & 3.865 & 4.452 & 10.853 & 31.470 \\
\hline 1987 & 9.971 & 2.976 & 4.063 & 4.705 & 11.424 & 33.139 \\
\hline 1988 & 10.538 & 3.091 & 4.271 & 4.972 & 12.026 & 34.898 \\
\hline 1989 & 11.137 & 3.210 & 4.489 & 5.255 & 12.659 & 36.751 \\
\hline 1990 & 11.770 & 3.334 & 4.719 & 5.554 & 13.326 & 38.703 \\
\hline 1991 & 12.292 & 3.471 & 4.913 & 5.852 & 13.861 & 40.388 \\
\hline 1992 & 12.836 & 3.613 & 5.115 & 6.166 & $14.41 \overline{7}$ & 42.147 \\
\hline 1993 & 13.405 & 3.762 & 5.325 & 6.497 & 14.995 & 43.984 \\
\hline 1994 & 13.999 & 3.916 & 5.544 & 6.846 & 15.596 & 45.902 \\
\hline 1995 & 14.620 & 4.077 & 5.772 & 7.213 & 16.222 & 47.904 \\
\hline 996 & 15.281 & 4.239 & 6.001 & 7.539 & 16.886 & 49.946 \\
\hline $97^{\circ}$ & 15.972 & 4.407 & 6.239 & 7.880 & 17.577 & 52.075 \\
\hline 98 & 16.694 & 4.582 & 6.486 & 8.236 & 18.296 & 54.295 \\
\hline 99 & .449 & 4.764 & 6.744 & 8.609 & 19.045 & 56.610 \\
\hline 00 & .238 & 4.953 & 7.011 & 8.9 & .824 & 9.024 \\
\hline & .865 & & 7.2 & 9.327 & 20.4 & 60.934 \\
\hline & .513 & 5.2 & 7.421 & 9.668 & 21.073 & 62.907 \\
\hline & .183 & 5.376 & 7.6 & 10.022 & 21.727 & 64.944 \\
\hline 2004 & 0.877 & 5.525 & 7.856 & 10.388 & 22.401 & 67.047 \\
\hline 2005 & 1.594 & 5.678 & 8.082 & 10.768 & 23.096 & 69.219 \\
\hline 2006 & .336 & 5.836 & 8.3 & 11.161 & 23.813 & 71.461 \\
\hline 2007 & .104 & 5.997 & 8.555 & 11.570 & 24.552 & 73.777 \\
\hline 2008 & 3.898 & 6.164 & 8.802 & 11.993 & 25.314 & 76.169 \\
\hline 2009 & 4.719 & 6.334 & 9.056 & $12: 431$ & 26.099 & 78.639 \\
\hline 2010 & .568 & 6.510 & 9.317 & 12.886 & 26.909 & 81.189 \\
\hline 2011 & 0.447 & 6.690 & 9.586 & 13.357 & 27.744 & 83.823 \\
\hline 2012 & 7.356 & 6.876 & 9.862 & 13.845 & 28.604 & 86.543 \\
\hline 2013 & 8.296 & 7.066 & 10.146 & 14.351 & 29.492 & 89.351 \\
\hline 2014 & 29.268 & 7.262 & 10.439 & 14.876 & 30.407 & 92.252 \\
\hline 2015 & 30.273 & 7.463 & 10.740 & $15.420^{\circ}$ & 31.351 & 95.247 \\
\hline 2016 & 31.314 & 7.670 & 11.050 & 15.984 & 32.323 & 98.341 \\
\hline 2017 & 32.390 & 7.882 & 11.369 & 16.568 & 33.326 & 101.535 \\
\hline 2018 & 33.503 & 8.101 & 11.696 & 17.174 & 34.360 & 104.834 \\
\hline 2019 & 34.654 & 8.325 & 12.034 & 17.802 & 35.426 & 108.241 \\
\hline 2020 & 35.845 & 8.556 & 12.381 & 18.453 & 36.526 & 111.761 \\
\hline
\end{tabular}


Table 26. Annual cumulative additions of new capacity after 1986 by load center

\begin{tabular}{lcccccr}
\hline Year & Nashville & Paducah & Evansville & Huntsville & Memphis & Total \\
\hline 1987 & 0.536 & 0.111 & 0.198 & 0.253 & 0.572 & 1.669 \\
1988 & 1.103 & 0.225 & 0.406 & 0.521 & 1.173 & 3.428 \\
1989 & 1.702 & 0.345 & 0.624 & 0.804 & 1.806 & 5.281 \\
1990 & 2.335 & 0.469 & 0.854 & 1.102 & 2.473 & 7.233 \\
1991 & 2.857 & 0.605 & 1.048 & 1.400 & 3.008 & 8.919 \\
1992 & 3.402 & 0.748 & 1.250 & 1.715 & 3.564 & 10.678 \\
1993 & 3.971 & 0.896 & 1.460 & 2.045 & 4.142 & 12.515 \\
1994 & 4.565 & 1.051 & 1.679 & 2.394 & 4.743 & 14.432 \\
1995 & 5.185 & 1.212 & 1.907 & 2.761 & 5.369 & 16.434 \\
1996 & 5.847 & 1.373 & 2.136 & 3.088 & 6.033 & 18.476 \\
1997 & 6.537 & 1.542 & 2.374 & 3.428 & 6.724 & 20.605 \\
1998 & 7.260 & 1.717 & 2.621 & 3.785 & 7.443 & 22.825 \\
1999 & 8.014 & 1.898 & 2.878 & 4.157 & 8.192 & 25.140 \\
2000 & 8.803 & 2.088 & 3.146 & 4.546 & 8.971 & 27.554 \\
2001 & 9.430 & 2.225 & 3.348 & 4.875 & 9.586 & 29.465 \\
2002 & 10.078 & 2.366 & 3.556 & 5.216 & 10.220 & 31.437 \\
2003 & 10.749 & 2.511 & 3.770 & 5.570 & 10.874 & 33.474 \\
2004 & 11.442 & 2.660 & 3.990 & 5.936 & 11.548 & 35.577 \\
2005 & 12.160 & 2.813 & 4.217 & 6.316 & 12.243 & 37.749 \\
2006 & 12.902 & 2.970 & 4.450 & 6.710 & 12.960 & 39.992 \\
2007 & 13.669 & 3.132 & 4.690 & 7.118 & 13.699 & 42.308 \\
2008 & 14.463 & 3.298 & 4.937 & 7.541 & 14.461 & 44.699 \\
2009 & 15.284 & 3.469 & 5.190 & 7.980 & 15.246 & 47.169 \\
2010 & 16.134 & 3.644 & 5.452 & 8.434 & 16.056 & 49.720 \\
2011 & 17.012 & 3.825 & 5.720 & 8.905 & 16.891 & 52.353 \\
2012 & 17.921 & 4.010 & 5.997 & 9.394 & 17.752 & 55.073 \\
2013 & 18.861 & 4.201 & 6.281 & 9.900 & 18.639 & 57.882 \\
2014 & 19.833 & 4.396 & 6.574 & 10.425 & 19.554 & 60.782 \\
2015 & 20.839 & 4.598 & 6.875 & 10.969 & 20.498 & 63.778 \\
2016 & 21.879 & 4.804 & 7.185 & 11.532 & 21.470 & 66.871 \\
2017 & 22.955 & 5.017 & 7.503 & 12.117 & 22.473 & 70.066 \\
2018 & 24.068 & 5.235 & 7.831 & 12.723 & 23.507 & 73.365 \\
2019 & 25.219 & 5.460 & 8.169 & 13.351 & 24.573 & 76.772 \\
2020 & 26.410 & 5.691 & 8.516 & 14.001 & 25.673 & 80.291 \\
\hline & & & & & & \\
\hline & & & & & & \\
\hline
\end{tabular}


Table 27. Demand from energy centers by load center

\begin{tabular}{lcccccc}
\hline Year & Nashville & Paducah & Evansville & Huntsville & Memphis & Total \\
\hline 1988 & 0.76 & 0.16 & 0.28 & 0.36 & 0.81 & 2.36 \\
1990 & 1.54 & 0.31 & 0.56 & 0.73 & 1.63 & 4.76 \\
1992 & 2.28 & 0.50 & 0.84 & 1.15 & 2.39 & 7.16 \\
1994 & 3.02 & 0.70 & 1.11 & 1.59 & 3.14 & 9.56 \\
1996 & 3.78 & 0.89 & 1.38 & 2.00 & 3.91 & 11.96 \\
1998 & $4 . .57$ & 1.08 & 1.65 & 2.38 & 4.68 & 14.36 \\
2000 & 5.35 & 1.27 & 1.91 & 2.77 & 5.46 & 16.76 \\
2001 & 6.13 & 1.45 & 2.18 & 3.17 & 6.23 & 19.16 \\
2003 & 6.92 & 1.62 & 2.43 & 3.59 & 7.00 & 21.56 \\
2005 & 7.72 & 1.79 & 2.68 & 4.01 & 7.77 & 23.96 \\
2006 & 8.50 & 1.96 & 2.93 & 4.12 & 8.54 & $? 6.36$ \\
2008 & 9.31 & 2.12 & 3.18 & 4.85 & 9.30 & 28.76 \\
2009 & 10.10 & 2.29 & 3.43 & 5.27 & 10.07 & 31.16 \\
201.1 & 10.91 & 2.45 & 3.67 & 5.71 & 10.83 & 33.56 \\
2012 & 11.70 & 2.62 & 3.92 & 6.13 & 11.59 & 35.96 \\
2014 & 12.52 & 2.77 & 4.15 & 6.58 & 12.34 & 38.36 \\
2015 & 13.32 & 2.94 & 4.39 & 7.01 & 13.10 & 40.76 \\
2017 & 14.14 & 3.09 & 4.62 & 7.46 & 13.84 & 43.16 \\
2018 & 14.95 & 3.25 & 4.86 & 7.90 & 14.60 & 45.56 \\
2020 & 15.78 & 3.40 & 5.09 & 8.36 & 15.34 & 47.96 \\
\hline
\end{tabular}

Using the data in the Olsen memorandum of April 2, 1975,15 to extend to 1980 the capacity projections and the cumulative additions in Table 24 , one finds that

$$
\begin{aligned}
& C(2020)=y 5.301 \quad C(1980)=20.368, \\
& \sum_{t=1981}^{2020} A(t)=87.775 \sum_{t=1981}^{2020} R(t)=12.842 .
\end{aligned}
$$

Thus, the methodology used to correct for retirements underestimates the cumulative retirements and additions. Because underestimation is better than overestimation and because the magnitude of the error in the cumulative additions is not large, the demand projections in Table 27 are not seriously influenced by this error. 


\section{Appendix B \\ DISPERSED SITES WITHIN 300 MILES OF THE KENTUCKY LAKE SURROGATE SITE}

To obtain some insight as to siting difficulties that may arise in providing for future power growth, a preliminary and rather cursory exercise was done to locate possible dispersed sites within. a 300-mile radius of the Kentucky Lake Surrogate Site. The criteria and assumptions used in selecting these sites are as follows:

1. The total installed capacity at each site was $4800 \mathrm{MWe}$ (four 1200-MWe reactors).

2. The spacing between plants was about 30 to 40 miles and no closer than about 15 miles to population centers of 25,000 people.

3. No sites were located in the NRC designated zone III selsmic area.

4. Each site used wet cooling towers, and the thermal efficiency of the units was assumed to be $33.3 \%$.

5. The consumptive water use was based on typical hot weather conditions - a value of 30 cfs per 1200 MWe, or 120 cfs per site.

6. The requirement for local river flow rates was such that the consumptive use of water would be no greater than $10 \%$ of the annual 20-year low flow at the site with the additional restriction that the cumulative water use on a river system would not exceed, at any point, $10 \%$ of the annual 20 -year low flow at that point.

A total of 60 potential sites were located within a $300-m i l e$ radius of the Kentucky Lake Surrogate Site and are shown in Fig. 26. Table 28 gives the location of the sites and the mean annual flow for the rivers on which the plants are located.

The criteria used for this exercise are greatly simplified, and a more detailed analysis would probably eliminate some of these sites and also find others that may be acceptable. However, the interesting aspect 


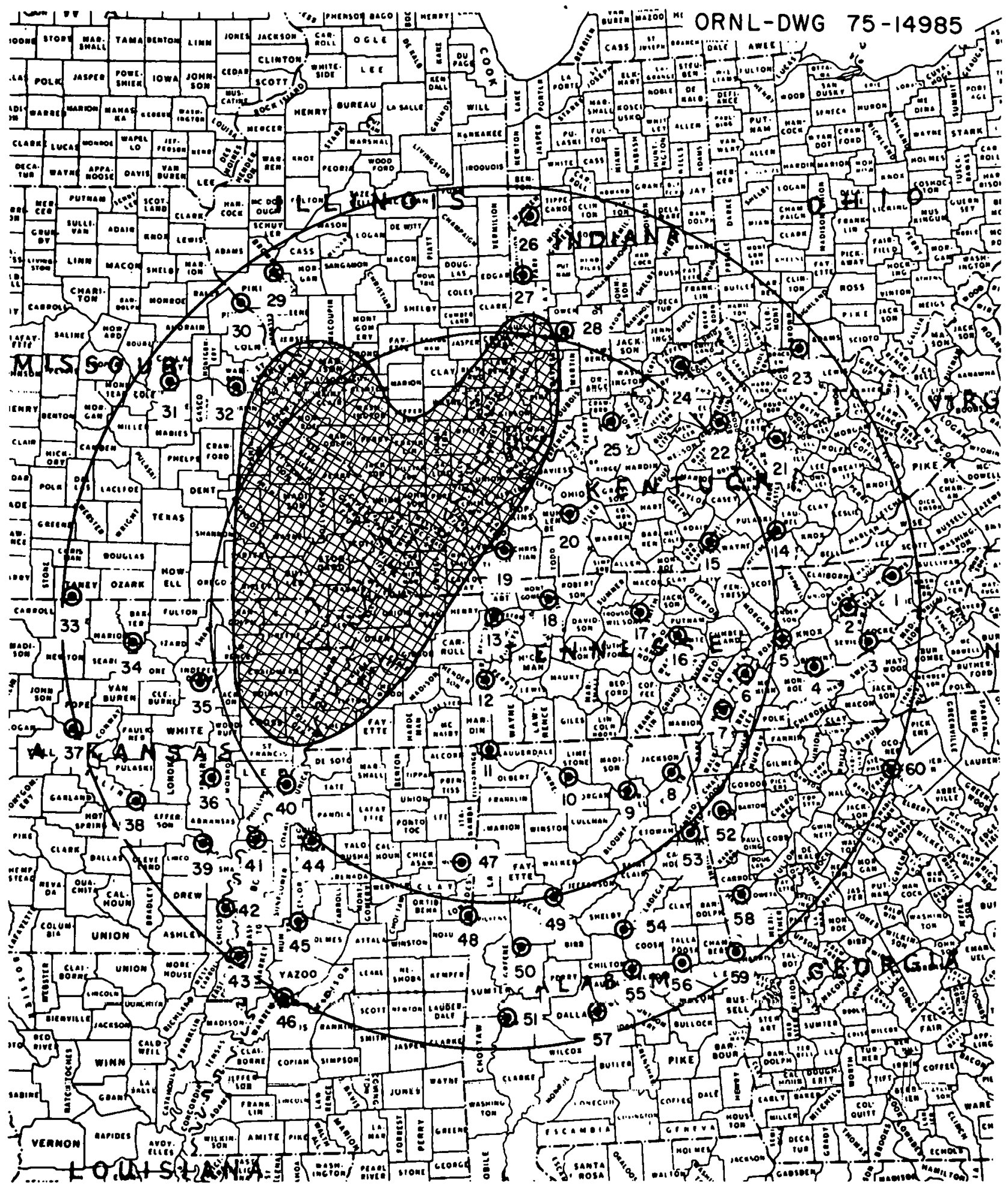

Fig. 26. Location of 60 potential sites within a 300-mile radius of the Kentucky Lake Surrogate Site. 
Table 28. Dispersed (4800-MWe) sites within 300 miles of the Kentucky Lake Surrogate Site

\begin{tabular}{|c|c|c|c|}
\hline $\begin{array}{c}\text { Site } \\
\text { number }\end{array}$ & River & Location & $\begin{array}{c}\text { Mean annual flow } \\
\text { (cfs) }\end{array}$ \\
\hline
\end{tabular}

Tennessee River Basin

$\begin{aligned} 1 & \text { Holston } \\ 2 & \text { Holston } \\ 3 & \text { French Broad } \\ 4 & \text { Little Tennessee } \\ 5 & \text { Clinch } \\ 6 & \text { Tennessee } \\ 7 & \text { Tennessee } \\ 8 & \text { Tennessee } \\ 9 & \text { Tennessee } \\ 10 & \text { Tennessee } \\ 11 & \text { Tennessee } \\ 12 & \text { Tennessee } \\ 13 & \text { Tennessee }\end{aligned}$

Surgeonville, TN
Cherokee Lake
Douglass Lake.
Calderwood Lake
Watts Bar Lake
Watts Bar Lake*.
Chickamauga Lake*
Guntersville Lake*
Below Guntersville Dam
Wheeler Lake*..
Pickwick Lake
Kentucky Lake, near
Parsons, TN
Kentucky Lake Surrogate
Site

Cumberland River Basin

14 Cumberland

15 Cumberland

16 Caney Fork

17 Cumberland

18 Cumberland

19 Cumberland

Downstream of Cumberland Falls, KY

Lake Cumberland

Center Hill Reservoir

Near Hartsville, TN*

20,000

12 miles SE of

24,000

Clarksville, TN

Lake Barkley, 7 miles . . $\quad 25,000$

$W$ of Cadiz, KY

\section{Ohio River Basin}

$\begin{array}{ll}20 & \text { Green } \\ 21 & \text { Kentucky } \\ 22 & \text { Kentucky } \\ 23 & \text { Ohio } \\ 24 & \text { Ohio } \\ 25 & \text { Ohio } \\ 26 & \text { Wabash } \\ 27 & \text { Wabash } \\ 28 & \text { White }\end{array}$

Drakesboro, $\mathrm{KY}$

7,700

Between Richmond and

5,200

Winchester, $\mathrm{KY}$

20 miles SW

6,500

Lexington, $\mathrm{KY}$

Near Maysulile, KY

92,000

Near Madison, IN

100,000

Meade County, KY

120,000

Near Attica, IN

6,300

Near Mecca, IN

10,000

Near Worthington, IN

3,800 
Table 28. (continued)

\begin{tabular}{|c|c|c|c|}
\hline $\begin{array}{l}\text { Site } \\
\text { number }\end{array}$ & River & Location & $\begin{array}{c}\text { Mean annual flow } \\
(\mathrm{cfs})\end{array}$ \\
\hline
\end{tabular}

Missouri and Upper Mississippi River Basin

$\begin{array}{llll}29 & \text { T.1.1inois } & \text { Near Meredosia, IL } & 20,000 \\ 30 & \text { Mississipp1 } & \text { Near Loulsiana, MO } & 62,000 \\ 31 & \text { Missour1 } & \text { Near Fulton, MO* } & 75,000 \\ 32 & \text { Missour1 } & \text { Near Washington, MO } & 80,000\end{array}$

White and Arkansas Rivers

33 . White

3!. "White

35 White

36 White

37 Arkansas

38 Arkansas

$39 \quad$ Arkansas
Upper end of Bull Shoals Lake

Between Bull Shoals Lake and Norfolk Lake

Between Batesville and Newport, AR

Near DeValls Bluff, AR

Dardanelle Reservo1r*

Between Little Rock and Pine Bluff, AR

35 miles $S E$ of. Pine Bluff, AR
5,000

6,000

12,000

28,000

37,000

41,000

42,000

\section{Lower Mississippi River Basin}

$\begin{array}{ll}40 & \text { Mississippi } \\ 41 & \text { Mississippi } \\ 42 & \text { Mississippi } \\ 43 & \text { Mississippi } \\ 44 & \text { Tallahatchi } \\ 45 & \text { Yazoo } \\ 46 & \text { Yazoo }\end{array}$
Near Banks, MS
West of Clarksdale, MS
Near Greenville, MS
Near Chatham, MS
18 miles $E$ of Clarksdale, MS
15 milee $s$ of Greenwood, MS
30 miles $\mathrm{NE}$ of Vicksburg, MS

$$
\begin{array}{r}
450,000 \\
450,000 \\
450,000 \\
450,000 \\
6,800 \\
9,700 \\
10,000
\end{array}
$$

\section{Mobile River Basin}

$\begin{array}{ll}47 & \text { Tombigbee } \\ 48 & \text { Tombigbee } \\ 49 & \text { Black Warrior }\end{array}$

Near Aberdeen, MS

3,000

15 miles $S$ of

6,000

Columbus, MS

30 miles $W$ of ..

Birmingham, AL

6,000 
Table 28. (continued)

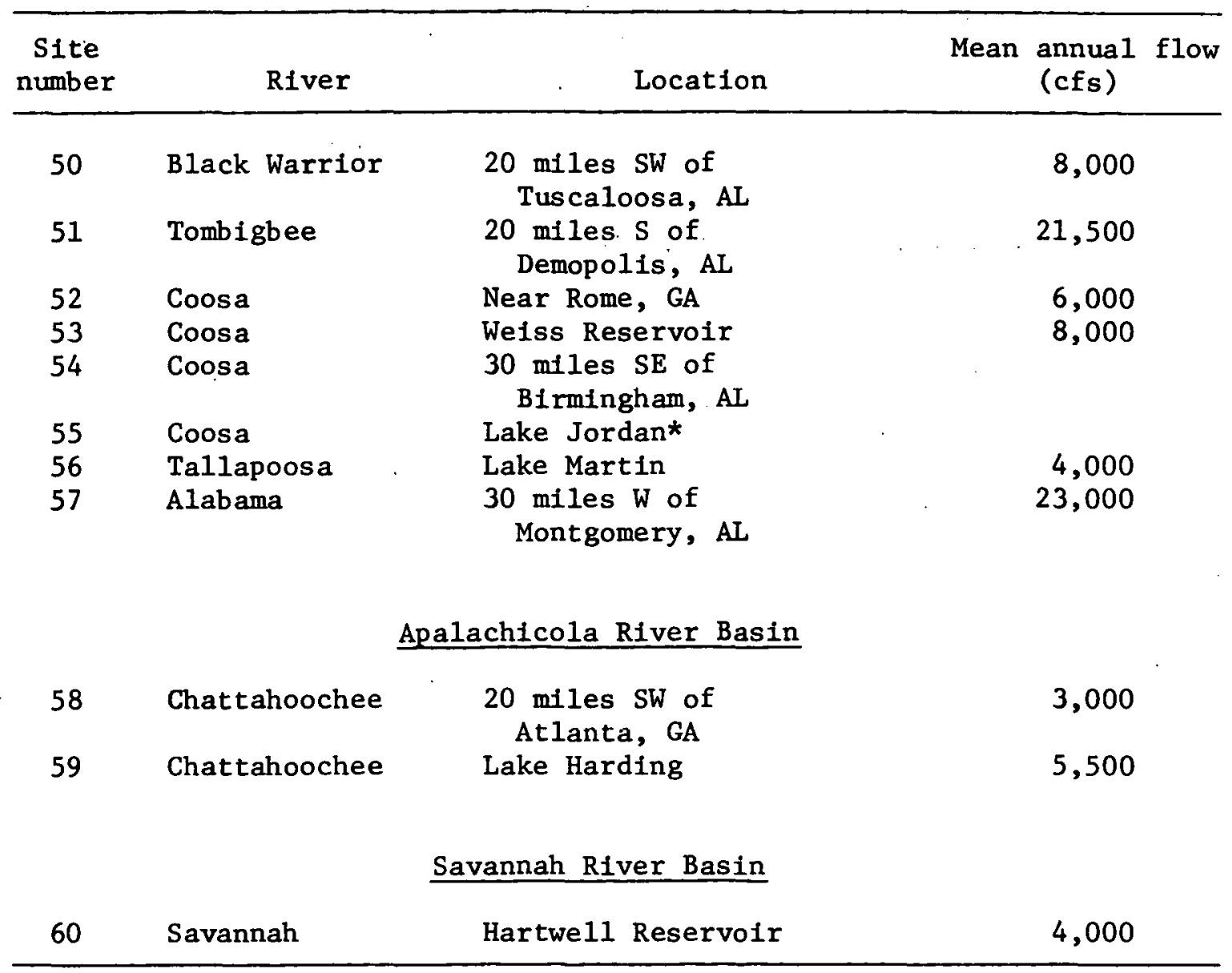

of this study is that the total installed capacity of these 60 sites (288 MWe) is only about $60 \%$ of the projected capacity requirements of 485 to 490 MWe for this area in the year 2020. Another manner in which one can corroborate the overall aspect of the problem is to divide the total projected capacity requirements for the year 2020 by the service area. The area in this case is $283,000 \mathrm{sq} \mathrm{miles}$ and the capacity requirements are $1.72 \mathrm{MWe} / \mathrm{sq}$ mile. Thus, a site with 4800 MWe will serve an area of $2790 \mathrm{sq}$ miles or the equivalent of a square 53 miles on the side. Arbitrarily spacing sites on a rectangular pattern would then lead to a four-unit power plant every 53 miles. Adding restrictions for population centers and water requirements implies that, even in an 
area as rich in water resources as the one used here, the major rivers w111 be lined with power stations. The alternative would be a larger spacing of very large energy centers.

Regardless of the simplicity of the approach used here, such an exercise emphasizes the need for rather long-range planning for both land and water resources as well as for future power transmission systems. 
Appendix C

\section{DERIVATION OF DEMAND}

The derivation of the demand for the load centers is based on allocated share of capacity for the corresponding BEA region (as shown in Table 2) adjusted for excess capacity over the demand (20\%) and local generating plants. Thus, for example,

\begin{tabular}{llc} 
Memphis in 1985: & \multicolumn{3}{c}{$8483: 1.2=7069 \mathrm{MW}$} \\
Allen steam plant & 879 & -1593 \\
Peak (gas turbine) & 714 & $5476 \mathrm{MW}$
\end{tabular}

In 2005, the GT peaking unit was retired; and In 2020, the base steam plant.

\begin{tabular}{cc}
$\begin{array}{l}\text { Chattanooga in 2005, basic demand: } \\
\text { Sequoyah } \\
\text { Raccoon }\end{array}$ & $\begin{array}{r}4680 \\
1300\end{array}$ \\
\hline "Net" Demand & $1828 \mathrm{MW}$ \\
\hline
\end{tabular}

In 2020, the "Net" Demand is 12,583 - 6100 = 6483 MW because Sequoyah's capacity increased to $4800 \mathrm{MW}$.

In Paducah, $1700 \mathrm{MW}$ were added to the demand to allow for the operation of AEC's diffusion plant.

The 1985 Evansville's demand was reduced by $623 \mathrm{MW}$, the capacity of the Warrick plant; thereafter, the plant was retired. 
THIS PAGE

WAS INTENTIONALLY

LEFT BLANK 
ORNL/TM-5311.

(Second Volume of ORNL/TM-5310)

UC-80

INTERNAL DISTRIBUTION

1. S. I. Auerbach

2. J. A. Auxier

3. L. L. Bennett

4-13. C. C. Burwell

1.4. R. S. Carlsmith

15. C. V. Chester

16. J. E. Cope

17. F. L. Culler

18. G. G. Fee

19. A. P. Fraas

20. W. Fulkers on

21. R. F. Hibbs

22. S. I. Kaplan

23. S. V. Kaye

24. R. L. Lyons

25. R. J. Olsen
26. H. Postma

27. H. P. Raaen

28. C. S. Rosemarin

29. M. W. Rosenthal

30. T. H. Row

31. G. Samuels

32-33. 0. Sisman

34. I. Spiewak

35. E. G. Struxness

36. J. S. Suffern

37. L. W. Zelby

38-41. Central Research Library

42. Document Reference Section

43-45. Laboratory Records

46. Laboratory Records, ORNL R. C.

47. ORNL Patent Office

\section{EXTERNAL DISTRIBUTION}

48. R. E. Balzhiser, Director, Fossil Fuel and Advanced Systems Division, Electric Power Research Institute, P. 0. Box 10412 Palo Alto, CA 94304

49. S. D. Freeman, 7211 Pyle Road, Bethesda, MD 20034

50. H. Landsberg, Director, Diviston of Energy and Resource Commodities, Resources for the Future, 1755 Massachusetts Avenue, N.W., Washington, D.C. 20036

51. Louise Markel, Information Officer, Oak Ridge Associated Universities, Institute for Energy Analysis, Oak Ridge, TN 37830

52. L. D. Taylor, Professor of Economics, University of Arizona, Tucson, AZ 85721

53-72. Office of Special Studies Branch, Nuclear Regulatory Commission, Washington, D.C. 20555

73. Director, Research and Technical Support Division, ERDA, ORO

74-198. Given distribution as shown in TID-4500 under General Reactor Technology Cagegory (25 copies - NTIS) 